Deise Mota Alves

\title{
QUANTIFICAÇÃO DA GLICEMIA ATRAVÉS DE ANÁLISES DE IMAGENS DA ÍRIS HUMANA UTILIZANDO REDES NEURAIS
}

\begin{abstract}
Dissertação apresentada à Escola de Engenharia de São Carlos da Universidade de São Paulo, como parte dos requisitos para a obtenção do Título de mestre em Engenharia Elétrica.
\end{abstract}

Orientador: Professor Dr. Adilson Gonzaga

São Carlos 
A Deus, aos meus pais, Laci e Nilda, às irmãs Luly e Débora, ao irmão Lucas, ao namorado Thiago e sua família, com todo meu amor, carinho e dedicação. 


\section{Agradecimentos}

À Coordenação de Aperfeiçoamento de Pessoal de Nível Superior (Capes) pela concessão da bolsa de mestrado e pelo apoio financeiro para a realização desta pesquisa.

Ao Prof. Dr. Adilson Gonzaga, meu orientador, pelos ensinamentos e orientações, contribuindo para meu crescimento científico e intelectual.

Ao Prof. Dr. Armando Albertazzi Gonçalves Júnior, Pai do GlucoÍris, e também orientador desse trabalho, pela oportunidade de participar desta pesquisa, pela dedicação, otimismo e persistência para a conclusão deste trabalho, e por ser um exemplo de uma natural capacidade objetiva, produtiva e criativa.

Ao Prof. Dr. Ivan Nunes da Silva pelas orientações e idéias para a obtenção dos resultados deste trabalho.

Aos meus queridos pais, Laci e Nilda e meus irmãos, Débora, Lucas, e Lucy, e ao cunhado Adriano, por todo o apoio e pelas preciosas palavras de motivação que foram determinantes para a realização dessa pesquisa.

Ao meu estimado namorado Thiago Crivelaro, e toda sua família, por todo o apoio e ajuda para que esse sonho se tornasse realidade, pelas palavras de carinho, pela paciência.

À Escola de Engenharia de São Carlos (USP/EESC), pela oportunidade de realização do curso de mestrado.

À querida Marinilda Machado e toda sua família, que nos momentos de alegrias e de lutas, mesmo na distância, se fizeram presentes, pelas palavras de encorajamento.

Ao querido Ricardo Coser Mergulhão, pelos primeiros passos na pesquisa, pelo incentivo, pelas idéias propostas, pelo carinho. Minha sincera gratidão.

A todos os amigos e colegas do Laboratório de Visão Computacional (LAVI), pelo aprendizado, pelos momentos de amizades, pelas muitas horas fazendo trabalhos e simulações das disciplinas as quais me deram um grande impulso e incentivo.

Aos funcionários do Departamento de Engenharia Elétrica (EESC - USP) que sempre estiveram dispostos a colaborar, e em especial, às secretárias Denise e Marisa, pela atenção e amizade, ao colaborador José Carlos da secretaria de graduação, pelo incentivo, apoio, carinho, pelas horas dispensadas para a conclusão desse trabalho, meu muito obrigada.

Enfim, a todos aqueles que contribuíram de forma direta ou indiretamente para a realização desse trabalho. 


\section{RESUMO}

ALVES, D.M. (2007). Quantificação da glicemia através de análises de imagens da íris humana utilizando redes neurais. Dissertação (Mestrado) - Escola de Engenharia de São Carlos, Universidade de São Paulo, São Carlos, 2007.

Este trabalho contribui para o projeto de um sistema não-invasivo capaz de quantificar o nível de glicose no sangue através de imagens da íris humana, o projeto recebeu o nome de GlucoÍris. Este foi desenvolvido pelo Departamento de Engenharia Mecânica (LabMetro), da Universidade Federal de Santa Catarina (UFSC) onde foi concebido e avaliado um sistema óptico/mecânico e um programa de computador para extrair parâmetros quantitativos associados à coloração e estrutura da íris humana. Um primeiro protótipo de dispositivo capaz de adquirir imagens digitais coloridas da íris foi desenvolvido juntamente com uma primeira versão de um programa de computador. Alterações na íris com 24 voluntários foram avaliadas. Os resultados atingidos em trabalhos anteriores mostraram que, de fato, a cor da imagem de uma íris sofre alterações em função de variações no nível de glicose na corrente sanguínea, indicando que é possível medir a glicemia através da íris humana. Partindo-se dos resultados das fases anteriores do projeto, este trabalho se dedicou em desenvolver um sistema, utilizando redes neurais, para se fazer uma estimação / previsão do valor de glicemia através de análises de imagens da íris humana. Com os dados de cor extraídos das imagens e os valores de glicemia conhecidos, para os casos estudados, avaliou-se a capacidade da rede em estimar novos valores de glicemia para os voluntários em questão.

Palavras-chave: Medição da Glicemia, GlucoÍris, Redes Neurais. 


\section{ABSTRACT}

ALVES, D. M. (2007). Blood glucose rate measured through the analysis of the human iris image, using neural networking. M.Sc. Dissertation - Escola de Engenharia de São Carlos, Universidade de São Paulo, São Carlos, 2007.

This work contributes to the project of a non-invasive system which is able to quantify the glucose level in the blood through the human iris images; the project was named GlucoÍris. It was developed by the mechanical engineering department (LabMetro) of the Federal University of Santa Catarina (UFSC) where it was placed and analyzed an optical/mechanical system. Also, it was created a computer program to find out quantitative parameters associated with the color and the structure of the human iris. Together with the prime version of a computer program it was developed an earliest prototype of the apparatus which was able to obtain digital colored images of the iris. The alterations found out in the iris of the twenty-four volunteers where evaluated. Actually, due to the variations of the glucose level in the blood, previous studies showed that the color of the image of an iris experiences changes, indicating that it is possible to measure the sugar rate in the blood through the human iris. Applying the results of previous stages of the project, the purpose of this study was to develop a system, using neural networking, to estimate the blood glucose rate through the analysis of the images of the human iris. Employing the color data found in the images and the known blood glucose amount on the studied cases, it was evaluated the networking ability to estimate new sugar rates in the mentioned volunteers's blood.

Key-words: Blood glucose rate, GlucoÍris, Neural Networking 


\section{LISTA DE FIGURAS}

Figura 2.1- Ilustração do Mapa Iridológico da íris direita ...............................................

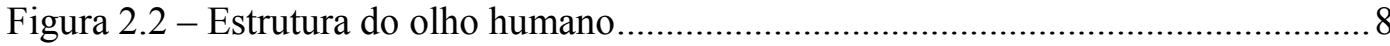

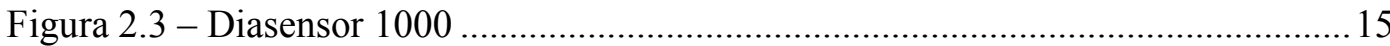

Figura 2.4 - Tiras reagentes para o teste de glicosúria ................................................. 16

Figura 2.5 (a) Imagem original da retina de um paciente diabético. (b) Resultado segmentado depois do processamento da imagem.................................................. 18

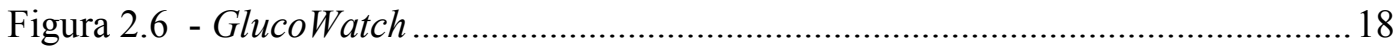

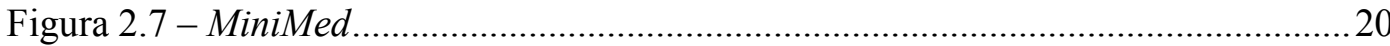

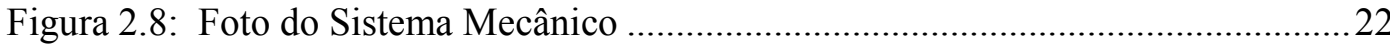

Figura 2.9 - Tela principal do programa de extração de dados da coloração de 36

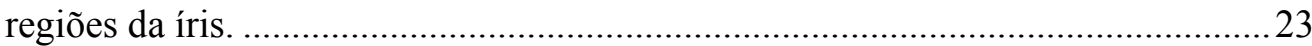

Figura 3.1 - Componentes do neurônio Biológico ........................................................25

Figura 3.2- Modelo de um neurônio Artificial; ............................................................... 28

Figura 3.3 - Gráficos das funções de Ativação mais comumente empregadas na

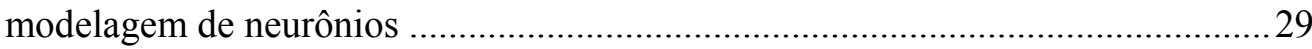

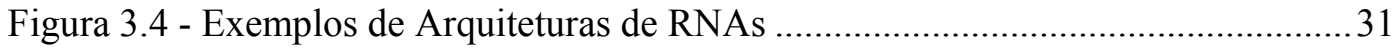

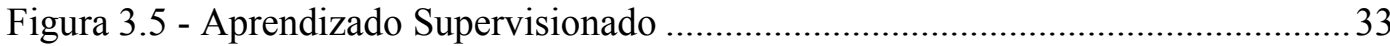

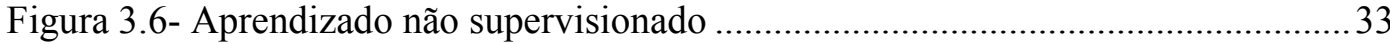

Figura 3.7 - Curva de aprendizagem idealizada do algoritmo LMS .................................36

Figura 3.8 - Rede de função de Base Radial ....................................................................42

Figura 4.1 - Esquema do Programa GlucoÍris ................................................................. 46

Figura 4.2 - Esquema do sistema para previsão / estimação da glicemia proposto........ 47

Figura 4.3 : (a) Imagem original (b) Imagem contendo apenas as regiões de interesse 51 Figura 4.4: Nomeação das divisões da íris: (a) Componente de cor Vermelha (R). (b)

Componente de cor Verde(G). (c) Componente de cor Azul (B) ..........................52

Figura 4.5: Procedimento para o cálculo dos valores de normalização do RGB médio. 53

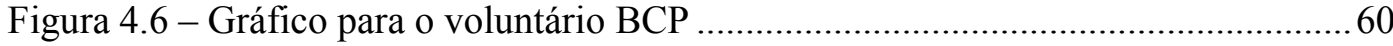

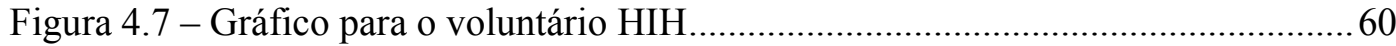

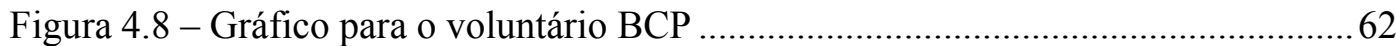

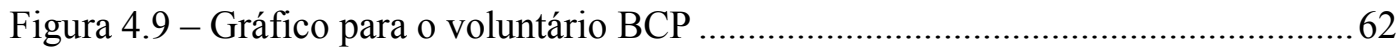




\section{LISTA DE TABELAS}

Tabela 2.1 - Classificação etiológica do Diabetes Mellitus ........................................... 10

Tabela 3.1 - Comparação entre as redes neurais RBF e MLP .........................................4

Tabela 4.1 - Dados coletados do voluntário para compor o Banco de imagens ............. 48

Tabela 4.3: Dados comparativos para o voluntário LBG dos 36 setores para a

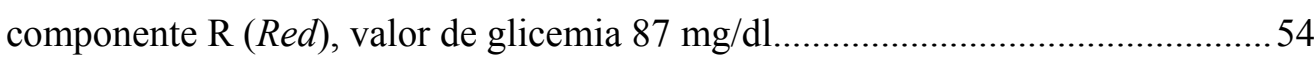

Tabela 4.4 : Dados comparativos para o voluntário LBG dos 36 setores para a

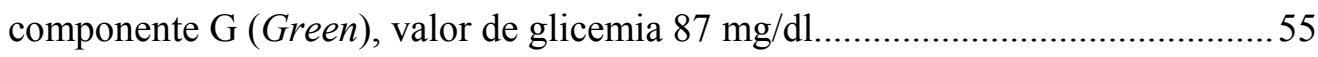

Tabela 4.5: Dados comparativos para o voluntário LBG dos 36 setores para a componente B (Blue), valor de glicemia $87 \mathrm{mg} / \mathrm{dl}$...........................................56

Tabela 4.6 - Topologias e os parâmetros utilizados durante a fase de treinamento da rede MLP

Tabela 4.7 - Topologias e parâmetros utilizados durante a fase de treinamento da rede $\mathrm{RBF}$

Tabela A1: Valores obtidos pela RNA para cada voluntário utilizando a rede

MLP/topologia 2 com 4 características..

Tabela A2: Valores obtidos pela RNA para cada voluntário utilizando a rede

MLP/topologia 1 com 4 características .71

Tabela A3: Valores obtidos pela RNA para cada voluntário utilizando a rede

MLP/topologia 1 com 8 características .72

Tabela A4: Valores obtidos pela RNA para cada voluntário utilizando a rede MLP/topologia 2 com 8 características. .73

Tabela A5: Valores obtidos pela RNA para cada voluntário utilizando a rede

$\mathrm{RBF} /$ topologia 1 com 4 características

Tabela A6: Valores obtidos pela RNA para cada voluntário utilizando a rede

$\mathrm{RBF} /$ topologia 1 com 8 características .75

Tabela A7: Valores obtidos pela RNA para cada voluntário utilizando a rede $\mathrm{RBF} /$ topologia 2 com 4 características .76

Tabela A8: Valores obtidos pela RNA para cada voluntário utilizando a rede $\mathrm{RBF} /$ topologia 2 com 8 características 


\section{Sumário}

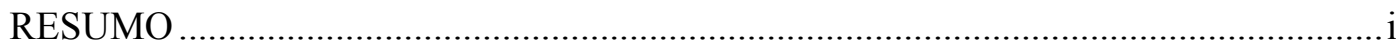

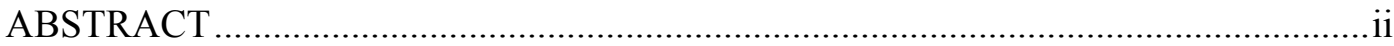

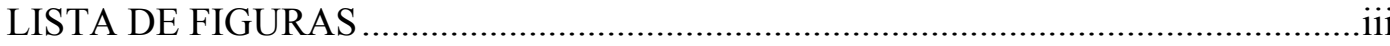

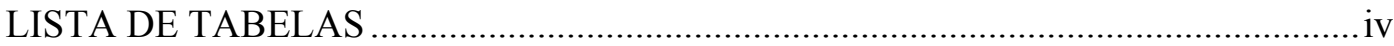

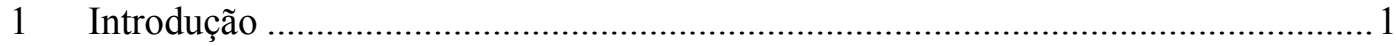

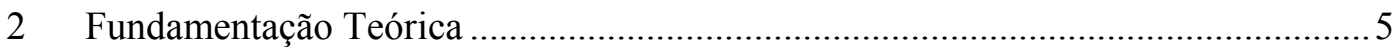

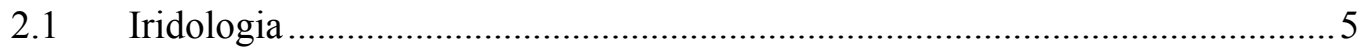

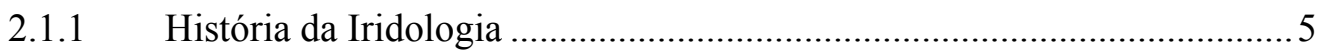

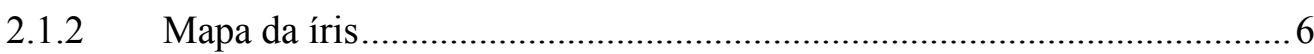

2.2 Anatomia e Estrutura do Olho Humano ............................................................

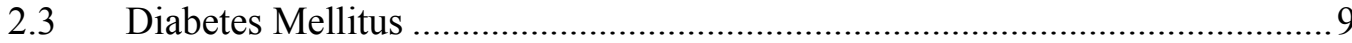

2.3.1 Diabetes Mellitus Tipo I.................................................................... 10

2.3.2 Diabetes Mellitus Tipo II ................................................................ 11

2.3.3 Diabetes Mellitus Tipo III................................................................. 11

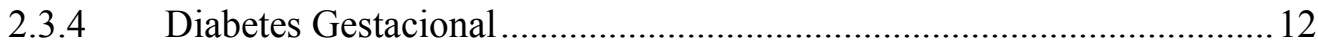

2.4 Automonitorização: técnicas para o controle domiciliar do diabetes .............. 12

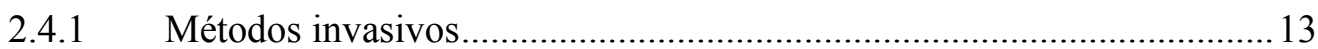

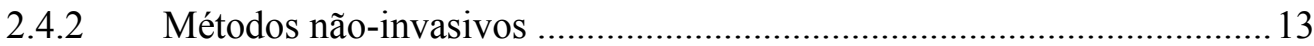

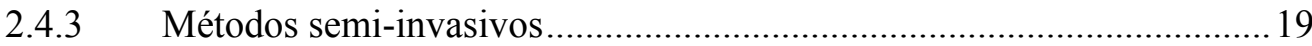

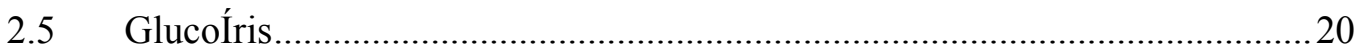

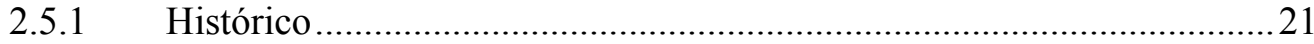

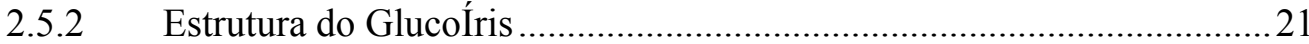

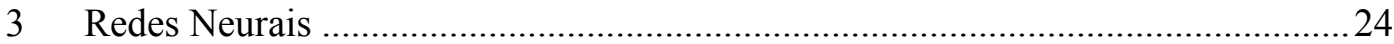

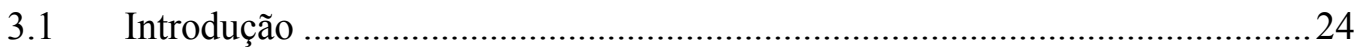

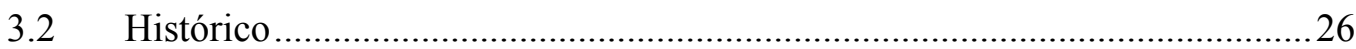

3.3 Modelo de Neurônio Artificial.....................................................................27

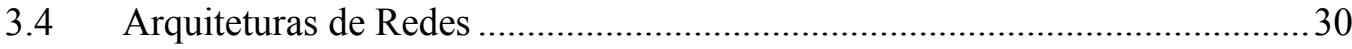

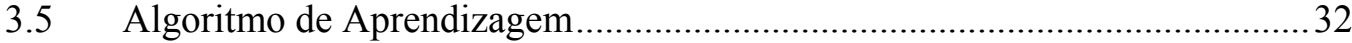

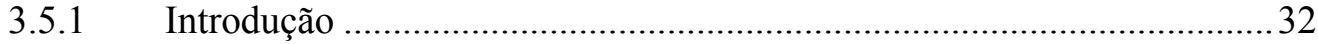

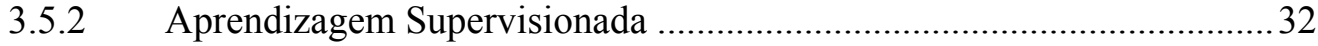

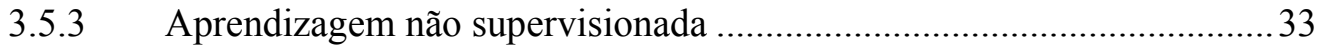

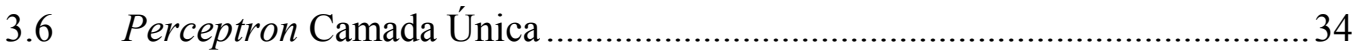




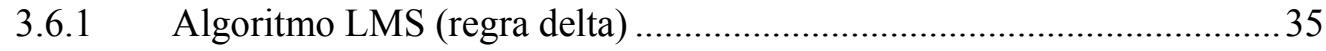

$3.7 \quad$ Perceptron multicamadas (MLP - Multilayer perceptron) ….........................37

3.7.1 Algoritmo de treinamento Backpropagation .......................................... 37

3.7.2 Algoritmo de Levenberg-Marquardt .............................................. 40

3.8 Redes de Função de Base Radial (RBF - Radial-basis function) .....................42

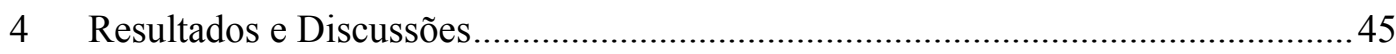

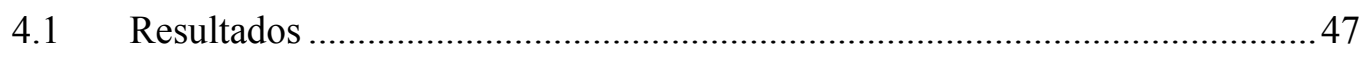

4.2 Estimação dos valores de Glicemia usando rede neural MLP ........................57

4.3 Estimação dos valores de Glicemia usando rede neural RBF .........................61

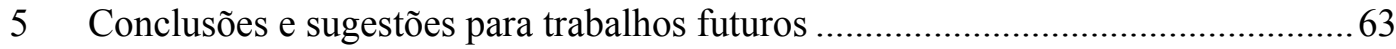

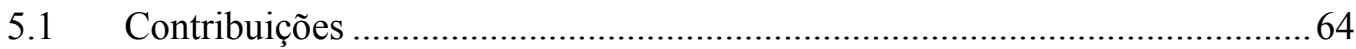

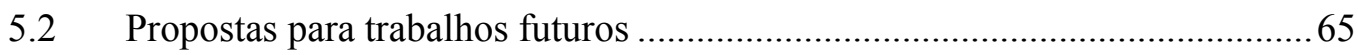

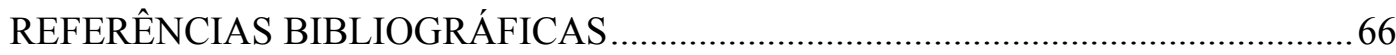

APÊNDICE A - Dados obtidos das simulações da rede MLP ...................................... 70

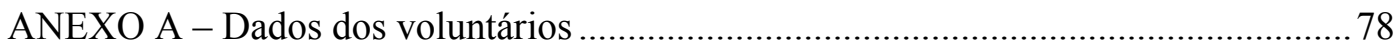




\section{Introdução}

O Diabetes Mellitus é um problema de saúde pública com elevado ônus social e econômico, cujo diagnóstico é desconhecido em metade dos indivíduos portadores. Em 2001, o Ministério da Saúde realizou a Campanha Nacional para a Detecção do Diabetes Mellitus. Em países em desenvolvimento, como o Brasil, está previsto aumento na prevalência de Diabetes Mellitus de 170\% no período de 1995 a 2025 (KING et al., 1995). Mesmo em países desenvolvidos, apesar dos avanços científicos e o acesso fácil a cuidados contínuos de saúde, a prevalência do diabetes está aumentando e intervenções com finalidade de prevenir tal condição, como a atividade física e dieta, são sub-utilizadas (WAREHAM;GRIFFIN, 2001). A prevalência desse mal não diagnosticado é alta e até $25 \%$ dos indivíduos tem evidência de complicações microvasculares no momento do diagnóstico clínico (HARRIS et al., 1992).

O Diabetes Mellitus está entre as 10 principais causas de mortalidade. Alguns fatores contribuem para esse cenário desfavorável como grande quantidade de diabéticos não diagnosticados e além da expressiva proporção de casos com evidência de complicações ao diagnóstico.

Além disso, o diabetes é uma das principais causa clínicas de hospitalização no Brasil, o que significa altos custos financeiros. Suas manifestações crônicas ou complicações são causas freqüentes de invalidez precoce. (MINISTÉRIO DA SAÚDE, 1993).

Estima-se que de 3 a $5 \%$ da população geral sejam diabéticos e que metade desse total desconheça a sua condição diabética. Do total de casos, $90 \%$ são do tipo nãoinsulino-dependente, 5 a 10\%, tipo insulino dependente, $2 \%$, do tipo secundário ou associado a outras condições. No diabetes gestacional, uma condição transitória durante a gravidez, ocorrem em torno de 2 a 5\% das gestações. (MINISTÉRIO DA SAÚDE, 1993). 
O custo envolvido no controle do Diabetes Mellitus ou de suas complicações é exorbitante. Isso tem sido motivo de grande preocupação nos países desenvolvidos, visto que o mesmo poderia ser reduzido a mais de $50 \%$ se fossem tomadas medidas de prevenção de forma adequada (RHEE et al., 2005).

As conseqüências decorrentes desse mal são diversas, como: cegueira, doença renal grave, amputações de membros, hiperglicemia, os ataques cardíacos e os acidentes vasculares cerebrais, a nefropatia ou a neuropatia diabética; $8 \%$ das hospitalizações de pacientes diabéticos são as doenças macrovasculares, e, 75\% das mortes nos diabéticos são as cardio-vasculares, sendo que isto ocorre principalmente nos pacientes com diabete do tipo 2 , e se não tratado pode ocasionar o coma e até mesmo a morte (ASSUNÇÃO et al., 2002).

Para evitar tais complicações é necessário que seja feito um controle rígido do nível de glicose no sangue. Existem várias formas de se realizar a mensuração da glicemia, cada uma tendo suas vantagens e desvantagens. Um fator que deve ser levado em consideração é que a técnica seja a mais rápida e com maior grau de precisão possível. Os sistemas de medição que são utilizados atualmente podem ser divididos em duas categorias: laboratoriais e portáteis. Mais confiáveis e consideravelmente mais caros, os glicosímetro de laboratório estão quase que exclusivamente restritos a laboratório de análise clínica. Os portáteis, embora susceptíveis a maiores incertezas nas medições, também são considerados seguros e são utilizados pela população para a auto-monitoração. (PICA et al, 2003)

Conforme o método de operação, estes aparelhos, podem ser classificados em invasivos, não-invasivos e semi-invasivos. Os métodos invasivos requerem que uma amostra de sangue seja extraída do organismo utilizando-se uma agulha, os semiinvasivos utilizam amostras de sangue ou líquido intersticial em volumes muito menores do que necessitam os métodos anteriores que, em sua maioria usam biosensores implantados no organismo, os métodos não-invasivos são muito recentes e a maioria está em fase de pesquisa, além de propriedades do sangue, utilizam para medir a glicose: fluído intersticial, suor, saliva, lágrimas e líquidos oculares. (MENEZES, 2004)

Atualmente, estima-se que cerca de $15 \%$ do total gasto em saúde está envolvido com o tratamento do diabetes e suas complicações. Estabelecer e manter um controle efetivo da glicemia em pacientes com diabetes reduz o risco de complicações 
microvasculares como retinopatia, nefro e neuropatia e complicações macrovasculares como infarto do miocárdio e acidente vascular cerebral (TAMBASCIA, 2004).

Devido à importância de medições freqüentes da glicemia muitos dispositivos de auto-medição têm sido criados. Os aparelhos mais utilizados atualmente medem a quantidade de glicose por meio de reações químicas, envolvendo uma tira reagente e uma amostra de sangue extraída por perfuração da pele. Esses aparelhos são de alta tecnologia e bem difundidos no mercado, apresentam bons resultados, porém, por serem invasivos e necessitarem de uma nova tira para cada medição esse método se torna caro. Um diabético que necessite de três leituras diárias gasta em média U\$ 800/ano apenas com tiras reagentes, e por isso muitos diabéticos deixam de medir a glicemia com a freqüência que deveriam (MENEZES, 2004).

Este trabalho tem como objetivo desenvolver uma rede neural que seja capaz de estimar valores de glicemia a partir dos dados de cor extraídos das imagens e os valores de glicemia conhecidos. O software do projeto GlucoÍris é responsável por coletar os dados referentes as componentes de cor RGB e HSI para os 36 setores de cada íris (esquerda e direita). Esses dados servirão de entrada para uma rede neural artificial MLP (Multilayer Perceptron) para que possa ser ensinada (treinada). Um estudo preliminar foi realizado para avaliar a capacidade de generalização da RNA.

Além dessa introdução serão apresentados os seguintes capítulos:

2: Fundamentação Teórica: Neste capítulo são apresentados os conceitos básicos que serão utilizados no decorrer do trabalho. Uma breve abordagem sobre a Iridologia e como esta teoria pode auxiliar na determinação da glicemia por meio de uma tecnologia não-invasiva. Uma introdução sobre a anatomia e a estrutura do olho humano, Diabetes Mellitus e suas respectivas classes. Ainda são descritas algumas técnicas de automonitorização para o controle domiciliar do diabetes, os tipos de métodos existentes. E por fim uma breve abordagem sobre o sistema GlucoÍris que teve seu início em 1998, e que vem sendo cada vez mais aprimorado com o intuito de se tornar um método não-invasivo eficiente e indolor para se medir a glicemia.

3: Redes Neurais: Apresenta-se um breve histórico sobre as RNA, o modelo de um neurônio, os tipo de algoritmos de aprendizagem. São descritos a rede MLP (Multilayer Perceptron) e o processo de aprendizagem backpropagation. E por fim é apresentado o algoritmo de Levenberg-Marquardt que foi utilizado neste trabalho. Esse algoritmo de treinamento é o mais rápido para as redes neurais, quando se trabalha com um número moderado de parâmetros na rede. 
4: Resultados e Discussões: Esse capítulo descreve a metodologia utilizada para a implementação do algoritmo para estimar os valores de glicemia através de análises da cor de imagens da íris humana, bem como as topologias de redes neurais artificiais empregadas.

5: Conclusões e sugestões para trabalhos futuros: São apresentadas as conclusões e sugestões para trabalhos futuros. 


\section{Fundamentação Teórica}

\subsection{Iridologia}

A iridologia é a arte e a ciência que analisa a cor e a estrutura da íris dos olhos para obter uma informação valiosa da saúde. Ela vai desde a sua anatomia, fisiologia, histologia até a possibilidade de se conhecer os estágios evolutivos das alterações que acometem um ou mais órgãos, ou o organismo como um todo (BATELLO, 1999). O preceito da iridologia é que a informação, obtida a partir da íris, diz respeito à saúde e o bem-estar da pessoa. Fundamentada no final do século 19, na Hungria, a análise da íris está sendo estudada em muitos países do mundo (JENSEN; BODDEN, 1992). Ela ainda pressupõe que cada órgão do corpo possui uma correspondência na íris, podendo-se assim, determinar se um órgão é ou não saudável examinando a íris ao invés do próprio órgão.

A íris representa, em sua topografia, muitas partes do organismo. Isso é possível graças ao Sistema Nervoso Autônomo, composto de duas cadeias nervosas - o simpático e o parassimpático - que inervam todas as partes do organismo e levam impulsos sobre a situação de cada região até o cérebro (Sistema Nervoso Central) e até a íris, onde essas impressões ficam registradas (JENSEN, 1980). Alguns mapas da íris foram desenvolvidos para facilitar a identificação dos sinais característicos de cada paciente.

\subsubsection{História da Iridologia}

Phillipus Meyens foi o primeiro a publicar um trabalho sobre Iridologia. Isso foi em 1670 em Dresden, Alemanha, e seu livro (Chiromatic Medica) fazia um interessante estudo sobre sinais iridológicos e suas relações com determinadas doenças, apresentando um pequeno mapa da íris com áreas representativas de alguns órgãos do corpo humano. Depois foi a vez de Joahann Eltholtz (Nuremberg, 1695) se aprofundar mais no estudo de Meyens. Quase um século mais tarde, em Goettinger, Christian 
Haertls, baseado nos estudos de Meyens e Eltholtz, lança um polêmico e importante trabalho (BATELLO, 1999).

Porém, foi com o médico húngaro, Ignatz von Peczely (1822-1911), que a Iridologia tornou-se conhecida. Segundo JENSEN (1980), Peczely, aos 11 anos idade, caçou uma coruja que, ao fraturar uma pata na armadilha, apresentou um fino traço na região inferior da íris correspondente ao lado fraturado. A partir desse fato, Peczely acompanhou a consolidação da fratura, constatando que o traço da íris desaparecia aos poucos, restando apenas uma marca muito tênue. Estudando outros autores sobre o assunto, Peczely desenvolveu então pesquisas comparativas em hospitais, formando um considerável grupo de discípulos. Em 1881, após muitas dificuldades, conseguiu lançar seu primeiro trabalho. Muitas obras sobre o assunto surgiram depois na Europa, principalmente na Alemanha.

O interesse pela Iridologia espalhou-se pela Europa, no início da década de 1900 o novo sistema foi introduzido nos Estados Unidos pelo Dr. Nils Liljequist, um homeopata sueco. E foi um norte-americano, o Dr. Bernard Jensen, que desenvolveu o mapa da íris que atualmente é mais conhecido e utilizado.

\subsubsection{Mapa da íris}

O mapa iridológico representa graficamente as áreas da íris correspondentes aos órgãos, sistemas e regiões do corpo humano conforme Figura 2.1. A melhor maneira de compreender a perfeita e simétrica distribuição dos órgãos na íris é observando o mapa iridológico com todo o cuidado. À primeira vista surge um certo grau de dificuldade para localizar um órgão ou região na íris, e, na prática, também aparecem obstáculos que podem ser superados à medida que o estudante se aprofunda no assunto. 


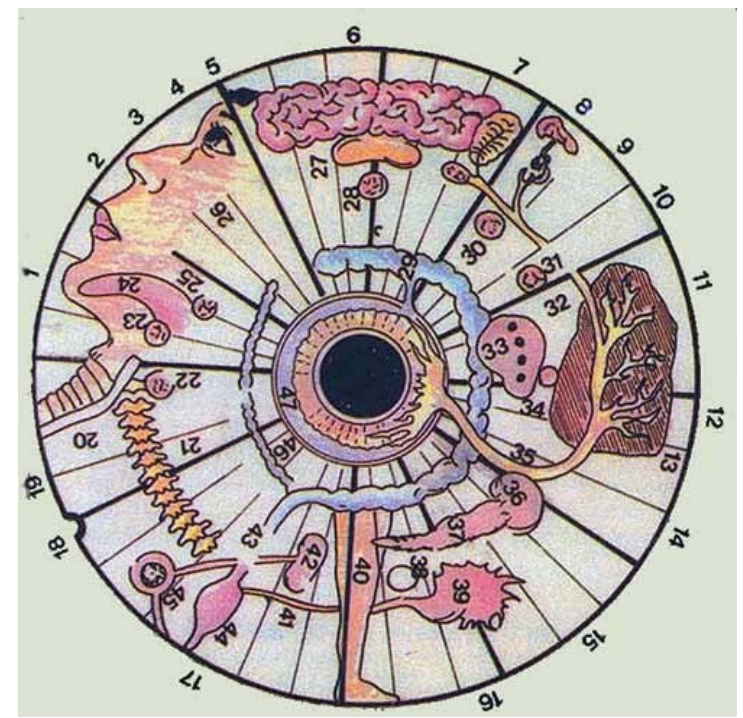

1)Maxilar inferior; 2)Maxilar Superior; 3)Nariz; 4)Olho; 5)Testa; 6)Cérebro; 7)Cerebelo; 8)Ouvido; 9)Pescoço; 10)Axila; 11)Pulmão superior; 12)Pulmão inferior; 13)Pleura; 14)Braço; 15)Alto ventre; 16)Baixo Ventre; 17)Área Sexual: 18)Umbigo; 19)Região Lombar; 20)Esôfago; 21)Coluna Vertebral; 22)Glândula Tireóide; 23)Glândula Lingual; 24)Língua; 25)Amídala; 26)Trigêmeo; 27)Corpo Caloso; 28)Glândula pineal; 29)Intestino Grosso; 30)Glândula Carótida; 31)Glândula auxiliar; 32)Brônquios; 33)Coração; 34)Timo; 35)Vago; 36) Baço; 37)Pâncreas; 38)Gânglio Linguinal; 39)Ovário; 40)Perna; 41)Trompa; 42)Rim; 43)Reto; 44)Útero; 45)Uretra; 46)Intestino Delgado; 47)Área estomacal.

\section{Figura 2.1- Ilustração do Mapa Iridológico da íris direita}

Fonte: http://www1.folha.uol.com.br/folha/equilibrio/equi20000726_iris.shtml, acessado em 05/12/2005

\subsection{Anatomia e Estrutura do Olho Humano}

O olho faz parte dos cinco órgãos do sentido: visão, olfato, tato, paladar e audição. Quando se olha na direção de algum objeto, a imagem atravessa a córnea e chega à íris, que regula a quantidade de luz recebida por meio de uma abertura chamada pupila. Quanto maior a pupila, maior a quantidade de luz que os olhos recebem. Posteriormente, a imagem chega ao cristalino e é focalizada sobre a retina. A lente do olho produz uma imagem invertida, e o cérebro a converte para a orientação correta. $\mathrm{Na}$ retina, mais de cem milhões de células fotorreceptoras transformam as ondas luminosas em impulsos eletroquímicos, que são decodificados pelo cérebro (GRAZIANO; LEONE, 2005).

Dos cinco sentidos, a visão humana é o que provê o maior volume de informações a serem processadas pelo cérebro. Estima-se que metade do potencial de processamento cerebral humano seja usado para lidar com informações visuais, isso explica porque os cegos desenvolvem tanto os demais sentidos: o potencial que seria utilizado para processar a visão é aplicado no processamento das informações fornecidas pelos outros órgãos sensoriais. $\mathrm{O}$ olho humano possui enormes quantidades de sensores responsáveis pela captação da informação visual, decisão final acerca da 
análise de uma cena, bem como as atitudes que serão tomadas em função dessa análise, é fruto de um complexo processo que envolve os centros cerebrais. No entanto, o cérebro pode errar em sua interpretação e comandar atitudes equivocadas (FILHO; NETO, 1999).

A Figura 2.2 apresenta algumas das diferentes partes da estrutura do olho humano seguida de uma breve descrição (GONÇALVES, 1975).

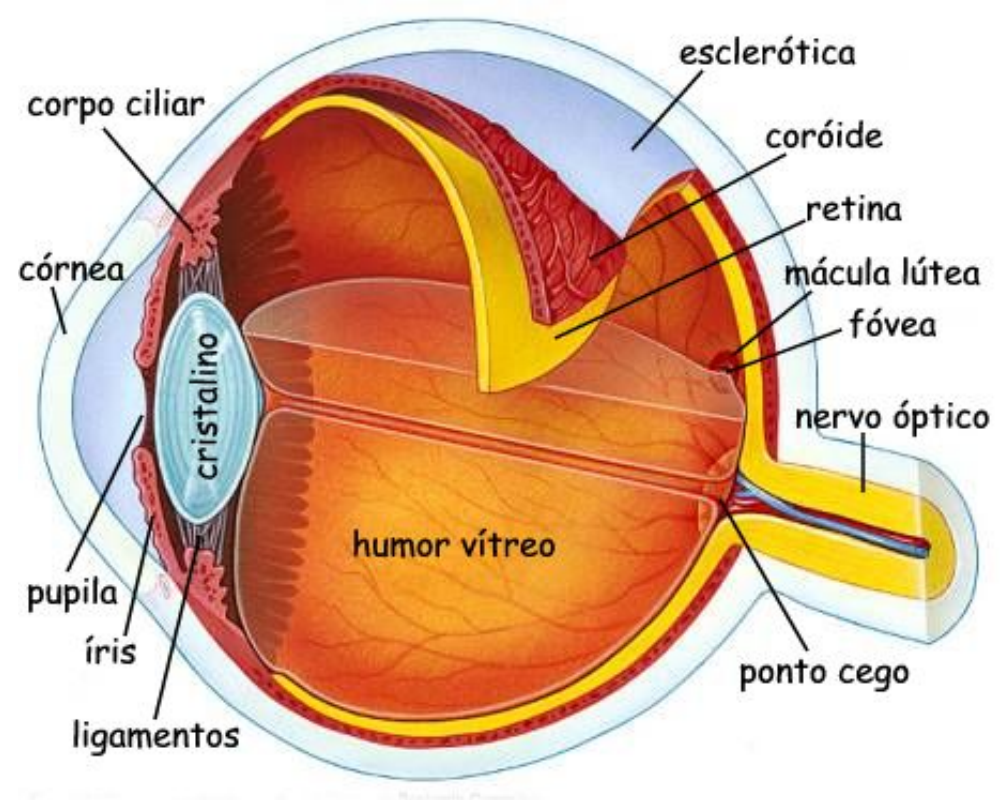

Figura 2.2 - Estrutura do olho humano

Fonte: http://satelite.cptec.inpe.br/uv/R-UV_e_olho.html, acessado em 31/01/2006

- Córnea: Tecido transparente que cobre a pupila, a abertura da íris. Junto com o cristalino, a córnea ajusta o foco da imagem no olho.

- Coróide: Estrutura do olho que está situada abaixo da esclerótica e é intensamente pigmentada. Esses pigmentos absorvem a luz que chega à retina, evitando sua reflexão. Acha-se intensamente vascularizada e tem a função de nutrir a retina.

- Corpo ciliar: Responsável pela formação do humor aquoso e pela acomodação (processo de mudança de curvatura), ou seja, mobilidade do cristalino, localizase atrás da íris. 
- Cristalino: Lente transparente e flexível, localizada atrás da pupila. Funciona como uma lente, cujo formato pode ser ajustado para focalizar objetos em diferentes distâncias, num mecanismo chamado acomodação.

- Esclerótica: Espessa camada de tecido conjuntivo denso.

- Fóvea: A fóvea está no eixo óptico do olho, em que se projeta a imagem do objeto focalizado, e a imagem que nela se forma tem grande nitidez. É a região da retina mais altamente especializada para a visão de alta resolução. A fóvea contém apenas cones e permite que a luz atinja os fotorreceptores sem passar pelas demais camadas da retina, maximizando a acuidade visual. .

- Íris: membrana contrátil que tem, no centro, uma abertura circular ajustável chamada de pupila.

- Ligamentos: unem os ossos nas articulações e seguram as lentes dos olhos (cristalino). Responsáveis por variarem o tamanho da lente.

- Mácula lútea: Ponto central da retina. É a região que distingue detalhes no meio do campo visual.

- Nervo óptico: Estrutura formada pelos prolongamentos das células nervosas que formam a retina. Transmite a imagem capturada pela retina para o cérebro.

- Ponto cego: O ponto em que o nervo ótico se une à retina.

- Pupila: Controla a entrada de luz: dilata-se em ambiente com pouca claridade e estreita-se quando a iluminação é maior. Esses ajustes permitem que a pessoa enxergue bem à noite e evitam danos à retina quando a luz é mais forte.

- Retina: Sua função é receber ondas de luz e convertê-las em impulsos nervosos, que são transformados em percepções visuais.

\subsection{Diabetes Mellitus}

O Diabetes é uma doença provocada pela deficiência de produção e/ou de ação da insulina, que leva a sintomas agudos e a complicações crônicas características.

O distúrbio envolve o metabolismo da glicose, das gorduras e das proteínas e tem graves conseqüências tanto quando surge rapidamente como quando se instala lentamente. Nos dias atuais se constitui em problema de saúde pública pelo número de pessoas que apresentam a doença, principalmente no Brasil (ALBERTI et al., 2004).

O pâncreas é o órgão responsável pela produção do hormônio denominado insulina. Este hormônio é responsável pela regulação da glicemia (nível de glicose no sangue). Para que as células das diversas partes do corpo humano possam realizar o 
processo de respiração aeróbica (utilizar glicose como fonte de energia), é necessário que a glicose esteja presente na célula. Portanto, as células possuem receptores de insulina, que quando acionados "abrem" a membrana celular para a entrada da glicose presente na circulação sanguínea. Uma falha na produção de insulina resulta em altos níveis de glicose no sangue, já que a mesma não é devidamente dirigida ao interior das células (PIMENTA et al., 2002).

Visando manter a glicemia constante, o pâncreas também produz outro hormônio antagônico à insulina, denominado glucagon. Ou seja, quando o nível de glicemia cai, mais glucagon é secretado visando reestabelecer o nível de glicose na circulação (ROZMAN et al., 2004).

A classificação atual do Diabetes Mellitus está representada na Tabela 2.1. As formas mais freqüentes de diabetes são o diabetes tipo 1 e o diabetes tipo 2 e os termos “dependente de insulina" e "não dependente de insulina" anteriormente atribuídos respectivamente aos dois tipos de diabetes foram eliminados (GROSS et al., 2002).

\section{Tabela 2.1 - Classificação etiológica do Diabetes Mellitus}

Fonte: (Adaptado) (GROSS et al, 2002)

\section{Diabetes tipo 1}

- destruição das células beta, usualmente levando à deficiência completa de insulina

A. auto-imune

B. idiopático

\section{Diabetes tipo 2}

- graus variados de diminuição de secreção e resistência à insulina

\section{Outros tipos específicos}

A. Defeitos genéticos da função da célula $\beta$

B. Defeitos genéticos da ação da insulina

C. Doenças do pâncreas exócrino

D. Endocrinopatias

E. Indução por drogas ou produtos químicos

F. Infecções

G. Formas incomuns de diabetes imuno-mediado

\section{Diabetes Gestacional}

\subsubsection{Diabetes Mellitus Tipo I}

Normalmente inicia-se na infância ou adolescência, e se caracteriza por um déficit de insulina, devido à destruição das células beta do pâncreas por processos autoimunes ou idiopáticos. Só cerca de 1 em 20 pessoas diabéticas tem diabetes tipo 1, a qual se apresenta mais freqüentemente entre em jovens e crianças. Este tipo de diabetes era conhecido como Diabetes Mellitus insulino-dependente ou diabetes infantil. Nela, o corpo produz pouca ou nenhuma insulina. As pessoas que padecem dela devem receber 
injeções diárias de insulina. A quantidade de injeções diárias é variável em função do tratamento escolhido pelo endocrinologista e também em função da quantidade de insulina produzida pelo pâncreas. A insulina sintética pode ser de ação lenta ou rápida: a de ação lenta é ministrada ao acordar e ao dormir; a de ação rápida é indicada logo após grandes refeições. O controle rigoroso da dieta é importantíssimo para o diabético tipo 1, devendo o mesmo evitar carboidratos simples (refrigerantes, doces,...) e também evitar grandes variações de ingestão calórica. O diabético com dieta descontrolada pode ter surtos de hipoglicemia ou hiperglicemia, que se não tratado a tempo pode levar a seqüelas ou até mesmo à morte. $\mathrm{O}$ diabetes tipo 1 tem maior probabilidade de conduzir à insuficiência renal antes dos 50 anos. Algumas apresentam insuficiência renal antes dos 30 (FERNANDES et al., 2005).

\subsubsection{Diabetes Mellitus Tipo II}

Provocado predominantemente por um estado de resistência à ação da insulina associada a uma relativa deficiência de sua secreção.A mesma possui um mecanismo fisiopatológico complexo e não completamente elucidado. Parece haver uma diminuição na resposta dos receptores de glicose presentes no tecido periférico à insulina, levando ao fenômeno de resistência à insulina. As células beta do pâncreas aumentam a produção de insulina e, ao longo dos anos, a resistência à insulina acaba por levar as células beta à exaustão. Desenvolve-se freqüentemente em etapas adultas da vida e é muito freqüente a associação com a obesidade; anteriormente denominada diabetes do adulto, diabetes relacionada com a obesidade, diabetes não insulino-dependente. Vários fármacos e outras causas podem, contudo, causar este tipo de diabetes. É muito freqüente a diabetes tipo 2 associada ao uso prolongado de corticóides, freqüentemente associada à hematocromatose não tratada (PÉRES et al., 2006).

\subsubsection{Diabetes Mellitus Tipo III}

$\mathrm{Na}$ medida em que têm sido elucidados os processos de patogênese do diabetes, tanto em relação a marcadores genéticos como aos mecanismos de doença, tem crescido o número de tipos distintos de diabetes, permitindo uma classificação mais específica e definitiva. Portanto, novas categorias têm sido acrescidas à lista de tipos específicos de diabetes, incluindo defeitos genéticos da célula beta e da ação da insulina, processos de doenças que danificam o pâncreas, diabetes relacionado a outras endocrinopatias e os casos decorrentes do uso de medicamentos conforme Tabela 2.1 (GROSS et al, 2002). 


\subsubsection{Diabetes Gestacional}

O diabetes gestacional é definido como a tolerância diminuída aos carboidratos, de graus variados de intensidade, diagnosticado pela primeira vez durante a gestação, podendo ou não persistir após o parto. Está presente de 2 a 5\% de todas as gestações. Entre 20 e 50\% destas mulheres desenvolvem diabetes tipo 2 após o término da gravidez. Isto ocorre porque, neste período, a placenta produz substâncias que bloqueiam a ação da insulina, o que pode provocar a elevação da glicose (PACCOLA et al., 2001).

\subsection{Automonitorização: técnicas para o controle domiciliar do diabetes}

A glicemia expressa o nível de glicose no sangue, cujo normal no indivíduo em jejum é 70 a $110 \mathrm{mg} / \mathrm{dL}$. Nos diabéticos descontrolados quando as taxas estão abaixo de $45 \mathrm{mg} / \mathrm{dL}$ há risco de coma hipoglicêmico e quando acima de $400 \mathrm{mg} / \mathrm{dL}$ há risco de coma hiperglicêmico. Os níveis da glicemia sofrem influência de vários fatores, tais como exercício, estresse, alimentação, álcool e medicamentos, e estão sujeitas às contínuas flutuações ao longo do dia (GROSS et al, 2002).

Para se evitar as complicações do diabetes, as taxas de açúcar no sangue devem ser mantidas o mais próximo possível do normal. Pessoas que contenham diabetes podem estar se sentindo bem, mesmo com taxas elevadas de açúcar. Por esta razão, é importante que se meça as taxas de glicose nos horários indicados por um especialista.

As lesões progressivas dos olhos, dos nervos, dos rins e das artérias ameaçam a saúde dos diabéticos. Observações clínicas, assim como a experimentação animal, provam, sem contestação que um controle mais adequado do diabetes (ou seja, a manutenção de uma glicemia próxima dos níveis normais) diminui a freqüência dessas complicações.

Todos os diabéticos deveriam fazer a automonitorização, independentemente de serem ou não insulino-dependentes. O que se deve variar é a indicação quanto aos tipos de testes a serem feitos, a freqüência e os horários em que os testes deverão ser realizados. Como regra geral, um diabético de controle mais instável deve fazer mais testes e com freqüência maior do que um diabético estável (MINISTÉRIO DA SAÚDE, 1993).

Conforme o método de operação, os glicosímetros podem ser classificados em invasivos, não-invasivos e semi-invasivos (MENEZES, 2004). 


\subsubsection{Métodos invasivos}

Os sistemas de medição utilizados hoje podem ser divididos em duas categorias: laboratoriais e portáveis. Os aparelhos utilizados atualmente medem a quantidade de glicose por meio de reações químicas, por isso são denominados de métodos invasivos. (PICA, et al, 2003).

É um método que agride o organismo. Para que a glicemia possa ser mensurada, é necessário analisar uma gota de sangue obtida com a ajuda de uma agulha. Atualmente, esses são os sistemas mais utilizados, em todos os sistemas laboratoriais e em quase todos os sistemas portáteis de auto-monitoração (PICA, 2002). O aparelho mais utilizado nesse método é o glicosímetro (aparelho utilizado para "ler" a glicemia do sangue colocado na fita).

O paciente pica o dedo com uma agulha especial, chamada lanceta, e colhe uma gota de sangue que será colocada na fita apropriada para o aparelho de medição, conhecido como glicosímetro. A lanceta pode ser utilizada junto com um lancetador, que facilita o procedimento e o torna menos doloroso. Antes de usar a lanceta, deve-se lavar as mãos com água e sabão. O melhor local para fazer a coleta é na lateral dos dedos, evitando a polpa digital. O valor da glicemia aparece no mostrador digital do glicosímetro. A maior parte dos glicosímetro disponíveis no mercado permite armazenar o valor de várias glicemias e até fazer um download dos resultados no computador. Os resultados obtidos com os glicosímetros geralmente são precisos. A maior parte dos erros acontece devido a procedimentos incorretos, tais como:

- limpeza inadequada do aparelho

- utilizar o glicosímetro ou a fita em temperaturas diferentes da temperatura ambiente

- fitas fora do período de validade

- glicosímetro não calibrado para a caixa de fitas em uso

- uma gota de sangue muito pequena

É recomendável fazer um "treino” antes de começar a utilizar o glicosímetro e as fitas. Um educador em diabetes pode ajudar o paciente a fazer este treino.

\subsubsection{Métodos não-invasivos}

Esses métodos de determinação da glicemia são bem recentes e existem muitos trabalhos em fase de pesquisa. Ao contrário do método citado acima, esse permite medir a glicemia sem dor. Existem muitas formas de medi-la como, por exemplo: fluído 
intersticial, suor, saliva, lágrimas, líquidos oculares, urina, eletrocardiograma. Algumas topologias, neste grupo, são:

- NIR (Near Infrared - Infravermelho próximo) Espectroscopia com luz na faixa próxima ao infravermelho: Similar à tecnologia usada em oximetria para a medição da saturação de oxigênio no sangue, requer uma fonte infravermelha externa. É um sistema de monitoramento altamente confiável para medir a glicose no sangue que usa métodos espectrômétricos, é robusto e pode detectar e predizer as concentrações de glicose com um nível de precisão aceitável. A radiação dos infravermelhos-proximos corresponde à região espectral mais próxima da região visível, compreendida entre 1 e $5 \mu \mathrm{m}$ de comprimentos de onda, por isso, possui baixa energia e sua interação com a matéria produz apenas transições e excitação dentro do mesmo estado fundamental de vibração. A Espectroscopia NIR usa uma fonte infra-vermelha externa da luz visível que penetra numa parte do corpo. Parte da luz penetrada é absorvida pela glicose. A quantidade de energia absorvida é analisada pela técnica chamada espectroscopia e é comparada a um feixe de detecção e então é convertida em um valor de glicose de sangue. Os fatores que podem alterar os resultados são: as condições ambientais, temperatura corpórea, hidratação da pele, freqüentes recalibrações (HAM et al., 1997);

- FIR (Far Infrared - Infravermelho distante) Espectroscopia com luz na faixa distante do infravermelho: Esta técnica permite medir a absorção da glicose pela radiação infravermelha distante contida nas emissões naturais de calor do corpo humano. Fontes externas não são necessárias, todavia o protótipo desenvolvido necessita resfriamento criogênico. O corpo emite radiações térmicas. Quando a energia sai do corpo, parte dela é absorvida pela glicose. A absorção na "banda de glicose" é descrita pela suas concentrações. A quantidade de energia absorvida é determinada pela espectroscopia e convertida em níveis de glicose do sangue. Esta técnica permite analisar tecidos com profundidades de 10 a $50 \mu \mathrm{m}$, através da luz com comprimentos de onda de 50 a $100 \mu \mathrm{m}$. A energia emitida é muito pequena e a precisão para este procedimento não tem sido determinada. Alguns fatores que podem alterar os resultados são: mudança na temperatura e $\mathrm{pH}$ da amostra a ser medida, glóbulos vermelhos, albumina 
(proteína de alto valor biológico presente no sangue) e outros. A tecnologia de reflexão da radiação infra-vermelha resultou no primeiro sensor não invasivo de glicose disponível comercialmente, o Diasensor@ ilustrado na Figura 2.3;

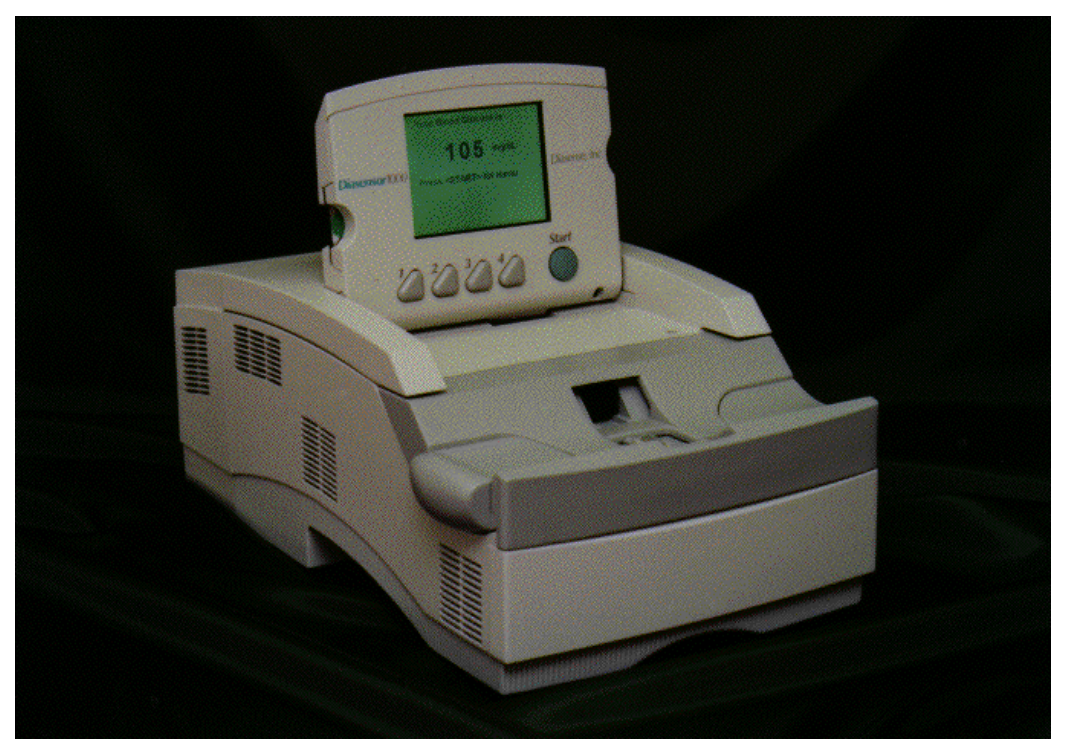

Figura 2.3 - Diasensor 1000

- Impedância das Ondas de Rádio. A glicose - como qualquer soluto não-iônico em uma solução aquosa - atenua a amplitude e desloca a fase de um feixe incidente de ondas de rádio de acordo com a sua concentração. Esta tecnologia é aplicada na indústria para a diferenciação dos tipos de cereais que compõem o alimento. Quando uma corrente alternada penetra numa solução, a amplitude e a fase da corrente são atenuadas em proporções para a concentração de solução. No sangue, a glicose é a substancia que apresenta a maior concentração comparada com outros solutos. A onda de rádio ou a corrente é aplicada a uma parte do corpo como um dedo e a corrente existente é comparada com uma corrente padrão e a diferença representa a impedância causada pela glicose. Esta é proporcional à concentração de glicose e ela pode ser expressada como tal. Existem poucos dados sobre a aplicação desta tecnologia. Um possível problema ocorre quando uma substância está presente no sangue com concentração maior do que a glicose (ORTIZ; BLANCO, 2004);

- Rotação óptica de luz polarizada ou Polarimetria. A rotação do plano de polarização em um feixe de luz que atravesse uma solução aquosa de glicose é proporcional a sua concentração. Descobriu-se que a glicose produz mudanças 
sensíveis na polarização da luz. Com a utilização de feixes de luz em vários comprimentos de onda é possível identificar uma correlação entre a polarização dos feixes e a glicose no sangue. Esse método sofre com mudanças no $\mathrm{pH}$, temperatura e concentração da amostra (COTÉ et al., 1992);

- Glicosúria: Este é o teste que mede a quantidade de glicose na urina. Embora ofereça as vantagens de ser indolor e de baixo custo, não oferece resultados de qualidade como o teste de ponta de dedo (glicemia capilar). Isso porque a glicosúria faz uma avaliação indireta da glicemia uma vez que o teste só é positivo a partir de $180 \mathrm{mg} / \mathrm{dl}$. É justamente a partir deste valor que os rins passam a "filtrar" a glicose na urina. Outra desvantagem do teste de glicosúria é que ele não detecta hipoglicemias. Dependendo da amostra de urina, pode-se observar valores que não condizem com o valor glicêmico no momento da coleta, o que pode ocorrer no estado de jejum. Nesses casos, verifica-se um resultado positivo na urina, porém a pessoa pode estar em plena hipoglicemia naquele momento. Isto ocorre se o exame não for feito de forma certa (DIB, 2000);

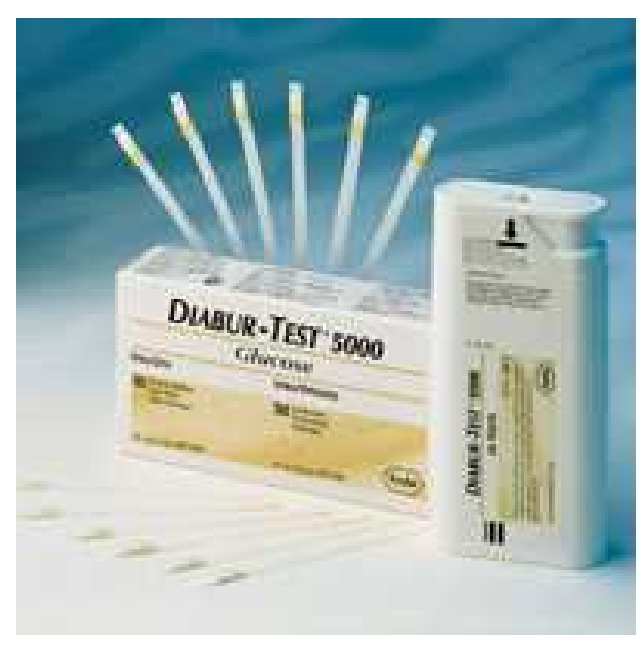

Figura 2.4 - Tiras reagentes para o teste de glicosúria

- Cetonúria: É uma técnica que também utiliza uma amostra de urina. A medida é feita pela presença de cetonas (resíduos no qual o corpo converte as gorduras que são consumidas), sendo mais comum no diabetes do tipo 1 nas situações em que a quantidade de insulina é insuficiente para que o organismo utilize a glicose como fonte de energia. $\mathrm{O}$ teste também é feito com uma fita apropriada. Para realizá-lo, uma pequena quantidade de urina é coletada em um recipiente limpo 
e a fita é colocada em contato com esta urina. Após algum tempo (verificar as especificações na caixa), a coloração da fita vai modificar-se e deve ser comparada com as cores mostradas na embalagem. Cada coloração corresponde a um valor aproximado das cetonas na urina. Caso o resultado detecte pequenas quantidades de cetona, um novo teste deve ser realizado após algumas horas para verificar se o problema foi corrigido ou não. Quando o teste detecta quantidades moderadas ou grandes é um sinal de que o diabetes está fora de controle (LEMOS-MARINI et al., 2000);

- Características dos Fractais a partir de Imagens da Retina Humana: É um novo método de quantificar o diabetes a partir de imagens da retina do olho humano. Notou-se que pacientes com diabetes apresentam dimensão da distribuição vascular da retina em imagens melhor dos que os normais (não possuem diabetes) conforme Figura 2.5. Para obter os índices quantitativos do diabetes, utilizou-se como parâmetros de medidas a dimensão do fractal e a lacunaridade (que descreve as características dos fractais que tem a mesma dimensão fractal, porém com formas diferentes). Utilizou-se para a classificação dos resultados do diagnóstico, quatro aproximadores diferentes: algoritmo backpropagation (baseia-se no princípio do aprendizado por correção de erro, no qual o erro é retropropagado da camada de saída pra as camadas intermediárias da rede neural), redes neurais com funções de ativação de base radial (RBF caracteriza-se por apresentarem uma resposta que decresce, ou cresce, monotonicamente com a distância a um ponto central), algoritmo genético (família de modelos computacionais inspirados na evolução que se baseiam na estrutura do cromossomo visando uma solução potencial para um problema específico) e mecanismo de votação. A desvantagem desse método é que, para o processamento das imagens, o mesmo exige que as fotos possuam alta resolução. A precisão dos resultados está intimamente relacionada com a alta qualidade das imagens. Observou-se que fotos com baixa resolução não podem produzir uma dimensão fractal precisa para ser mensurada (CHENG; HUANG, 2003); 


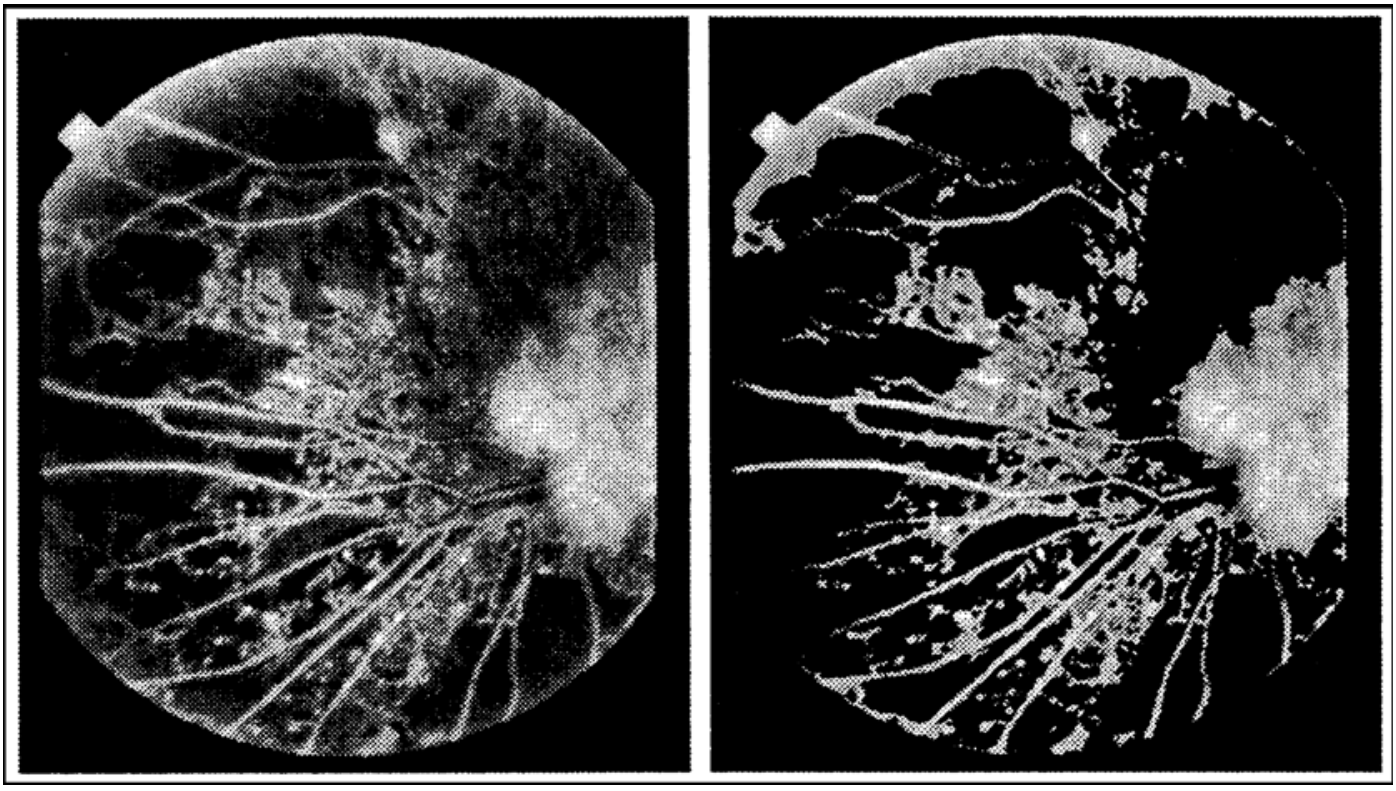

(a)

(b)

Figura 2.5 (a) Imagem original da retina de um paciente diabético. (b) Resultado segmentado depois do processamento da imagem.

Fonte: (CHENG; HUANG, 2003)

- Iontoforese Reversa. A glicose é extraída através da pele pela aplicação de uma corrente elétrica. Esta corrente atrai o sal que, por sua vez, traz consigo água e, conseqüentemente, glicose. O GlucoWatch Biographer@ (Figura 2.6) é um aparelho baseado nesta tecnologia e disponível comercialmente com o aval do FDA (Food and Drug Administration) para uso clínico. Concebido em formato de um relógio de pulso, após a extração da glicose, esta reage com a enzima glucose-oxidase presente em uma almofada na base do visor (TAMADA et al., 2002);

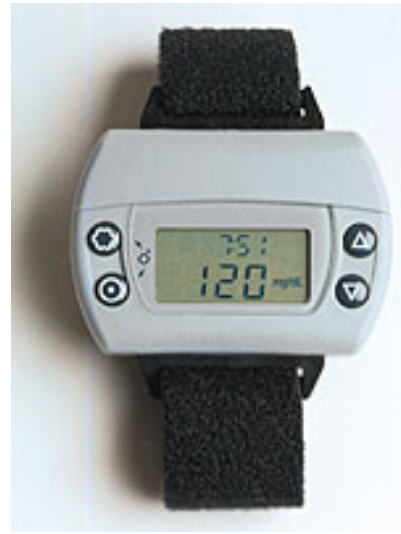

Figura 2.6 - GlucoWatch

Fonte: (TAMADA et al., 2002) 
- Medição de Glicemia baseada na análise do Eletrocardiograma: É um sistema portátil para a coleta e análise automática dos sinais de eletrocardiograma dos pacientes, com o objetivo do reconhecimento de padrões relativos à hipoglicemia tais como: freqüência cardíaca, arritmias, alterações morfológicas das ondas do eletrocardiograma. A desvantagem desse método é o período de coleta, das 23:00 às 7:00 horas. Os eletrodos devem ser posicionados de modo a permitir o máximo de conforto durante 8 horas ininterruptas de uso da aparelhagem. Entre os fatores mais comumente citados como fontes de erro para a detecção das mudanças morfológicas do Eletrocardiograma em resposta à hipoglicemia encontram-se: o tempo em que o paciente se encontra com diabetes, o uso de drogas e/ou medicação controlada - em especial, bloqueadores $\beta$-adrenérgicos (remédios que diminuem a carga de trabalho do coração), utilizados para controle de hipertensão - e histórico de doenças cardiovasculares (GARCIA; MARQUES, 2001);

\subsubsection{Métodos semi-invasivos}

Estes métodos são caracterizados por sistemas que determinam a glicemia de maneira menos agressiva, embora ainda invasivos. Os aparelhos utilizados neste método utilizam o sangue para a análise, porém em uma quantidade bem pequena.

- Biosensores: A glicose é medida por um ensaio eletroquímico por meio da enzima glicose-oxidase, que detecta valores de 40 a $400 \mathrm{mg} / \mathrm{dL}$. O sistema consiste em um aparelho semelhante a um pager conectado a um sensor implantado sob a pele. A cada dez segundos, é realizada uma medida da glicose e, a cada 5 minutos, um valor médio é registrado na memória do aparelho (288 medidas por dia e 864 no total de 72 h). Após os primeiros 60 minutos, a corrente elétrica é medida e convertida pelo aparelho em um valor que reflete a quantidade de glicose no sangue (MAIA; ARAUJO, 2005);

As desvantagens dessa técnica são a necessidade de trocar o sensor periodicamente e problemas com biocompatibilidade;

- Extração de Fluído Intersticial: Agulhas de micro-diálise são usadas para coletar o fluído intersticial e, junto consigo, glicose. Recentemente, um dispositivo baseado nesta tecnologia - Minimed CGMS (C - também recebeu a aprovação do FDA (Food and Drug Administration) para o uso pelos profissionais da área de saúde (Figura 2.7). Esse método requer 
acompanhamento minucioso, pois necessita que um médico insira um sensor (cateter) debaixo da pele abdominal do paciente. O sensor permanece nesta posição por mais de 72 horas, após esse período o médico deve removê-lo. A desvantagem desse método é que o usuário deve (através de punção digital) efetuar pelo menos (quatro) medições diárias da taxa de glicose sanguínea para efeitos de calibração. Outra desvantagem é que movimentos bruscos geram ruídos que diminuem a sensibilidade do sinal. Outras interações como a Vitamina $\mathrm{C}$ podem reagir com o eletrodo criando sinais espúrios. Além disso, quando os níveis de glicose são altos, o oxigênio pode tornar o reagente limitante no esquema sensitivo eletro-químico que o MinMed e outros utilizam (TAMADA et al., 2002).

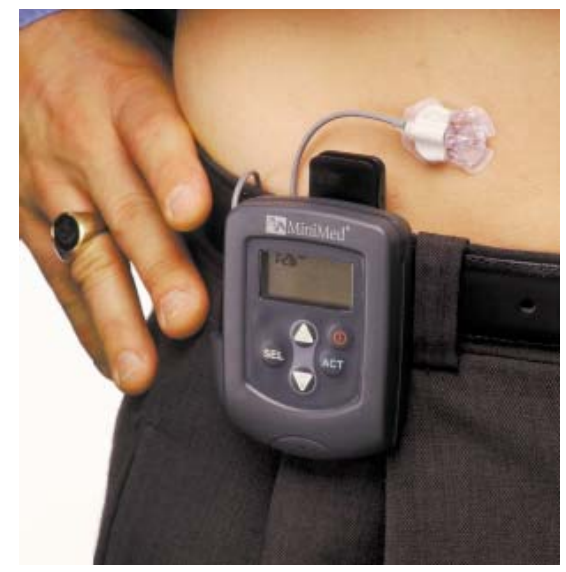

Figura $2.7-$ MiniMed

Fonte - (TAMADA et al. 2002)

\subsection{GlucoÍris}

O GlucoÍris é um sistema óptico digital idealizado para quantificar a glicemia em seres humanos de modo não invasivo. Composto de um aparato óptico/mecânico associado a um software, este sistema está sendo desenvolvido como alternativa para determinar a glicemia de maneira rápida, indolor e de baixo custo. (MENEZES, 2004)

Esse sistema foi projetado para obter uma imagem digital colorida de alta resolução da íris humana e extrair as componentes RGB e HSI destas imagens que, processadas, possibilitem correlacioná-las com o valor de glicemia, obtido com o auxílio de um glucômetro. 
O GlucoÍris tem sofrido algumas modificações para o seu aperfeiçoamento visando melhorar seu desempenho.

\subsubsection{Histórico}

Em 1998 surgiram os primeiros trabalhos que verificaram a existência de alterações na coloração da íris humana devido à glicemia. Nesta primeira fase desenvolveu-se o primeiro protótipo de dispositivo capaz de adquirir imagens digitais coloridas da íris junto com uma primeira versão do programa de computador. Utilizouse apenas um voluntário diabético para efeito de estudo, e os resultados mostraram a existência da correlação entre a glicemia e as componentes de cor. Em 2000, o protótipo físico foi revisado e otimizado obtendo-se imagens digitais com maior fidelidade. Envolveram-se sete voluntários que foram acompanhados por algumas semanas. Para cada leitura de glicemia realizada com um glicosímetro portátil, eram obtidas três imagens digitais de cada íris. As imagens foram processadas e os dados analisados, verificando-se que havia correlações em todos os voluntários, porém com graus diferentes. Em algumas pessoas, a relação entre a glicemia e a coloração de certas regiões da íris era linear e bem nítida. Porém, em outras essa relação não era tão bem definida, mas estava presente. Em 2002 construiu-se uma terceira versão do protótipo físico. Incorporou-se uma câmera digital de alta resolução e lente macro ao protótipo. $\mathrm{O}$ software foi aperfeiçoado para subdividir a íris em 36 regiões, e aplicou-se diferentes formas de normalização para compensar as variações naturais de iluminação e exposição. Nesta fase houve 24 voluntários, 19 destes eram diabéticos, foram acompanhados por 10 semanas (GONÇALVES JR., 2005);

\subsubsection{Estrutura do GlucoÍris}

O GlucoÍris é constituído de 3 partes principais: mecânico, óptico e do software. Mecanicamente o sistema deve assegurar que a posição e orientação relativa entre a câmera fotográfica e cada íris fotografada seja mantida dentro de certos limites. Conforme Figura 2.8, o sistema apresenta movimentos nos eixos X, Y e Z permitindo posicionar a câmera fotográfica de maneira adequada e obtendo-se imagens da íris na posição e orientação apropriadas (MENEZES, 2004). 


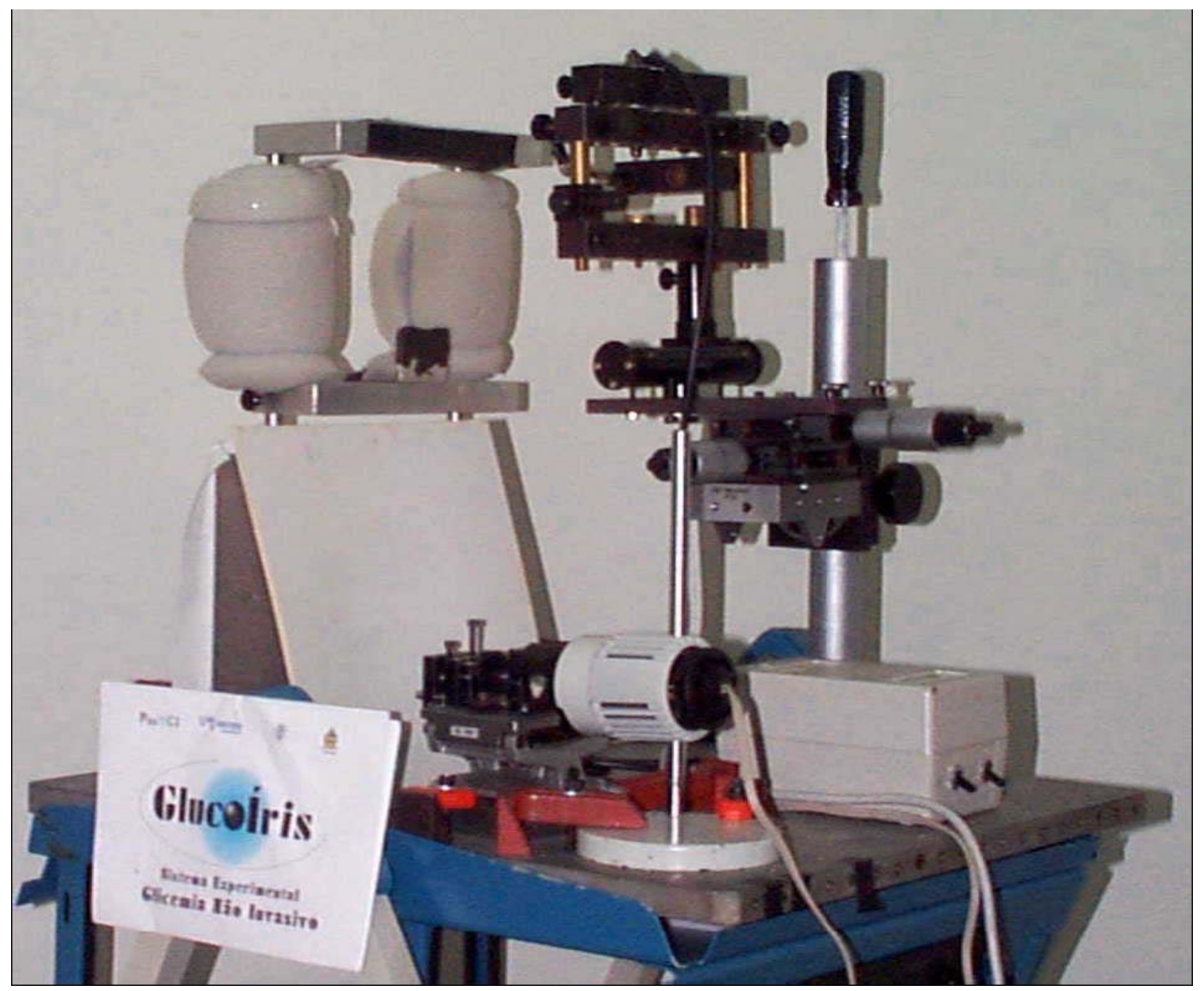

Figura 2.8: Foto do Sistema Mecânico

Fonte: MENEZES (2004)

A parte ótica é constituída por uma câmera fotográfica digital e um sistema de iluminação. Este permite iluminar a íris homogeneamente e de forma repetitiva, obtendo-se imagens com o mínimo de interferência de reflexos indesejados. Esse mecanismo utiliza-se de fibra ótica para deslocar o reflexo para dentro da imagem da pupila, deixando assim a região da íris isenta de reflexos que é região de interesse a ser estudada (PICA, 2002).

O software é considerado a principal parte do sistema. Este tem por finalidade processar e analisar as imagens das írides fotografadas extraindo das mesmas dados numéricos que representem as componentes da cor de regiões bem definidas da íris. Utiliza-se um algoritmo de busca para localizar as fronteiras externa da íris (íris/esclera) e interna (íris/pupila). Faz-se a subdivisão da íris em 36 elementos. Angularmente a subdivisão foi realizada em 12 partes, numeradas semelhantementes como às 12 horas 
de um relógio. Radialmente adotou-se a subdivisão em 3 partes, denominadas de (GONÇALVES JR., 2005):

- "Pupilar" (PU): a região mais interna

- "Colarete" (CO): a região central

- "Ciliar" (CI): região mais externa

Estas regiões podem ser verificadas na Figura 2.9.

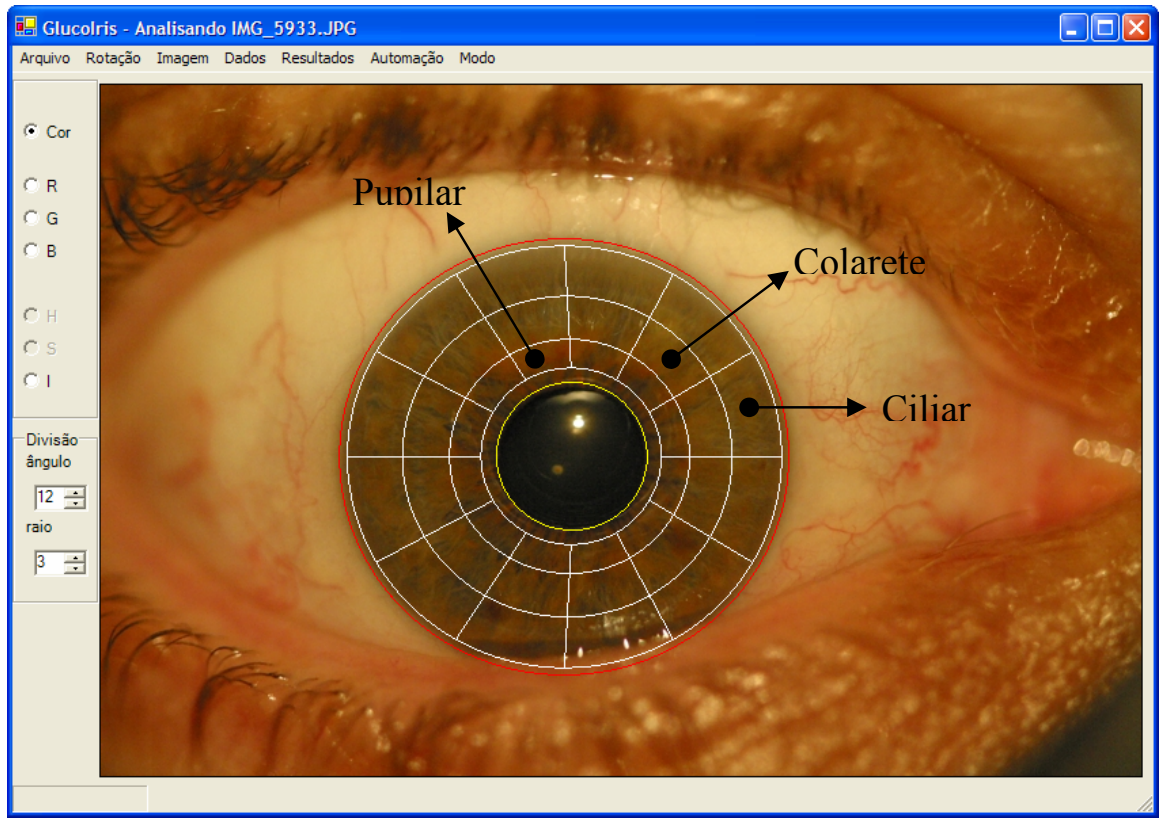

Figura 2.9 - Tela principal do programa de extração de dados da coloração de 36 regiões da íris.

Fonte: (GONÇALVES JR., 2005)

O software calcula a correlação linear entre o nível de glicemia e cada componente de cor de cada região de interesse para um conjunto de imagens. Cada imagem da íris corresponde a um momento onde o nível de glicemia do voluntário foi determinado por um método de referência invasivo. Esse valor e as componentes de cor normalizadas são utilizados para calcular o coeficiente de correlação linear.

O programa gera uma tabela contendo 216 valores correspondentes aos coeficientes de correlação para cada uma das seis componentes de cor normalizadas de cada uma das 36 regiões de interesses regulares. Esses serão os dados que serão utilizados nesse trabalho para automatizar o processo de obtenção dos valores de glicemia a partir de imagens das írides. 


\section{Redes Neurais}

As Redes Neurais Artificiais (RNAs) são ferramentas de Inteligência Artificial que possuem a capacidade de se adaptar e de aprender a realizar uma certa tarefa, ou comportamento, a partir de um conjunto de exemplos dados. A aplicação das RNAs junto a tarefas de processamento de imagens torna-se bastante atrativa dadas as características deste tipo de ferramentas, tais como: robustez, generalização, paralelismo e tolerância ao ruído. São de natureza multidisciplinar e abrangem o conhecimento de algumas ciências tais como: neurociência, matemática, estatística, física, ciência da computação e engenharia. Como elas são capazes de aprender a partir de dados de entradas, permitem inúmeras aplicações em diversas áreas como: reconhecimento de padrão, processamento de sinais e controle, modelagem, aproximação de funções, otimização (HAYKIN, 2001).

As RNAs baseiam-se no funcionamento do cérebro humano que é a estrutura mais complexa estudada pelo homem, sendo ainda, muito pouco compreendida. O principal objetivo das RNAs é o desenvolvimento de computadores e programas que são capazes de imitar e/ou entender aspectos do pensamento humano.

Neste capítulo, é realizada uma revisão dos conceitos sobre redes neurais artificiais, detalhando a arquitetura de rede neural perceptron multicamadas, que será usada para estimação do nível de glicemia a partir de imagens da íris humana, e o algoritmo de treinamento backpropagation.

\subsection{Introdução}

As Redes neurais artificiais (RNAs) foram inspiradas nas redes neurais biológicas. Elas resultaram do desejo de se construir máquinas capazes de exibir comportamento inteligente, ou seja, com inteligência artificial. A inteligência artificial é definida como um campo da ciência da computação que visa reproduzir por meios 
computacionais as características normalmente atribuídas à inteligência humana, tais como: compreensão da linguagem, aprendizagem, raciocínio, dentre outras.

A origem das RNAs está baseada no neurônio biológico típico, formado basicamente por dendritos, o corpo celular e o axônio que junto com outros neurônios podem ter muitas formas de conexão, com as mais variadas topologias, formando as redes neurais biológicas. Assim, a arquitetura de cada rede neural é baseada em blocos de construção similar que realizam o processamento de informação. A Figura 3.1 mostra um neurônio típico. Segue uma breve descrição dos seus componentes e estruturas (GUYTON, 1988):

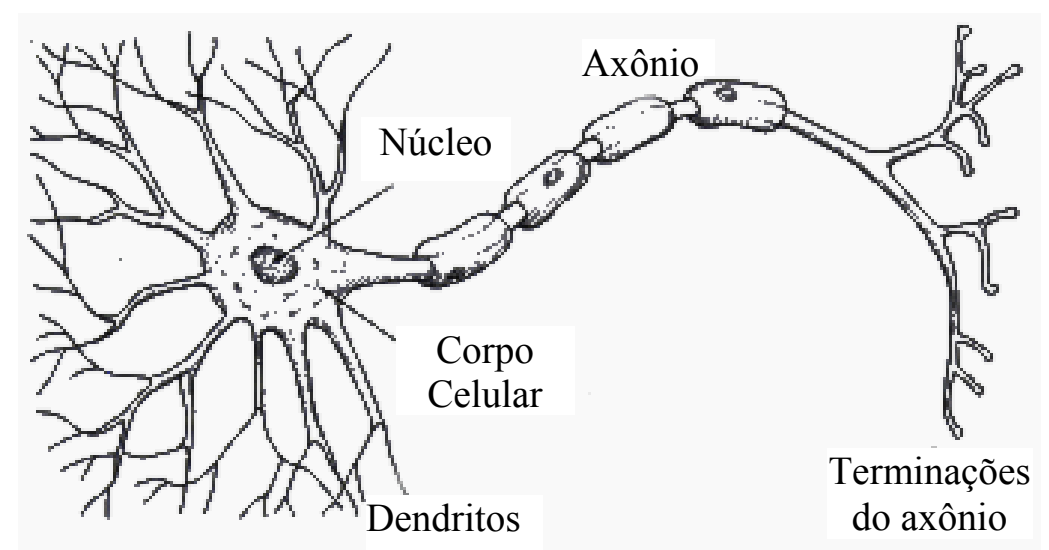

Figura 3.1 - Componentes do neurônio Biológico

- Corpo Celular: É a região de onde se diferenciam todas as outras partes do neurônio. É responsável, também, pela maior parte da nutrição e é necessário para a continuidade da vida de todo o neurônio.

- Dendritos: São prolongamentos múltiplos e ramificados, com origem no corpo celular. Constituem as partes receptoras principais do neurônio. Isto é, a maior parte dos sinais que devem ser transmitidos ao neurônio chegam a ele por meio dos dendritos, embora alguns sinais cheguem diretamente pela superfície do corpo celular. Os dendritos de cada neurônio, em geral, recebem sinais de muitos milhares de pontos de contato com outros neurônios, as sinapses (região de passagem do impulso nervoso de um neurônio para a célula adjacente).

- Axônio: Cada neurônio possui um axônio. Essa parte do neurônio é chamada de fibra nervosa. Seu comprimento pode ser de apenas alguns milímetros, como 
acontece com os axônios dos neurônios pequenos do cérebro, ou pode atingir até um metro, como no caso dos axônios que partem da medula para inervar os pés. Os axônios transmitem os sinais neurais para a célula seguinte no cérebro ou na medula espinhal, ou para músculos e glândulas nas regiões periféricas do corpo.

- Terminais Axônicos e Sinapses: Próximos a seus términos, todos os axônios ramificam-se extensamente, com o número total dessas ramificações, podendo atingir aos milhares. $\mathrm{Na}$ extremidade de cada uma dessas ramificações existe uma terminação neural especializada que, no sistema nervoso central, é chamada de botão sináptico. Por sua vez, esse botão sináptico fica situado sobre a superfície da membrana de um dendrito ou corpo celular de outro neurônio. Esse ponto de contato entre o botão sináptico e a membrana neural é a sinapse. É através das sinapses que os sinais são transmitidos de um neurônio a outro. Quando estimulado, o botão sináptico libera quantidade diminuta de um hormônio, chamado de substância transmissora, no espaço entre o botão e a membrana do neurônio, e a substância transmissora estimula este neurônio.

Assim, as RNAs podem ser mais adequadamente caracterizadas como modelos computacionais que têm propriedades particulares e habilidades para se adaptar ou aprender, para generalizar, para distribuir ou organizar dados, e cuja operação é baseada em processamento paralelo.

\subsection{Histórico}

O primeiro modelo matemático para um neurônio biológico foi proposto por Warren Mc-Culloch e Walter Pitts em 1943 e considera a saída do neurônio uma resposta binária a um estímulo fornecido. Este modelo se preocupou muito mais em descrever um modelo artificial de um neurônio e apresentar as suas capacidades computacionais do que apresentar técnicas de aprendizado. O modelo de McCulloch e Pitts, embora seja rudimentar quando comparado ao potencial dos modelos hoje disponíveis, foi inovador e pioneiro (CARVALHO et al., 1998).

Donald Hebb, em 1949, apresentou o primeiro trabalho utilizando conceitos de aprendizagem, propôs um princípio pelo qual o aprendizado em sistemas nervosos complexos poderia ser reduzido a um processo individual, em que a intensidade das conexões sinápticas é alterada apenas em função dos erros localmente detectáveis. A regra Hebb que foi interpretada do ponto de vista matemático até hoje vem sendo utilizada em muitos algoritmos de aprendizagem (KOVÁCS, 1996). 
Em 1960, o trabalho de Widrow teve uma contribuição realmente importante que foi a criação de um princípio de treinamento extremamente poderoso para as redes de adaline (modelo neural linear, muito simples conceitualmente, desenvolvido por Widrow), conhecido como Regra Delta, que mais tarde foi generalizado para redes com modelos neurais mais elaborados.

Em 1956, no "Darthmouth College", nasceram os dois paradigmas da Inteligência Artificial, a simbólica e a conexionista. A Inteligência Artificial Simbólica tenta simular o comportamento inteligente humano desconsiderando os mecanismos responsáveis por tal. Já a Inteligência Artificial Conexionista acredita que construindose um sistema que simule a estrutura do cérebro, este sistema apresentará inteligência, ou seja, será capaz de aprender, assimilar, errar e aprender com seus erros.

Frank Rosemblatt, em 1958, a partir do seu novo modelo, o perceptron, descreveu uma topologia de RNA, estruturas de ligação entre os neurônios, e o mais importante, propôs um algoritmo para treinar a rede para executar determinadas funções. Este tipo de modelo comporta-se como um classificador de padrões, porém é limitado pela capacidade de classificar classes que sejam apenas linearmente separáveis.

Apesar do aparente sucesso dos modelos desenvolvidos, em 1969, Minsky e Papert mostraram as limitações da rede perceptron para problemas não linearmente separáveis, o que levou a um declínio nas investigações de metodologias relacionadas à área de redes neurais.

Entretanto, alguns trabalhos importantes foram publicados durante essa década, destacando-se os mapas auto-organizáveis. No início da década de 80, o interesse na teoria das RNAs foi reativado após a publicação dos estudos de John Hopfield baseados no princípio físico de armazenamento de informação em configurações dinamicamente estáveis, sendo este um dos primeiros modelos a introduzir dinâmica em RNAs.

Em 1986, através da publicação do livro Parallel Distributed Processing, o algoritmo de retropropagação (backpropagation), previamente proposto por Werbos, foi divulgado e, atualmente, é o algoritmo mais popular para o treinamento de RNAs estáticas multicamadas.

\subsection{Modelo de Neurônio Artificial}

O neurônio artificial é uma estrutura lógico-matemática que procura simular a forma, o comportamento e as funções de um neurônio biológico. Assim sendo, os dendritos foram substituídos por entradas, cujas ligações com o corpo celular artificial 
são realizadas através de elementos chamados de peso (simulando as sinapses). Os estímulos captados pelas entradas são processados pela função de soma, e o limiar de disparo do neurônio biológico foi substituído pela função de transferência.

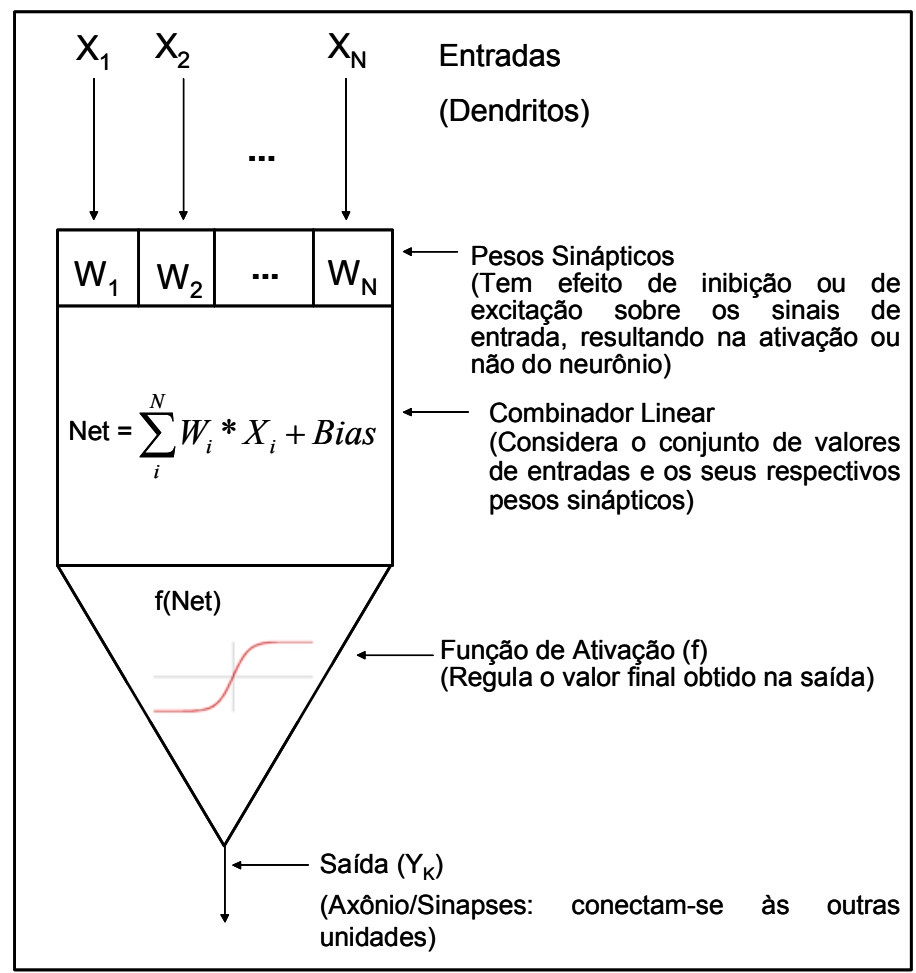

Figura 3.2- Modelo de um neurônio Artificial; adaptado de Osório \& Bittencourt (2000)

A Figura 3.2 ilustra o modelo de um neurônio, que forma a base para o projeto de redes neurais artificiais. É possível identificar os elementos básicos neste modelo neuronal (HAYKIN, 2001).

Cada conexão $\mathrm{j}$ possui um valor de entrada $\mathrm{x}_{\mathrm{j}}$ (ou sinal de entrada) e um peso $\mathrm{w}_{\mathrm{kj}}$, onde o primeiro índice do peso identifica o neurônio k e o segundo, a conexão.

$\mathrm{O}$ combinador linear calcula a entrada líquida (Net) do neurônio como o somatório de todas as entradas multiplicadas pelos pesos respectivos, mais o valor do bias. O bias é uma espécie de excitador ou inibidor e tem o efeito de aumentar ou diminuir a entrada líquida da unidade, dependendo se o seu valor for positivo ou negativo, respectivamente.

Em seguida, a função de ativação f é aplicada sobre a entrada líquida gerando o valor de saída $Y_{K}$ do neurônio. Essa função é também conhecida como função restritiva, já que limita o intervalo possível da saída a um valor finito. As funções logística e 
tangente hiperbólica, que fornecem resultados no intervalo entre 0 e 1 e entre -1 e 1 , respectivamente, são bastante usadas como funções de ativação de neurônios. As funções de ativação mais típicas são ilustradas na Figura 3.3.

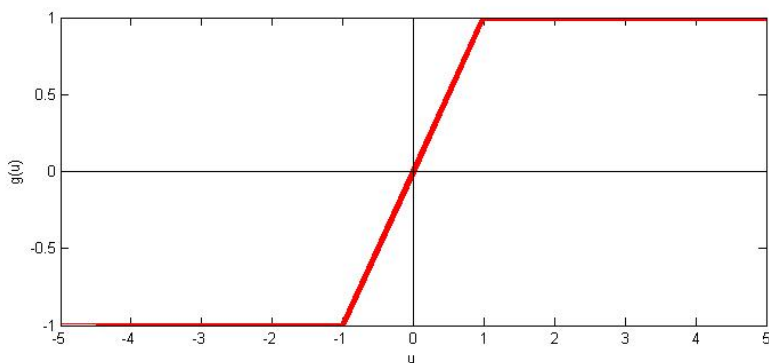

Função Rampa :

$g(u)=\left\{\begin{array}{l}a, \text { se } u>a \\ u, \text { se }-a \leq u \leq a \\ -a, \text { se } u<a\end{array}\right.$

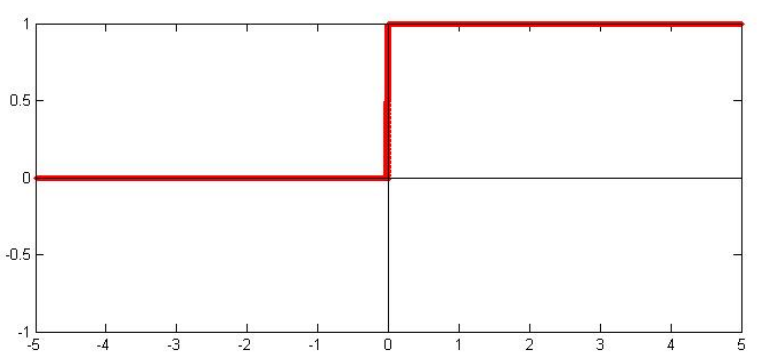

Função Degrau

$g(u)=\left\{\begin{array}{l}1, \text { se } u \geq 0 \\ 0, \text { se } u<0\end{array}\right.$

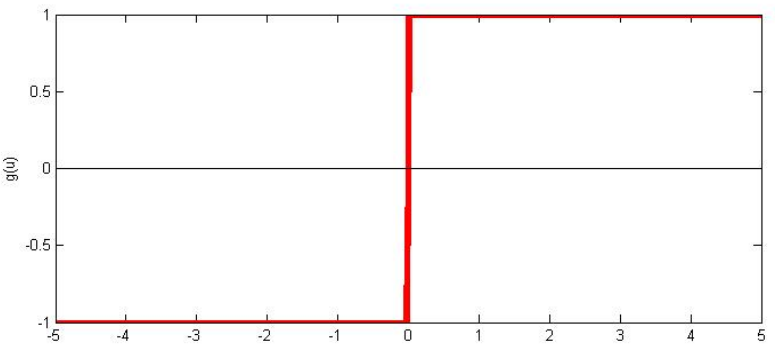

Função Sinal

$g(u)=\left\{\begin{array}{r}1, \text { se } u>0 \\ 0, \text { se } u=0 \\ -1, \text { se } u<0\end{array}\right.$

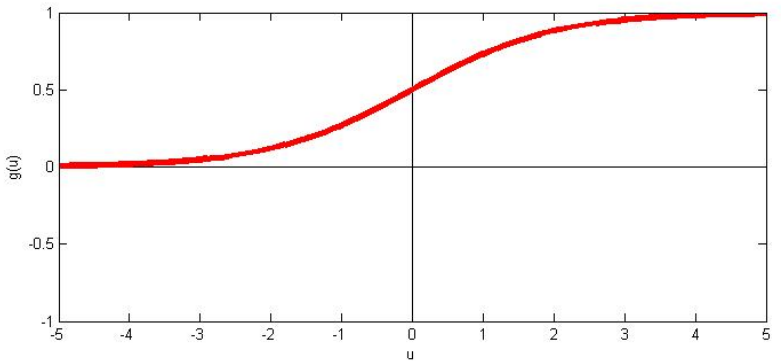

Função Sigmóide (ou

Função Logística)

$g(u)=\frac{1}{1+e^{-\beta u}}$

Função Tangente hiperbólica

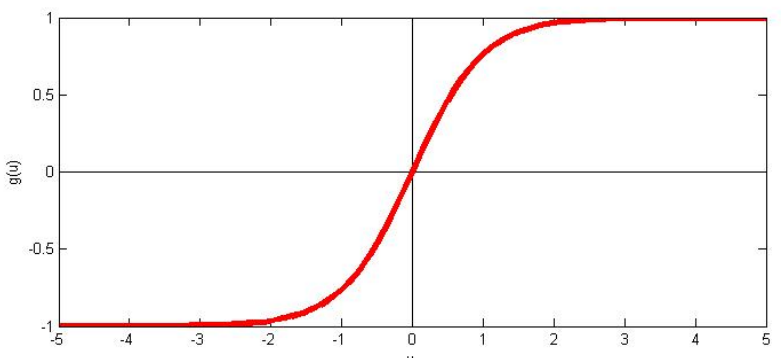

$g(u)=\frac{1-e^{-\beta u}}{1+e^{\beta u}}$

Figura 3.3 - Gráficos das funções de Ativação mais comumente empregadas na modelagem de neurônios 
Matematicamente, pode-se representar um neurônio k por meio do seguinte par de equações:

$$
\begin{gathered}
u_{k}=\sum \omega_{k j} x_{j}+b_{k} \\
y_{k}=\varphi\left(u_{k}\right),
\end{gathered}
$$

onde $\mathrm{u}_{\mathrm{k}}$ é a saída do combinador linear devido aos sinais de entrada, e $\mathrm{y}_{\mathrm{k}}$ é o sinal de saída do neurônio.

\subsection{Arquiteturas de Redes}

Uma rede neural artificial possui sempre uma camada de entrada e uma camada de saída. Entre a camada de entrada e a de saída, existe um número variável de camadas intermediárias. A esta disposição das camadas e número de neurônios por camada, dá-se o nome de arquitetura da rede neural.

A definição da arquitetura de uma RNA é um parâmetro importante na sua concepção, uma vez que ela restringe o tipo de problema que pode ser tratado pela rede. Redes com uma camada única de neurônios, por exemplo, só conseguem resolver problemas linearmente separáveis. Redes recorrentes, por sua vez, são mais apropriadas para resolver problemas que envolvem processamento temporal. Os seguintes parâmetros fazem parte da definição da arquitetura de uma RNA: número de camadas da rede, número de neurônios em cada camada, tipo de conexão entre os neurônios e topologia da rede. São apresentados na Figura 3.4 alguns exemplos de arquiteturas de RNA (CARVALHO et al., 1998).

Quanto ao número de camadas, pode se ter redes de camada única, que tem uma camada de entrada e uma única camada de neurônios que é a própria camada de saída (Figura 3.4 a), ou redes de múltiplas camadas, difere da anterior por apresentar uma ou mais camadas escondidas de neurônios (Figura 3.4 b).

As conexões entre os neurônios podem ser do tipo feedforward ou acíclica, onde a saída de um neurônio na i-ésima camada da rede não pode ser usada como entrada de neurônios em camadas de índice menor ou igual a $i$ (Figura 3.4 a); ou feedback ou cíclica, onde a saída de algum neurônio na i-ésima camada da rede é usada como entrada de neurônios em camadas de índices menor ou igual a $i$ (Figura $3.4 \mathrm{c}$ ). 
Além disso, as RNAs podem ser classificadas quanto à sua conectividade em rede fracamente (ou parcialmente) conectada ou rede totalmente conectada. A rede neural é dita totalmente conectada, se cada um dos nós de uma camada da rede está conectado a todos os nós da camada adjacente (Figura 3.4 a, b, c), entretanto, se alguns dos elos de comunicação (conexões sinápticas) estiverem faltando na rede, diz-se que a rede é parcialmente conectada.

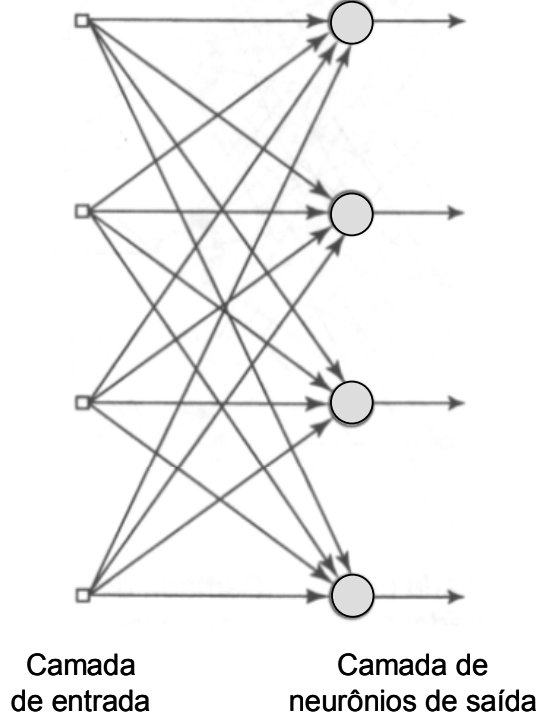

(a)

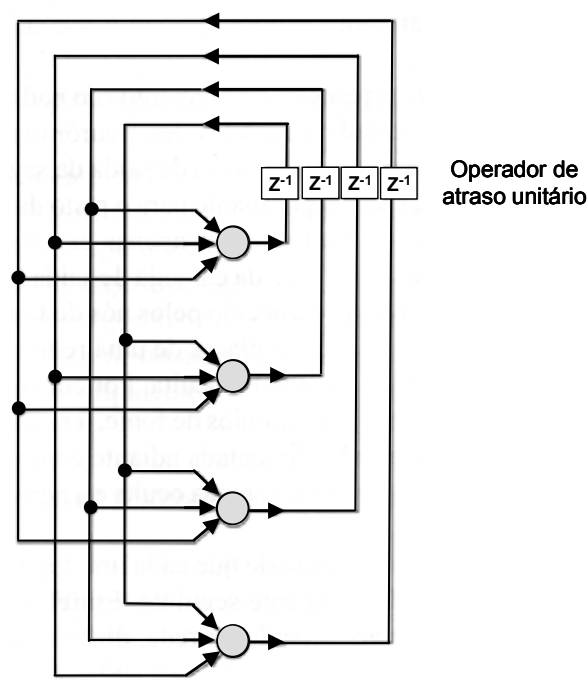

(c)

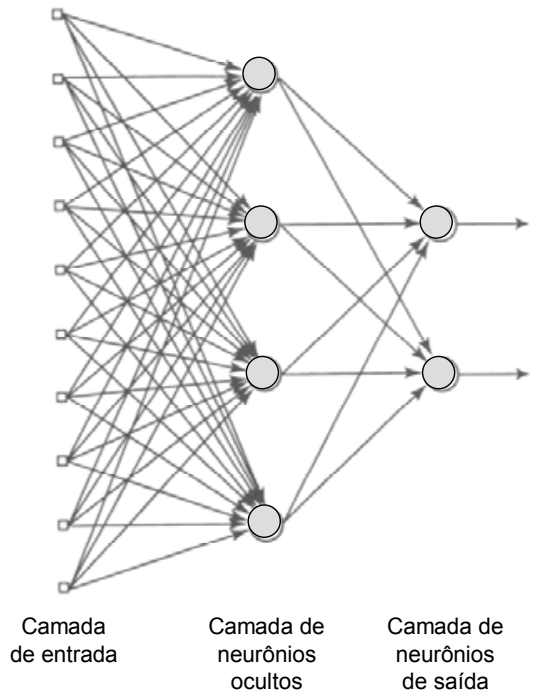

(b)

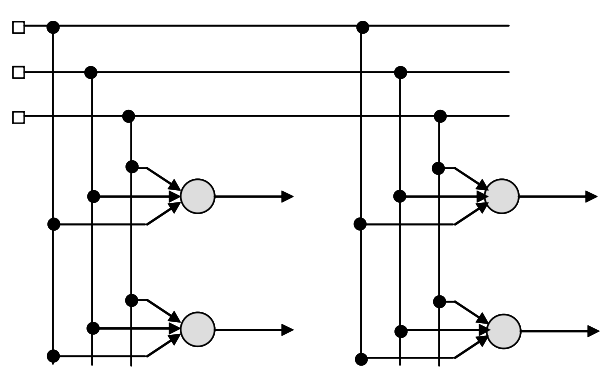

Lattice $(2 \times 2)$

Figura 3.4 - Exemplos de Arquiteturas de RNAs

Para que as RNAs tenham uma boa generalização, é necessário fornecer à rede a maior quantidade possível de informação a respeito do problema a ser solucionado. 
Contudo, por problemas de complexidade computacional (espaço e tempo), deve-se buscar reduzir ao mínimo o número de neurônios e a quantidade de conexões entre eles. Assim, é importante definir algoritmos que não somente otimizem os pesos para uma dada arquitetura , como também otimizem a própria arquitetura. Isto significa otimizar o número de camadas e o número de neurônios por camada (KOVÁCS, 1996).

\subsection{Algoritmo de Aprendizagem}

\subsubsection{Introdução}

A habilidade de aprender a partir de seu ambiente e de melhorar seu desempenho através da aprendizagem é uma importante propriedade para uma rede neural. Um conjunto de procedimentos bem definidos para adaptar os parâmetros de uma RNA para que a mesma possa aprender uma determinada função é chamado de algoritmo de aprendizado. Nota-se que não existe um único algoritmo de aprendizado. O que se tem é um conjunto de ferramentas representadas por diversos algoritmos, cada qual com suas vantagens e desvantagens. Eles diferem entre si pela forma como é formulado o ajuste de um peso sináptico de um neurônio.

Existem vários algoritmos para o treinamento da rede, eles podem ser agrupados em dois paradigmas principais: Aprendizado Supervisionado e Aprendizado Não Supervisionado.

\subsubsection{Aprendizagem Supervisionada}

Este método é o mais comum no treinamento das RNAs, sendo chamado de aprendizado supervisionado porque a entrada e a saída desejada para a rede são fornecidas por um supervisor (professor) externo. O objetivo é ajustar os parâmetros da rede, de forma a encontrar uma ligação entre os pares de entrada e saída fornecidos. A Figura 3.5 ilustra o mecanismo de aprendizado supervisionado. $\mathrm{O}$ professor indica explicitamente um comportamento bom ou ruim para a rede, visando direcionar o processo de treinamento. A rede tem sua saída corrente (calculada) comparada com a saída desejada, recebendo informações do supervisor sobre o erro da resposta atual. O sinal de erro é definido como a diferença entre a resposta desejada e a resposta real da rede. Realiza-se o ajuste, iterativamente, com o objetivo de fazer a rede neural emular o professor. Assim o conhecimento do ambiente disponível ao professor é transferido para a rede neural através de treinamento. Quando se alcança esta condição pode-se, então, 
dispensar o professor e a rede neural passa a lidar com o ambiente inteiramente por si mesma.

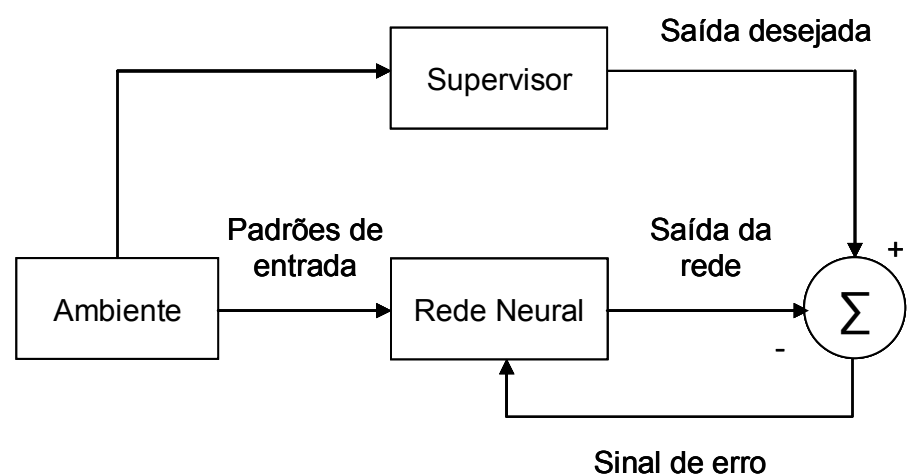

Figura 3.5 - Aprendizado Supervisionado

A desvantagem deste tipo de aprendizagem é que, na ausência do professor, a rede não consegue aprender novas estratégias para situações não cobertas pelos exemplos do treinamento da rede.

\subsubsection{Aprendizagem não supervisionada}

No aprendizado não supervisionado, como o próprio nome sugere, não há um professor ou supervisor para acompanhar o processo de aprendizado. Este método é ilustrado na Figura 3.6.

Apesar da semelhança do aprendizado supervisionado com o aprendizado nos seres humanos, muitos dos sistemas biológicos ocorrem através de aprendizado não supervisionado, como por exemplo os estágios iniciais dos sistemas de visão e audição.

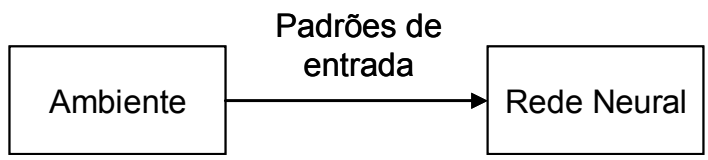

Figura 3.6- Aprendizado não supervisionado

Para estes algoritmos, somente os padrões de entrada estão disponíveis para a rede, ao contrário do aprendizado supervisionado, cujo conjunto de treinamento possui pares de entrada e saída. A partir do momento em que a rede estabelece uma harmonia com as regularidades estatísticas da entrada de dados, desenvolve-se nela uma habilidade de formar representações internas para codificar características da entrada e criar novas classes ou grupos automaticamente. Este tipo de aprendizado, só se torna 
possível quando existe redundância nos dados de entrada. Sem redundância seria impossível encontrar quaisquer padrões ou características dos dados de entrada.

A estrutura do sistema de aprendizado não supervisionado pode tomar uma variedade de formas diferentes. Ela pode, por exemplo, consistir de uma camada de entrada, uma camada de saída, conexões feed-forward da entrada para a saída e conexões laterais entre os neurônios da camada de saída. Um outro exemplo é uma rede feed-forward com múltiplas camadas, onde a livre organização procede na base de camada por camada. Nestes dois exemplos, o processo de aprendizado consiste em modificar repetidamente o peso sináptico de todas as conexões do sistema em resposta às entradas.

\subsection{Perceptron Camada Única}

As Redes perceptron com uma camada são o tipo mais antigo de redes neurais, as quais são formadas por uma camada única de neurônios de saída, os quais estão conectados por pesos às entradas. Esta é a forma mais simples de uma rede neural, e é utilizada na classificação de padrões que devem ser linearmente separáveis. A soma do produto entre os pesos e as entradas alimenta cada neurônio de saída, e se o resultado desta operação exceder um certo limiar, o neurônio coloca o valor 1 na saída; se o resultado for inferior ao limiar, o neurônio coloca o valor -1 na saída. Os neurônios com esse comportamento são chamados de neurônios de McCulloch-Pitts ou neurônios com limiar. $\mathrm{Na}$ literatura técnica o termo perceptron diz respeito a redes com apenas um desses neurônios.

O perceptron funciona matematicamente da seguinte maneira: para cada neurônio, os sinais de entrada são multiplicados pelos pesos, gerando um valor de saída do combinador linear (Equação 3.1). Para que os neurônios sejam ativados na saída da rede (Equação 3.2), é usada uma função de ativação Degrau, após a soma das entradas (Figura 3.3 b). Esta função de ativação ativa o neurônio no intervalo entre [0, 1], onde:

$$
\varphi(v)=\left\{\begin{array}{l}
1 \text { se } v \geq 0 \\
0 \text { se } v<0
\end{array}\right.
$$

O perceptron pode ser treinado por um algoritmo de aprendizagem simples, chamado geralmente de regra-delta. Este algoritmo calcula os erros entre a saída dos 
dados calculados e a saída desejada, e utiliza isso para ajustar os pesos, assim executando um formulário da descida do gradiente.

\subsubsection{Algoritmo LMS (regra delta)}

Em 1960, B. Widrow e M. Hoff criaram a regra de aprendizagem, também conhecida como algoritmo do erro quadrático médio (MSE) ou regra delta. O objetivo do algoritmo de aprendizagem é minimizar o erro quadrático médio (MSE) entre a saída da rede e a saída desejada.

O algoritmo LMS ou regra delta permite que a rede execute uma aprendizagem contínua mesmo após um dado padrão de entrada ter sido treinado. Uma vantagem do algoritmo LMS sobre a regra de aprendizado do perceptron é que torna a rede mais robusta a ruídos. Por este motivo, têm surgido várias aplicações para este algoritmo na área de processamento de sinais.

A regra delta é um outro exemplo de aprendizado supervisionado no qual a regra de aprendizagem é determinada por um conjunto de entradas e saídas desejadas $\left\{\mathrm{x}_{1}, \mathrm{~d}_{1}\right\}$, $\left\{\mathrm{x}_{2}, \mathrm{~d}_{2}\right\}, \ldots,\left\{\mathrm{x}_{\mathrm{n}}, \mathrm{d}_{\mathrm{n}}\right\}$, onde $\mathrm{x}_{\mathrm{j}}$ é o vetor do padrão $\mathrm{j}$ e $\mathrm{d}_{\mathrm{j}}$ corresponde ao alvo ou vetor de saída desejada. Esta regra ajusta os pesos da rede neural e o bias para minimizar a diferença (erro) entre a saída da rede e resposta desejada após o treinamento de todos os padrões. Isto é executado para reduzir o erro de cada padrão, um a um, através da correção dos pesos após um determinado número de padrões de treinamento. $\mathrm{O}$ sinal de erro é representado por e(n), como mostra a Equação 3.4:

$$
e(n)=d(n)-x(n) \cdot w(n)
$$

Após o cálculo do erro, são aplicadas as equações (Equação 3.5 e 3.6) de atualização dos pesos:

$$
\begin{gathered}
\Delta w(n)=\eta \cdot x(n) \cdot e(n) \\
w(n+1)=w(n)+\Delta w(n),
\end{gathered}
$$

Na Equação 3.5, o $\eta$ é o parâmetro da taxa de aprendizagem. Este parâmetro é responsável pela velocidade de treinamento da rede e determina o desempenho da aprendizagem por correção de erro. A correta escolha do parâmetro da taxa de 
aprendizagem deve ser feito com cautela, para assegurar que seja alcançada a estabilidade ou convergência do processo de aprendizagem (HAYKIN, 2001).

Uma maneira de analisar o comportamento da convergência do algoritmo LMS para o ADALINE é traçar a curva de aprendizagem. A curva de aprendizagem é um gráfico do valor médio quadrático do erro de estimação, em função do número de iterações n, conforme ilustrado na Figura 3.7:

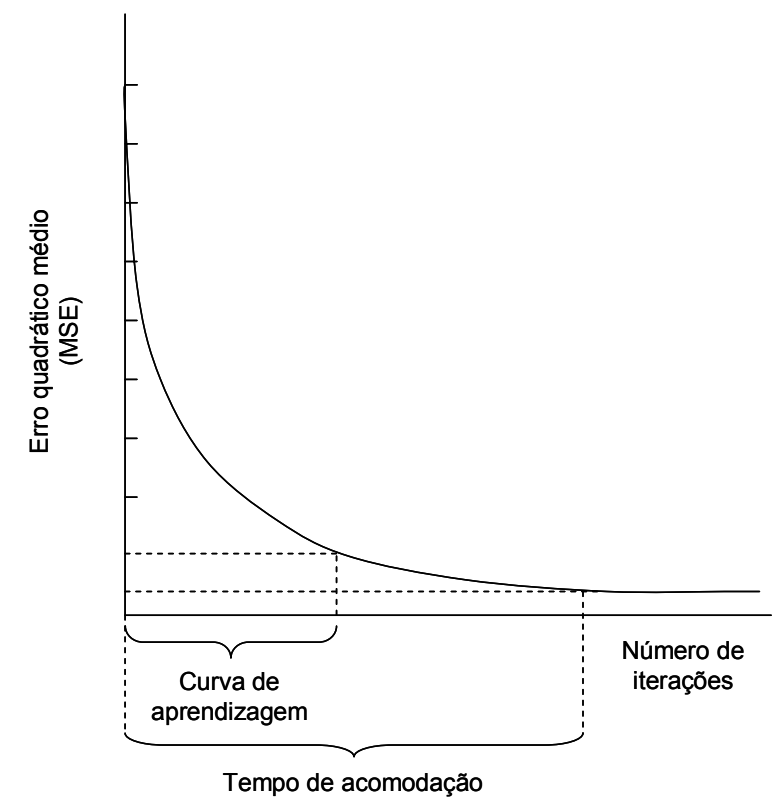

Figura 3.7 - Curva de aprendizagem idealizada do algoritmo LMS

Fonte: Adaptado (HAYKIN, 2001)

Uma outra característica muito importante no algoritmo LMS é o tempo de acomodação, que é o tempo para se atingir uma condição estável (a convergência do algoritmo LMS). Quanto menor for o parâmetro da taxa de aprendizagem $\eta$, menor serão as variações dos pesos sinápticos da rede, de uma iteração para a outra, e mais suave será a trajetória no espaço de pesos. Porém, desta maneira a taxa de aprendizagem é lenta. Por outro lado, se fizermos o parâmetro da taxa de aprendizagem $\eta$ muito grande, para acelerar a taxa de aprendizagem, as grandes modificações nos pesos sinápticos resultantes podem tornar a rede instável (oscilatória). Um método simples de aumentar a taxa de aprendizagem evitando, no entanto, o perigo de instabilidade, é modificar a regra delta, incluindo um termo de momento. 


\subsection{Perceptron multicamadas (MLP - Multilayer perceptron)}

Esta classe de rede consiste de múltiplas camadas de unidades computacionais, geralmente interconectadas em uma forma feedforward. Isso quer dizer que cada neurônio em uma camada tem conexões diretas a neurônios da próxima camada. Em muitas aplicações as unidades dessas redes aplicam uma função sigmóide (Figura 3.3 e) como a função de ativação.

O teorema de aproximação universal diz que toda função contínua que mapeia intervalos de números reais a algum intervalo de números reais de saída pode ser arbitrariamente aproximado com precisão por um perceptron multicamadas com somente uma camada oculta. Este resultado só é válido para classes restritas de funções de ativação, por exemplo funções sigmóides.

Redes multicamadas podem usar um grande número de técnicas de aprendizado, sendo que a mais popular é a propagação reversa. Neste caso os valores de saída são comparados com a resposta correta para computar o valor de alguma função-erro predefinida. Por alguma técnica o erro é então alimentado de volta na rede. Usando essa informação, o algoritmo ajusta os pesos de cada conexão para reduzir o valor da função erro. Isso será melhor descrito nos próximos itens.

O processo de treinamento destas redes é realizado através do algoritmo backpropagation.

\subsubsection{Algoritmo de treinamento Backpropagation}

$\mathrm{O}$ método de treino por retropropagação, ou backpropagation, foi o primeiro método de treino para a RNA. Este método consiste basicamente de duas etapas executadas através das camadas da rede: um passo para frente a propagação (forward) e um passo para trás, a retropropagação (backward).

Na propagação um vetor de entrada é aplicado aos pesos da rede e seu efeito é propagado para frente camada por camada até a camada de saída, produzindo um conjunto de valores de saídas como resposta da rede. Após é verificado se a resposta desejada da rede era igual a esperada de acordo com o vetor de saída, caso não seja é calculado um erro e este é retropropagado para correção de todos os pesos da rede (HAYKIN, 2001). Este ajuste dos pesos é executado de acordo com uma taxa de aprendizado, em que se for muito pequena irá convergir muito devagar e se for muito grande, irá saltar e nunca irá convergir. 
O principal objetivo do processo de treinamento é minimizar o sinal de erro entre a resposta desejada (alvo) e a atual resposta produzida pela rede. Este sinal de erro da saída do neurônio $y_{i}$ na interação n, é definido por:

$$
e_{i}(n)=d_{i}(n)-y_{i}(n)
$$

onde $d_{i}$ é a resposta desejada do $i$-th neurônio de saída.

Adicionando todos os erros quadráticos produzidos pelos neurônios de saída da rede com a respectiva $n$-th iteração, obtêm-se a seguinte função custo ou o erro para ser minimizado:

$$
E(\boldsymbol{w})=\frac{1}{2} \sum_{i} e_{i}^{2}=\frac{1}{2} \sum_{i}\left(d_{i}-y_{i}\right)^{2},
$$

A função custo é uma função continuamente diferenciada para cada peso. Onde, um algoritmo do gradiente descendente pode ser usado para ajustar os pesos. Para as conecções $\mathrm{w}_{\mathrm{ij}}$, que ligam a camada oculta e a camada de saída, a regra do gradiente descendente é dada por:

$$
\Delta w_{i j}=-\eta \frac{\partial E}{\partial w_{i j}}=\eta \cdot \delta_{i} \cdot v_{j}
$$

onde $\eta$ é a taxa de aprendizagem do algoritmo de backpropagation e $\delta_{\mathrm{i}}$ é o gradiente local definido por:

$$
\delta_{i}=\varphi^{\prime}\left(c_{i}\right) \cdot\left(d_{i}-y_{i}\right)
$$

onde $c_{i}$ é o sinal de entrada dos pesos aplicado para o neurônio $y_{i}$ e $\varphi($.) é a função de ativação do neurônio. As conexões $\mathrm{w}_{\mathrm{ij}}$ são iterativamente atualizadas aplicando a seguinte equação:

$$
w_{i j}^{\text {novo }}=w_{i j}^{\text {velho }}+\Delta w_{i j}
$$

Para as conecções $\mathrm{w}_{\mathrm{jk}}$, que ligam a camada de entrada e a camada oculta, a função custo é diferenciada com o respectivo $\mathrm{w}_{\mathrm{jk}}$ usando a regra da cadeia, que é dada por: 


$$
\Delta w_{j k}=-\eta \frac{\partial E}{\partial w_{j k}}=-\eta \cdot \sum \frac{\partial E}{\partial v_{j}} \cdot \frac{\partial v_{j}}{\partial w_{j k}}=\eta \cdot \delta_{j} \cdot x_{k}
$$

Na Equação 3.12, o gradiente local $\delta_{\mathrm{j}}$ em relação ao $\mathrm{w}_{\mathrm{jk}}$ é expresso pela seguinte equação:

$$
\delta_{j}=\varphi^{\prime}\left(h_{i}\right) \sum w_{i j} \cdot \delta_{i}
$$

onde $\mathrm{h}_{\mathrm{i}}$ é o peso do sinal de entrada aplicado para o neurônio $\mathrm{v}_{\mathrm{j}}$. Finalmente, todas as conecções $\mathrm{w}_{\mathrm{jk}}$ são iterativamente atualizadas de acordo com a seguinte equação:

$$
w_{j k}^{\text {novo }}=w_{j k}^{v e l h o}+\Delta w_{j k}
$$

Após o processo de treinamento, a rede é capaz de fornecer a relação funcional entre as variáveis de entrada e saída do processo.

Existem algumas técnicas que auxiliam a melhorar o desempenho do treinamento da MLP:

- Validação cruzada: metodologia utilizada para testar o poder de generalização de uma MLP. Neste contexto, deve-se seguir os passos adiante:

o Particionar o conjunto de dados disponível em dois subconjuntos:

- Conjunto de treinamento: utilizado para treinar a rede $(80 \%$ a $90 \%$ do total);

- Conjunto de teste: utilizado para avaliar se a rede está generalizando de forma satisfatória ( $10 \%$ a $20 \%$ do total).

o Utilizar o mesmo conjunto de treinamento para ajustar todas as topologias candidatas;

o Após o treinamento, utilizar o conjunto de teste para avaliar e escolher (validar) o melhor modelo (melhor generalização):

- Em certos casos, uma determinada topologia pode ter desempenho satisfatório no treinamento, mas durante a fase de validação (aplicação do conjunto teste), a rede produz resultados insatisfatórios (não consegue generalizar); 
- O aumento de neurônios e de camadas não significa que a rede irá generalizar melhor;

- Para duas topologias que estão generalizando como o mesmo grau de precisão, deve-se optar por aquela com menor número de neurônios.

- Inserção do termo de momento: a velocidade do algoritmo backpropagation pode ser aumentada (sem perigo de instabilidade) através da inclusão de um termo de momento $\alpha$, como mostrada na Equação 3.15:

$$
\Delta w_{j i}(t+1)=w_{j i}(t)+\alpha\left(w_{j i}(t)-\Delta w_{j i}(t-1)\right)+\eta * d_{j} * y_{i}
$$

Normalização dos dados: as variáveis referentes às entradas da rede devem ser normalizadas para a faixa $[0,1]$ se estiver sendo utilizada a função sigmóide, ou então, para $[-1,1]$ se for utilizada a tangente hiperbólica.

O algoritmo backpropagation padrão é muito lento para várias aplicações e seu desempenho piora sensivelmente para problemas maiores e mais complexos. Mesmo para problemas relativamente simples, este algoritmo geralmente requer que todos os padrões de treinamento sejam apresentados centenas ou até mesmo milhares de vezes. Isto limita as utilizações práticas deste algoritmo, permitindo apenas o treinamento de pequenas redes, com poucos milhares de pesos ajustáveis. Embora alguns problemas do mundo real (problemas práticos) possam ser tratados utilizando redes deste tamanho, a maioria dos problemas, onde a tecnologia neural poderia apresentar uma solução adequada, demandariam redes maiores e mais complexas.

Pelo fato do algoritmo backpropagation apresentar um processo de convergência lento, foram desenvolvidos métodos alternativos que convergem a uma velocidade maior que aquele. Dentre estes métodos de otimização para treinamento de redes neurais, se destaca o algoritmo de Levenberg-Marquardt (HAGAN; MENHAJ, 1994).

\subsubsection{Algoritmo de Levenberg-Marquardt}

Esse algoritmo é considerado o método mais rápido para treinamento de redes feedfoward backpropagation, que possui uma quantidade moderada de pesos sinápticos. Ele se baseia, para a aceleração do treinamento, na determinação das derivadas de 
segunda ordem do erro quadrático em relação aos pesos, diferindo do algoritmo backpropagation tradicional que considera as derivadas de primeira ordem.

Este algoritmo representa a "ponte" entre o método Gauss-Newton e o de gradiente descendente. O primeiro método possui uma velocidade de convergência muito alta, devida a suas propriedades quadráticas. No entanto, há uma dependência elevada dos valores iniciais dos pesos e bias, cujas estimativas podem ser muito difíceis em uma aplicação em um sistema real. Já o segundo método citado, apresenta uma maior precisão quando a região próxima ao mínimo da função objetivo é alcançada. Entretanto, sua velocidade de convergência é baixa, pois minimiza a função objetivo de maneira linear. Combinando os atributos positivos dos dois métodos, o algoritmo de Levenberg-Marquardt faz uso de uma técnica de otimização híbrida, a qual pode ser aplicada no tratamento de muitos problemas reais (KERMANI et al., 1999).

$\mathrm{O}$ algoritmo de Levenberg-Marquardt baseia-se no método de otimização de Newton, que faz da matriz Hessiana H. Neste método faz-se uma aproximação para essa matriz, mostrada na equação 3.16, determinada em função da matriz Jacobiana, que contém as primeiras derivadas dos pesos em função dos pesos sinápticos, expressa na equação 3.17 :

$$
\begin{gathered}
H=\frac{\partial^{2} E_{R}(W)}{\partial W} \\
J=\frac{\partial e(W)}{\partial W}
\end{gathered}
$$

Onde:

$\mathrm{J}=$ Matriz Jacobiana, a qual contém as derivadas primeiras dos erros da rede com relação aos pesos e bias.

$\mathrm{H}=$ Aproximação da matriz Hessiana, a qual contém as derivadas segundas dos erros da rede com relação aos pesos e bias.

O erro (e(W)) é definido conforme a expressão (3.18):

$$
e(W)=\sum_{i=1}^{n}\left(y_{i}-y_{c i}\right)
$$

A determinação da matriz Jacobiana é muito mais simples que a determinação da matriz Hessiana. Como, para uma rede neural, o desempenho de treinamento é expresso em função da soma dos erros quadráticos, a matriz Hessiana pode ser expressa pela equação 3.19: 


$$
H=J^{T}(W) * J(W)
$$

O método de Newton atualiza os pesos segundo (equação 3.20):

$$
W(k+1)=W(k)-H^{-1} * g_{k}
$$

Onde $g_{\mathrm{k}}$ pode ser escrito conforme a equação 3.21 :

$$
g_{k}=2 J^{T}(W) * e(W)
$$

O algoritmo de Levenberg-Marquardt procede a atualização dos pesos baseado na mesma expressão do método de Newton (equação 3.20), realizando as modificações para a determinação da matriz Hessiana, mostrada na equação 3.22 :

$$
W(k+1)=W(k)-\left[J^{T}(W) * J(W)+\mu_{k} I\right]^{-1} * J^{T}(W) * e(W)
$$

Onde:

I: é a matriz identidade;

$\mu_{\mathrm{k}}$ : é a constante do método de Levenberg-Marquardt.

$\mathrm{O}$ parâmetro $\mu_{\mathrm{k}}$ funciona como um fator de estabilização do treinamento, ajustando a aproximação de forma a utilizar a rápida convergência do método de Newton e evitando passos muito grandes que possam levar a um erro de convergência.

Esse método apresenta uma rápida convergência com menos iteração, porém requer mais cálculos por interação devido ao cálculo de matrizes inversas. Apesar do grande esforço computacional, esse algoritmo de treinamento é o mais rápido para as redes neurais, quando se trabalha com um número moderado de parâmetros na rede. Se esse número for elevado, a utilização desse algoritmo se torna pouco prática.

\subsection{Redes de Função de Base Radial (RBF - Radial-basis function)}

Assim como o MLP (Multilayer Perceptron), as RBF são arquiteturas de redes neurais que são normalmente utilizadas na aproximação de funções e classificação de padrões em espaços com dimensão muito grande (HAYKIN, 2001). Ela é composta por 3 camadas conforme a Figura 3.8.

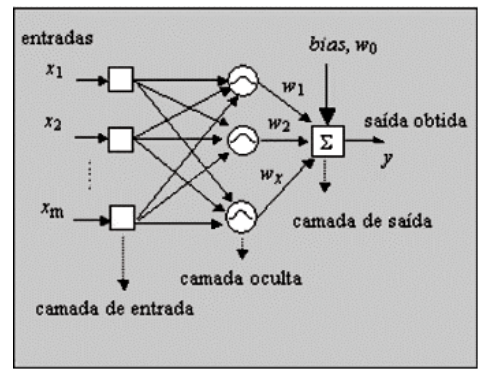

Figura 3.8 - Rede de função de Base Radial 
A construção de uma RBF em sua forma mais básica envolve três camadas, cujos os neurônios de saída formam uma combinação linear das funções de base radial calculados pelos neurônios da camada escondida. As funções de base radial na camada escondida produzem uma resposta localizada para o estímulo (padrão) de entrada, isto é, produzem uma resposta significativamente diferente de zero somente quando o padrão de entrada está dentro de uma região pequena localizada no espaço de entradas. RBF usando não-linearidade local com decréscimo exponencial, como é o caso da função de Gauss, constrói aproximações locais para mapas de entrada/saída não lineares. Nesse sentido, as RBFs são capazes de aprender mais rápido e têm sensibilidade reduzida com respeito à ordem de apresentação dos dados de treinamento.

$\mathrm{O}$ treinamento da RBF requer dois estágios, ou seja, o treinamento da camada escondida, seguido pelo treinamento da camada de saída. Para o treinamento da camada escondida, utiliza-se tipicamente um método não supervisionado, isto é, um algoritmo de agrupamento, com o intuito de ajustar os centros de cada gaussiana em regiões onde os vetores de entrada tenderão a se agrupar. O treinamento da camada de saída é executado somente após a determinação dos parâmetros das funções base que foi executada no treinamento da camada escondida. A camada de saída é treinada utilizando-se do mesmo algoritmo ("Regra Delta Generalizada") usado na camada de saída do MLP, sendo que o conjunto de treinamento será formado por pares de entrada/saída $(\mu, d)$, onde os vetores $\mu$ são especificados após o treino da primeira camada (HAYKIN, 2001)..

Normalmente, a função de base Gaussiana utilizada como função de ativação para os neurônios da camada escondida tem a forma dada por uma gaussiana, ou seja:

$$
\mu_{j}=\exp \left(\frac{-\left(x-w_{1 j}\right)^{T} *\left(x-w_{1 j}\right)}{2 \sigma^{2}{ }_{j}}\right) ; \mathrm{j}=1 \ldots . . \mathrm{N} 1
$$

Onde:

$\mu_{\mathrm{j}}$ : é a saída do j-ésimo neurônio da camada escondida;

w1j: é o vetor de pesos (médios) para o j-ésimo neurônio da camada escondida, correspondendo ao centro da função gaussiana do neurônio j.

$\sigma^{2} \mathrm{j}$ : é a variância associada à função gaussiana do neurônio $\mathrm{j}$.

Assim, a resposta máxima de cada neurônio deve ocorrer quando x estiver bem próximo de $\mathrm{w}_{1 \mathrm{j}}$. A resposta vai diminuindo à medida que $\mathrm{x}$ afasta $\mathrm{de} \mathrm{w}_{1 \mathrm{j}}$, sendo o cone 
gaussiano mais estreito quanto menor for a variância $\sigma^{2} \mathrm{j}$. Estes cones produzem uma saída idêntica para entradas que estão a uma distância radial fixa do centro da gaussiana.

A saída $\mathrm{y}_{\mathrm{j}}$ dos neurônios da camada de saída são calculados da mesma forma que nas redes perceptrons, ou seja:

$$
y_{i}=g\left(\sum_{i=0}^{N 1} w 2_{j i} * \mu_{i}\right)=\sum_{i=0}^{N 1} w 2_{j i} * \mu_{i} ; \mathrm{j}=1 \ldots \mathrm{N} 2
$$

Onde:

yj: é a saída do j-ésimo neurônio da camada de saída

w $2_{\mathrm{ji}}$ : é a matriz sináptica da segunda camada

$\mu$ : é o vetor de saída da primeira camada

Assim, a rede executa uma transformação não linear de $\mathrm{IR}^{\mathrm{N}} \rightarrow \mathrm{IR}^{\mathrm{N} 2}$ através de uma combinação linear das funções bases (gaussianas) não-lineares.

As redes de função de base radial (RBF) e os perceptrons de múltiplas camadas (MLP) são exemplos de redes em camadas alimentadas. Ambos são aproximadores universais, entretanto, essas duas redes diferem entre si em alguns apectos importantes como na Tabela 3.1 .

\section{Tabela 3.1 - Comparação entre as redes neurais RBF e MLP}

\begin{tabular}{|c|c|}
\hline MLP & RBF \\
\hline Possuem uma ou mais camadas escondidas & Possui apenas uma camada escondida \\
\hline $\begin{array}{l}\text { Todos os neurônios dessa rede } \\
\text { compartilham de um mesmo modelo } \\
\text { neural. }\end{array}$ & $\begin{array}{l}\text { Os neurônios da camada escondida são } \\
\text { completamente diferentes dos neurônios } \\
\text { da camada de saída. }\end{array}$ \\
\hline $\begin{array}{l}\text { A função de ativação executa o produto } \\
\text { interno entre as entradas e os pesos } \\
\text { sinápticos. }\end{array}$ & $\begin{array}{l}\text { A função de ativação da camada de } \\
\text { escondida comuta a norma Euclidiana } \\
\text { entre o valor de entrada e o centro da } \\
\text { unidade. }\end{array}$ \\
\hline $\begin{array}{l}\text { Constrói aproximadores globais } \\
\text { mapeamento de entrada-saída não lir }\end{array}$ & $\begin{array}{l}\text { Utiliza não-linearidades localizadas com } \\
\text { decaimento exponencial construindo } \\
\text { aproximadores locais para mapeamentos } \\
\text { de entrada-saída não lineares. }\end{array}$ \\
\hline
\end{tabular}




\section{Resultados e Discussões}

Com base na literatura revisada e apresentada nos capítulos anteriores, desenvolveu-se duas arquiteturas de redes neurais artificiais, MLP (MutiLayer Perceptron) e RBF (Radial-basis function), para quantificar o nível de glicemia no sangue a partir de informações sobre componentes de cores, saturação, intensidade e brilho, referentes a íris do olho direito e esquerdo. A principal característica de uma RNA é a sua habilidade em aprender a partir de seu ambiente e melhorar o seu desempenho através da aprendizagem. O problema descrito acima é uma aplicação potencial para o uso de RNAs, pois trata-se de um problema de estimação.

Diferentes disposições dos dados foram organizadas e apresentadas a diferentes configurações de RNAs, para que fosse possível a avaliação de seus desempenhos. Em todos os experimentos utilizou-se a técnica supervisionada de treinamento, pois tem-se em mãos correspondentes dados de entrada e saída de 24 voluntários.

Este trabalho baseou-se nos dados processados e gerados pelo programa GlucoÍris. O programa ainda está em desenvolvimento e está sendo implementado em $\mathrm{C} \#^{1}$ dentro da plataforma Visual Studio $\mathrm{Net}^{2}$ em ambiente Windows, pelo grupo de pesquisa LabMetro da Universidade Federal de Santa Catarina (UFSC). A base de imagens foi obtida utilizando-se 24 voluntários, que foram avaliados por um período de 10 dias e as medições ocorreram 2 vezes ao dia. Cada medição envolveu o registro da glicemia de referência, com o mesmo glicosímetro, e a aquisição de um mínimo de 3 imagens de cada íris. A base de imagens contém mais de 500 imagens da íris direita e esquerda.O projeto inicial realizou as seguintes etapas conforme o diagrama da

Figura 4.1 .

\footnotetext{
${ }^{1}$ Csharp: É a nova linguagem de propósito geral orientada a objetos criada pela Microsoft para sua nova plataforma .NET. C\# combina os melhores elementos de múltiplas linguagens de ampla difusão como $\mathrm{C}++$, Java, Visual Basic ou Delphi.

${ }^{2}$ A plataforma de Microsoft orientada à criação de software para Internet.
} 


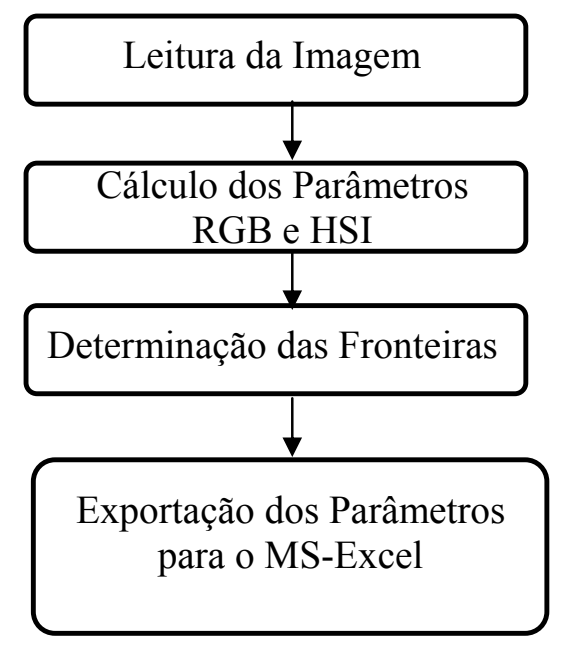

Figura 4.1 - Esquema do Programa GlucoÍris

O primeiro passo realizado foi o cadastro dos voluntários registrando informações como nome e outras pressupostas como interessantes para a pesquisa como a cor da íris, sexo e idade, tipo de diabetes / sem diabetes, tempo com diabetes, existência de outra disfunção crônica, medicamentos de uso constante, valor da hemoglobina glicosilada, possíveis problemas oftalmológicos (PICA, 2002).

A câmera digital utilizada foi a Cannon que proporciona imagens de $6 \mathrm{M}$ pixel. Em conjunto com a câmera utilizou-se um par de lentes de close-up com ganho aproximado de +17 vezes.

O software carrega a imagem e extrai automaticamente as componentes RGB (Red, Green e Blue) e HSI (Hue, Saturation e Intensity).

A definição dos contornos da íris na imagem foi feita a partir dos picos da segunda derivada ao longo de linhas radiais extraídas da imagem. Depois de determinada a equação é traçada uma elipsóide que melhor se ajusta aos pontos calculados pela derivada (MENEZES, 2004).

O software em questão trabalha em conjunto com o MS-Excel, para onde todos os dados selecionados são exportados, possibilitando uma ampla análise estatística. É possível obter automaticamente as seguintes informações (MENEZES, 2004):

- A média de cada componente RGB e HSI de cada pixel (ou grupo de pixels) entre todas as imagens transferidas para o MS-Excel;

- O desvio padrão de cada componente RGB e HSI de cada pixel (ou grupo de pixels) entre todas as imagens transferidas para o MS-Excel; 
- Normaliza os dados de cada pixel (ou grupo de pixels) de cada imagem dividindo-os pela média das componentes da respectiva imagem;

- A média de cada componente RGB e HSI, já normalizadas, de cada pixel ou (grupo de pixels) entre todas as imagens transferidas para o MS-Excel;

A partir desses dados é que se insere a proposta do nosso trabalho. Os passos envolvidos para a quantificação da glicemia são mostrados na Figura 4.2.

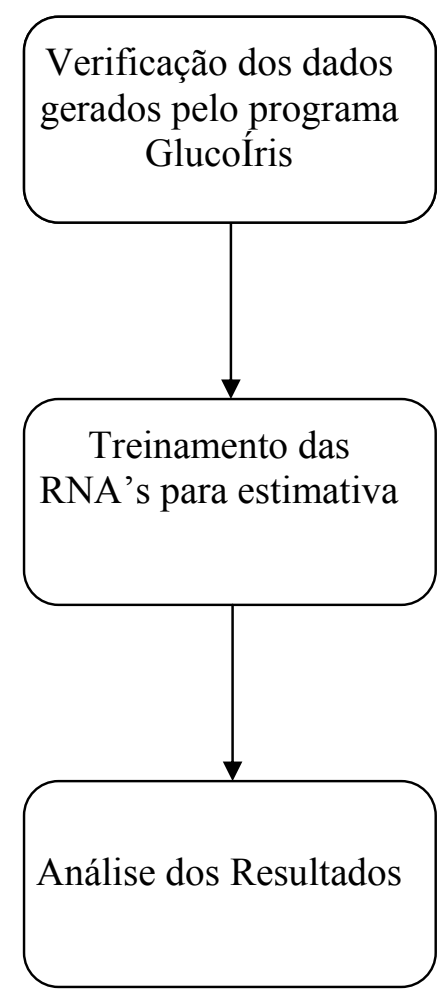

Figura 4.2 - Esquema do sistema para previsão / estimação da glicemia proposto

A primeira etapa do trabalho foi validar os valores gerados pelo programa GlucoÍris, referente às componentes de cor RGB e HSI. O trabalho foi desenvolvido no Matlab, versão 7.0 (R14).

\subsection{Resultados}

Os testes foram realizados com um dos voluntários. Os dados referentes ao teste podem ser verificados na Tabela 4.1, os dados dos demais voluntários estão descritos no Anexo A. 


\section{LBG:}

- Data de nascimento: 03/02/1952

- Sexo: Masculino

- Cor: Branca

- Procedência: Florianópolis

- Profissão: Médico

- Diabético (a): NÃO

- Apresenta outras enfermidades?: Enxaqueca

- Tratamentos que realiza:

- Enxaqueca: Depakote 2501 x pela manhã e Pamelor $25 \mathrm{mg} 1 \mathrm{cpr}$ ao deitar.

- Exame oftalmológico: A.O.= miopia e presbiopia (20/20 e J1 A.O.) / Biomicroscopia

O.D. = normal / O.E. = pinguécula. / Fundo de olho normal A.O. / Tonometria normal A.O.

-Taxas glicemia capilar:

Tabela 4.1 - Dados coletados do voluntário para compor o Banco de imagens

Fonte : Adaptado GONÇALVES JR.(2005)

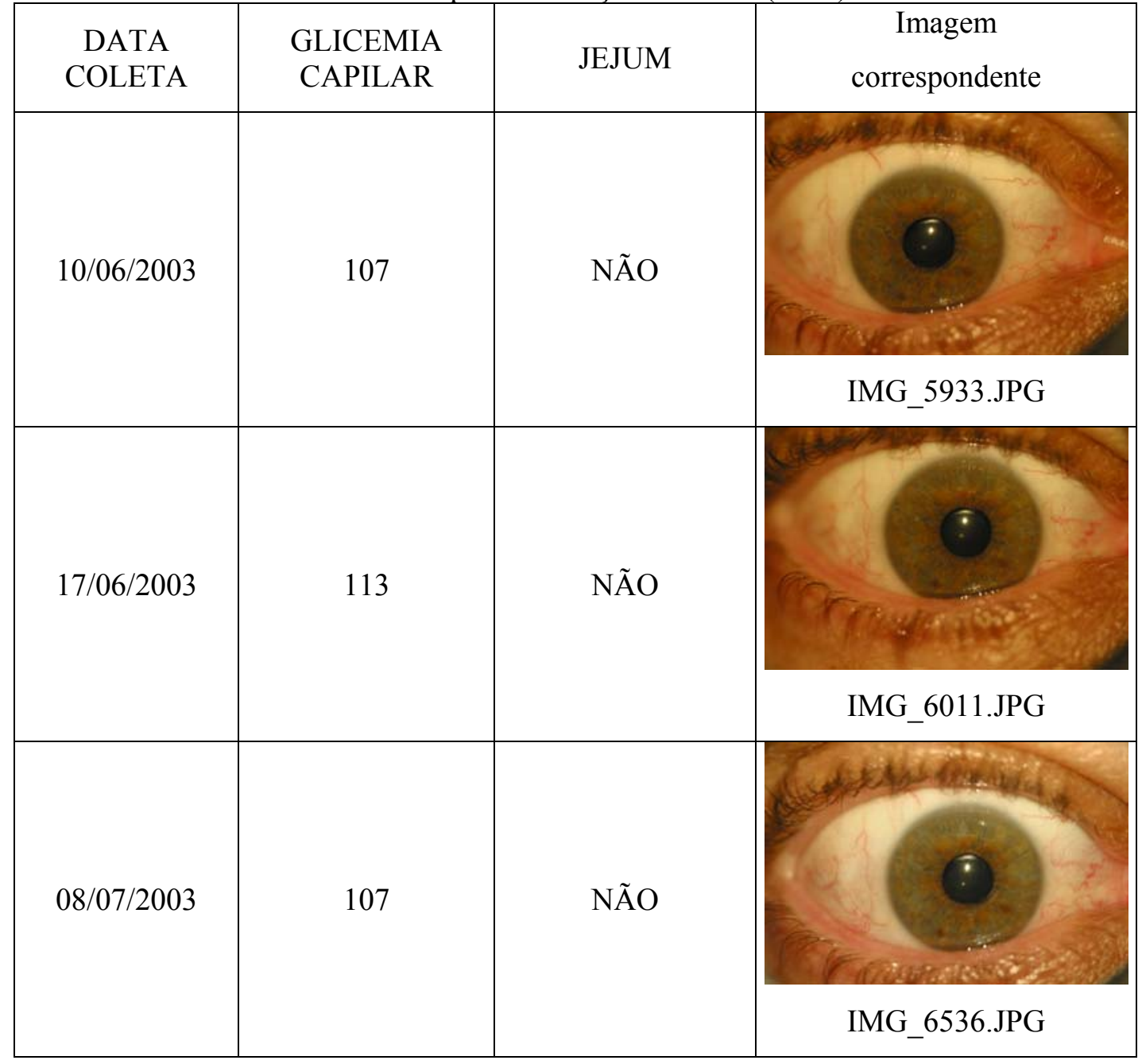


continuação

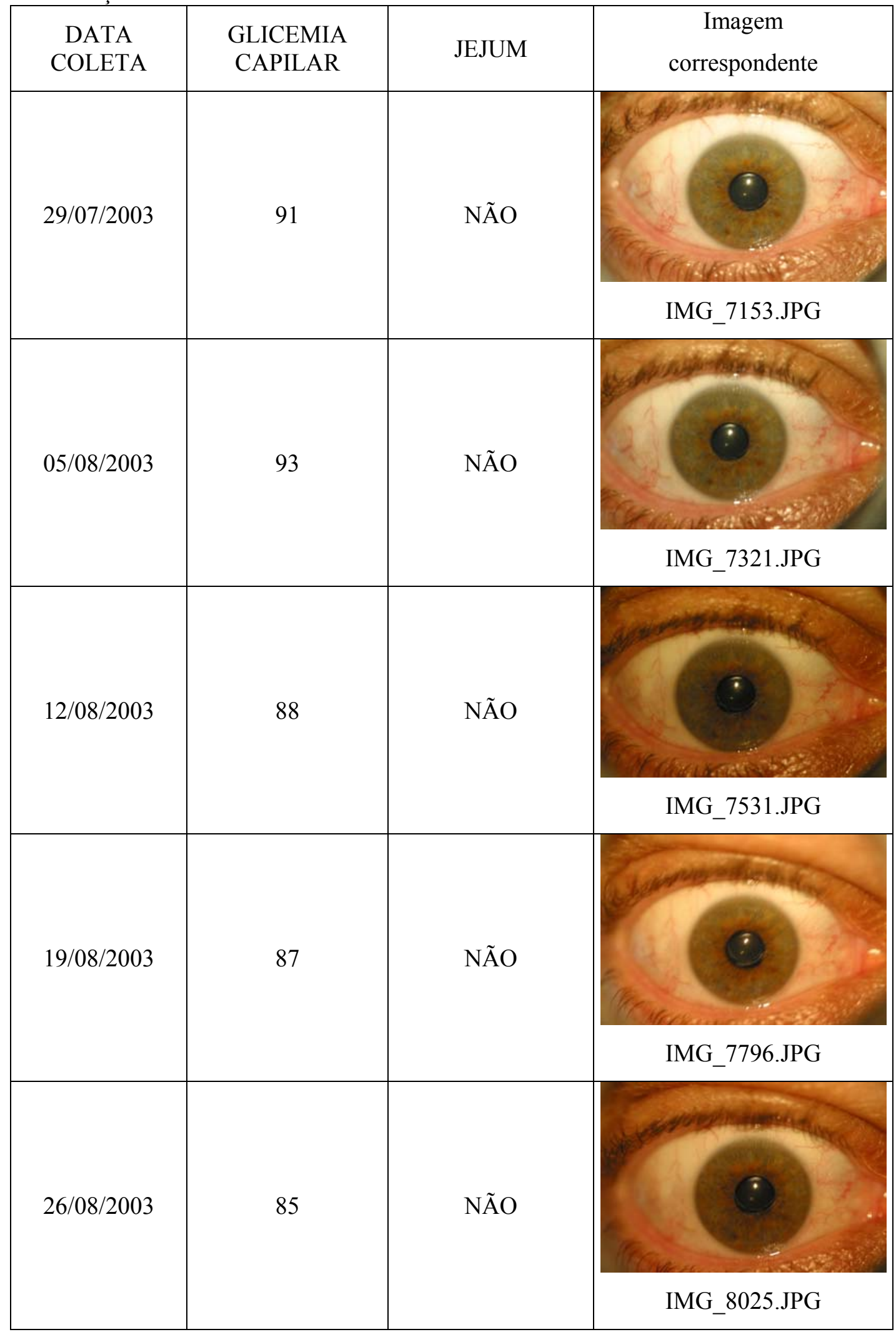


A Tabela 4.1 apresenta os dados colhidos de um determinado voluntário, a data em que foi realizada a coleta, o valor de glicemia obtido por um glicosímetro portátil, o estado do paciente no qual foi realizado o teste (em jejum ou não), e a imagem fotografada dos olhos. Cada imagem da íris corresponde a um momento onde o nível de glicemia do voluntário foi determinado por um método de referência invasivo. Em grande parte dos casos o valor de referência para glicemia foi medido na extremidade do dedo do voluntário por um glicosímetro portátil.

Idealmente se as imagens tivessem sempre a mesma intensidade não seria necessário fazer normalizações. Porém, nem todas as imagens foram obtidas em condições idênticas de iluminação, nem com as mesmas regulagens da máquina fotográfica. Pessoas com íris claras ou escuras exigem regulagens diferentes.

As normalizações estão sendo usadas não só para atenuar os efeitos das variações de intensidade das imagens de uma mesma pessoa, obtidas em dias diferentes, com pequenas variações da iluminação e/ou regulagens da máquina fotográfica, pois também há alterações de cores em fotos repetidas de uma mesma cena. Foram utilizados vários algoritmos, a normalização RGB atenua os efeitos descritos acima. Os melhores resultados foram obtidos pelo processo que chamaram de "normalização pelo RGB médio", que é descrito a seguir:

Para cada setor da íris calcularam-se as componentes R, G e B, denominadas de Ri, Gi, Bi para o setor “i”. Para a normalização são selecionados apenas os setores da íris que dificilmente estarão parcialmente obstruídos pelas pálpebras. Apenas usando os dados dos setores selecionados (não excluídos) calculou-se o valor médio das componentes R, G e B, que foram denominadas de Rm, Gm, Bm. A normalização foi feita dividindo-se as componentes Ri, Gi, Bi de cada setor por Rm, Gm e Bm, isto é:

$$
\begin{aligned}
& \mathrm{Rn}=\mathrm{Ri} / \mathrm{Rm} \\
& \mathrm{Gn}=\mathrm{Gi} / \mathrm{Gm} \\
& \mathrm{Bn}=\mathrm{Bi} / \mathrm{Bm}
\end{aligned}
$$

As imagens, inicialmente, foram recortadas para que se obtivesse apenas a região da íris de interesse. As demais regiões, pupila e fundo da imagem, assumiram o valor de pixel 0 (preto), conforme Figura 4.3. 


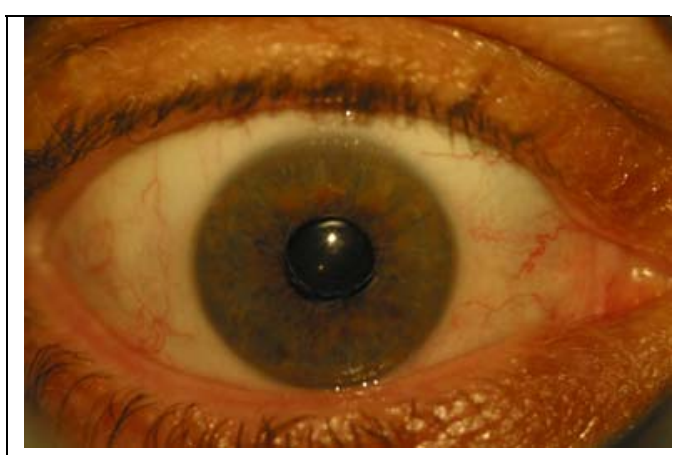

(a)

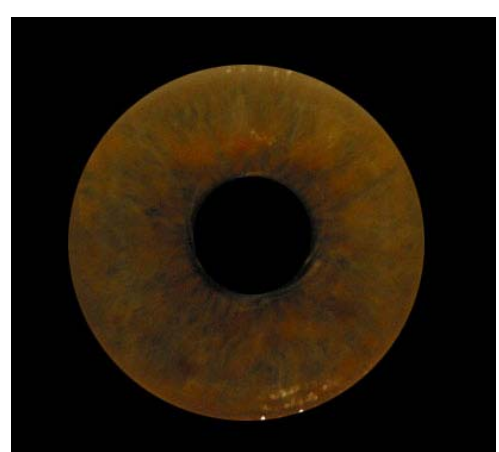

(b)

Figura 4.3 : (a) Imagem original (b) Imagem contendo apenas as regiões de interesse

A partir das imagens recortadas encontraram-se os limites de contornos superiores e inferiores, obtendo-se o centro das imagens. As equações 4.1 e 4.2 foram utilizadas para percorrer a imagem em x e y obtendo-se os valores médios de cada setor.

$$
\begin{aligned}
& \mathrm{x}=\cos (\text { angulo }) * \text { raio } \\
& \mathrm{y}=\operatorname{sen}(\text { angulo }) * \text { raio }
\end{aligned}
$$

A íris foi subdividida em 36 elementos. Angularmente a subdivisão foi realizada em 12 partes, numeradas semelhantementes como às 12 horas de um relógio. Radialmente adotou-se a subdivisão em 3 partes denominadas de Pupilar $(\mathrm{Pu}$ - a região mais interna), Colarete ( $\mathrm{Co}$ - a região central) e Ciliar $(\mathrm{Ci}$ - na região mais externa). Essa descrição é ilustrada na Figura 4.4 para as componentes R (red), G (green) e B (blue). 


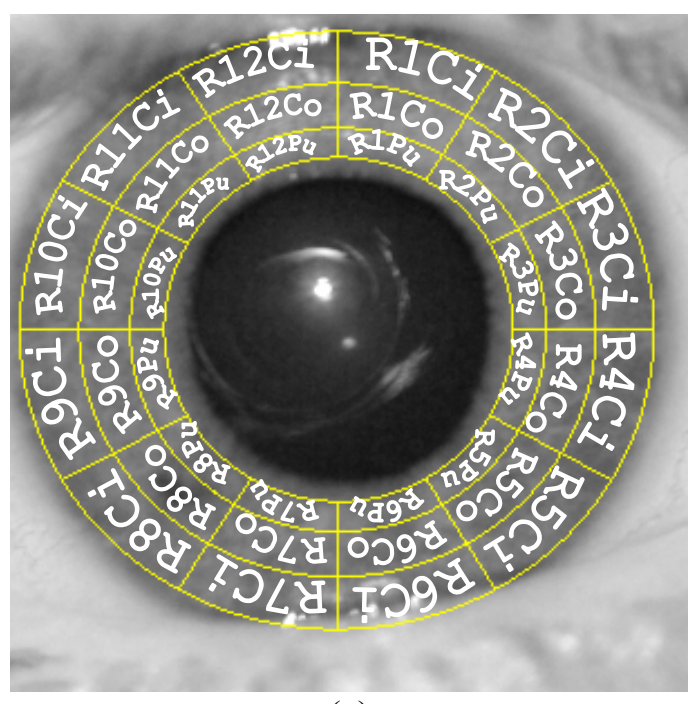

(a)

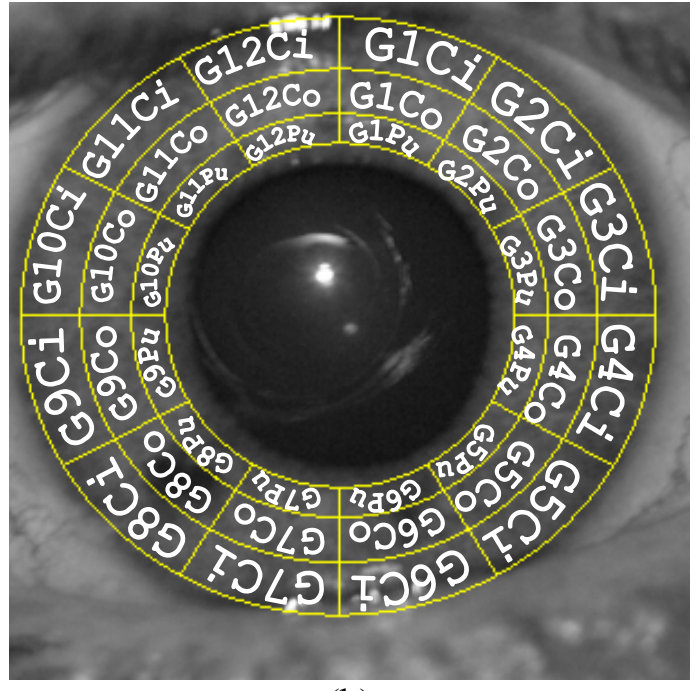

(b)

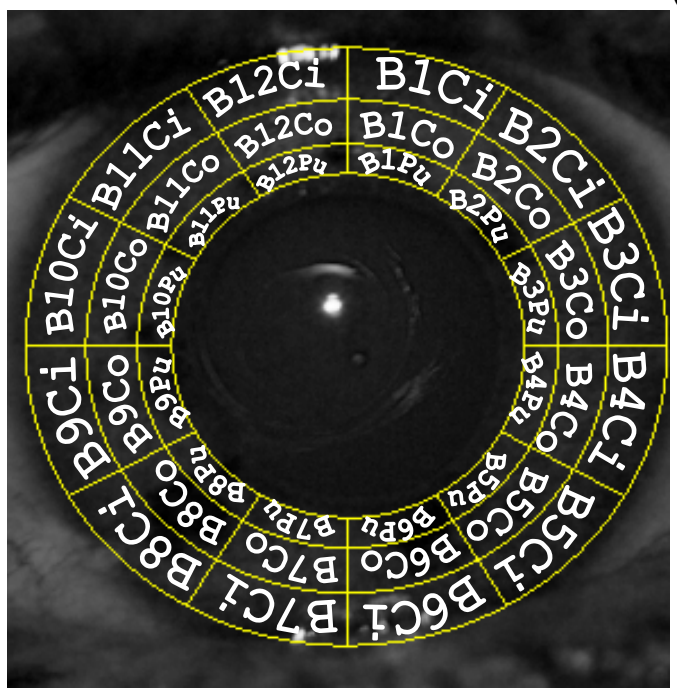

(c)

Figura 4.4: Nomeação das divisões da íris: (a) Componente de cor Vermelha (R). (b) Componente de cor Verde(G). (c) Componente de cor Azul (B)

Considerando-se as equações 4.1 e 4.2 e o procedimento descrito acima obtevese os valores de normalização pelo RGB médio para cada setor, isso pode ser verificado na Figura 4.5. 


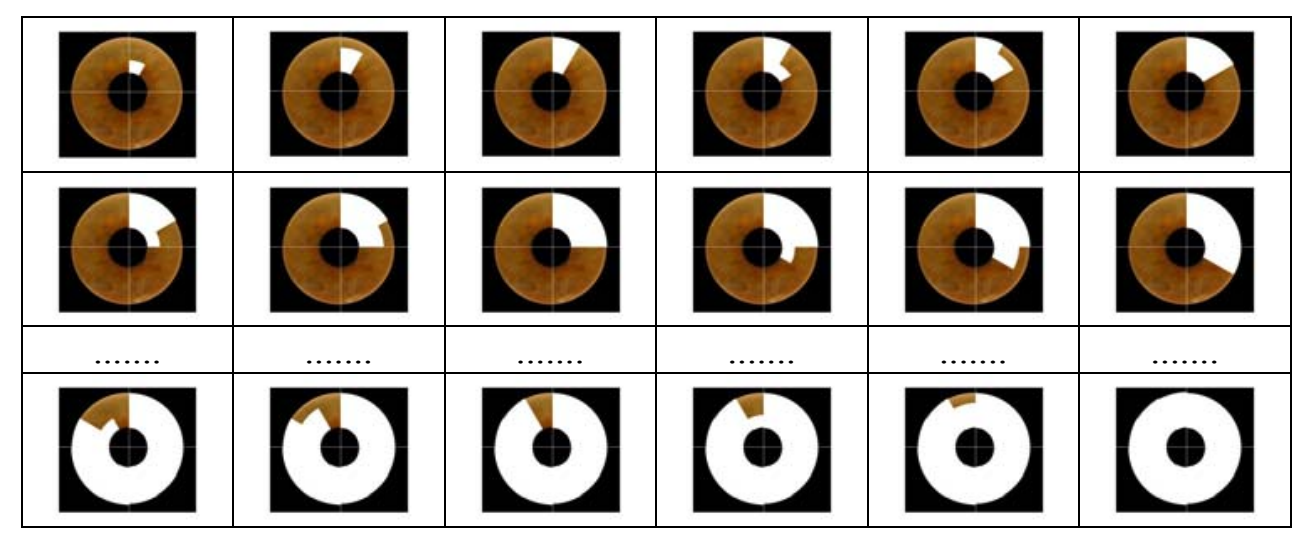

Figura 4.5: Procedimento para o cálculo dos valores de normalização do RGB médio.

Os valores obtidos pelo programa foram comparados com os valores gerados pelo software glucoÍris para 2 voluntários diferentes conforme as Tabela 4.2, Tabela 4.3, Tabela 4.4. 
Tabela 4.2: Dados comparativos para o voluntário LBG dos 36 setores para a componente R (Red), valor de glicemia $87 \mathrm{mg} / \mathrm{dl}$

\begin{tabular}{|l|r|r|r|}
\hline Setores & $\begin{array}{c}\text { Valor } \\
\text { gerado pelo } \\
\text { Software } \\
\text { GlucoIris }\end{array}$ & $\begin{array}{c}\text { Valor obtido } \\
\text { pelo } \\
\text { software } \\
\text { desenvolvido }\end{array}$ & $\begin{array}{c}\text { Erro Obtido } \\
(\%)\end{array}$ \\
\hline $\mathrm{R} 1 \mathrm{Pu}$ & 1.0456 & 0.9906 & 5.26 \\
\hline $\mathrm{R} 1 \mathrm{Co}$ & 1.1237 & 1.1614 & 3.35 \\
\hline $\mathrm{R} 1 \mathrm{Ci}$ & 1.2798 & 1.3136 & 2.64 \\
\hline $\mathrm{R} 21 \mathrm{Pu}$ & 0.9988 & 0.9675 & 3.13 \\
\hline $\mathrm{R} 2 \mathrm{Co}$ & 1.1705 & 1.1763 & 0.50 \\
\hline $\mathrm{R} 2 \mathrm{Ci}$ & 1.2876 & 1.194 & 7.27 \\
\hline $\mathrm{R} 3 \mathrm{Pu}$ & 0.9988 & 0.9461 & 5.29 \\
\hline $\mathrm{R} 3 \mathrm{Co}$ & 1.1159 & 1.1056 & 0.92 \\
\hline $\mathrm{R} 3 \mathrm{Ci}$ & 1.1393 & 1.0502 & 7.82 \\
\hline $\mathrm{R} 4 \mathrm{Pu}$ & 0.9442 & 0.9254 & 1.99 \\
\hline $\mathrm{R} 4 \mathrm{Co}$ & 1.03 & 1.0389 & 0.85 \\
\hline $\mathrm{R} 4 \mathrm{Ci}$ & 1.0847 & 1.0945 & 0.90 \\
\hline $\mathrm{R} 5 \mathrm{Pu}$ & 0.952 & 0.8893 & 6.59 \\
\hline $\mathrm{R} 5 \mathrm{Co}$ & 0.9988 & 0.9928 & 0.60 \\
\hline $\mathrm{R} 5 \mathrm{Ci}$ & 1.0456 & 1.127 & 7.78 \\
\hline $\mathrm{R} 6 \mathrm{Pu}$ & 0.9676 & 0.885 & 8.55 \\
\hline $\mathrm{R} 6 \mathrm{Co}$ & 0.991 & 0.9711 & 2.02 \\
\hline $\mathrm{R} 6 \mathrm{Ci}$ & 1.0456 & 1.1319 & 8.25 \\
\hline $\mathrm{R} 7 \mathrm{Pu}$ & 0.8896 & 0.8338 & 6.27 \\
\hline $\mathrm{R} 7 \mathrm{Co}$ & 0.9676 & 0.9679 & 0.03 \\
\hline $\mathrm{R} 7 \mathrm{Ci}$ & 1.0066 & 1.0607 & 5.36 \\
\hline $\mathrm{R} 8 \mathrm{Pu}$ & 0.8584 & 0.8074 & 5.94 \\
\hline $\mathrm{R} 8 \mathrm{Co}$ & 0.9286 & 0.9226 & 0.65 \\
\hline $\mathrm{R} 8 \mathrm{Ci}$ & 0.991 & 1.0357 & 4.51 \\
\hline $\mathrm{R} 9 \mathrm{Pu}$ & 0.9442 & 0.9284 & 1.67 \\
\hline $\mathrm{R} 9 \mathrm{Co}$ & 0.9598 & 0.9574 & 0.25 \\
\hline $\mathrm{R} 9 \mathrm{Ci}$ & 1.0144 & 1.0146 & 0.02 \\
\hline $\mathrm{R} 10 \mathrm{Pu}$ & 0.8974 & 0.8927 & 0.52 \\
\hline $\mathrm{R} 10 \mathrm{Co}$ & 0.9676 & 0.9727 & 0.53 \\
\hline $\mathrm{R} 10 \mathrm{Ci}$ & 1.0769 & 1.0854 & 0.80 \\
\hline $\mathrm{R} 11 \mathrm{Pu}$ & 0.9832 & 0.9771 & 0.63 \\
\hline $\mathrm{R} 11 \mathrm{Co}$ & 1.0691 & 1.0691 & 0.00 \\
\hline $\mathrm{R} 11 \mathrm{Ci}$ & 1.1627 & 1.1709 & 0.71 \\
\hline $\mathrm{R} 12 \mathrm{Pu}$ & 1.1315 & 1.0707 & 5.37 \\
\hline $\mathrm{R} 12 \mathrm{Co}$ & 1.1237 & 1.1139 & 0.87 \\
\hline $\mathrm{R} 12 \mathrm{Ci}$ & 1.2251 & 1.2721 & 3.84 \\
\hline & & & \\
\hline
\end{tabular}

Os dados gerados pelo software GlucoÍris referentes a média da componente de cor $\mathrm{R}$ foram verificados. Conforme a Tabela 4.2 o erro máximo obtido foi de $8.55 \% \mathrm{em}$ comparação com o desenvolvido no Matlab. Esse erro deve-se ao fato de que o 
algoritmo, desenvolvido no Matlab, não utilizou técnicas para detecção de contornos foi desenvolvido apenas com o intuito de verificação dos dados gerado pelo GlucoÍris.

Tabela 4.3 : Dados comparativos para o voluntário LBG dos 36 setores para a componente G (Green), valor de glicemia $87 \mathrm{mg} / \mathrm{dl}$

\begin{tabular}{|l|r|r|r|}
\hline Setores & $\begin{array}{c}\text { Valor } \\
\text { gerado pelo } \\
\text { Software } \\
\text { GlucoIris }\end{array}$ & $\begin{array}{c}\text { Valor obtido } \\
\text { pelo } \\
\text { software } \\
\text { desenvolvido }\end{array}$ & $\begin{array}{c}\text { Erro Obtido } \\
(\%)\end{array}$ \\
\hline G1Pu & 1.0169 & 0.9542 & $6.17 \%$ \\
\hline G1Co & 1.3277 & 1.2783 & $3.72 \%$ \\
\hline G1Ci & 1.6667 & 1.5496 & $7.03 \%$ \\
\hline G21Pu & 0.904 & 0.8799 & $2.65 \%$ \\
\hline G2Co & 1.3136 & 1.2202 & $7.10 \%$ \\
\hline G2Ci & 1.596 & 1.6288 & $2.05 \%$ \\
\hline G3Pu & 0.9605 & 0.9177 & $4.45 \%$ \\
\hline G3Co & 1.2571 & 1.1561 & $8.03 \%$ \\
\hline G3Ci & 1.3418 & 1.3367 & $0.38 \%$ \\
\hline G4Pu & 0.904 & 0.8901 & $1.53 \%$ \\
\hline G4Co & 1.1017 & 1.1147 & $1.18 \%$ \\
\hline G4Ci & 1.1864 & 1.1841 & $0.19 \%$ \\
\hline G5Pu & 0.8475 & 0.7924 & $6.49 \%$ \\
\hline G5Co & 0.9463 & 0.8695 & $8.12 \%$ \\
\hline G5Ci & 1.0593 & 1.0518 & $0.71 \%$ \\
\hline G6Pu & 0.8475 & 0.8415 & $0.71 \%$ \\
\hline G6Co & 1.0311 & 0.9451 & $8.34 \%$ \\
\hline G6Ci & 1.1299 & 1.1319 & $0.17 \%$ \\
\hline G7Pu & 0.7486 & 0.7255 & $3.09 \%$ \\
\hline G7Co & 0.9605 & 0.87 & $9.42 \%$ \\
\hline G7Ci & 1.0311 & 0.9918 & $3.81 \%$ \\
\hline G8Pu & 0.8051 & 0.8028 & $0.29 \%$ \\
\hline G8Co & 0.9605 & 0.9479 & $1.31 \%$ \\
\hline G8Ci & 1.0734 & 1.031 & $3.96 \%$ \\
\hline G9Pu & 0.8475 & 0.8752 & $3.28 \%$ \\
\hline G9Co & 1.0452 & 1.0264 & $1.80 \%$ \\
\hline G9Ci & 1.1017 & 1.0808 & $1.90 \%$ \\
\hline G10Pu & 0.8333 & 0.8231 & $1.22 \%$ \\
\hline G10Co & 1.0452 & 1.0423 & $0.28 \%$ \\
\hline G10Ci & 1.2288 & 1.1202 & $8.84 \%$ \\
\hline G11Pu & 0.9181 & 0.8925 & $2.79 \%$ \\
\hline G11Co & 1.1864 & 1.0953 & $7.68 \%$ \\
\hline G11Ci & 1.4407 & 1.3307 & $7.64 \%$ \\
\hline G12Pu & 1.0593 & 0.9978 & $5.81 \%$ \\
\hline G12Co & 1.3277 & 1.2261 & $7.65 \%$ \\
\hline G12Ci & 1.5819 & 1.4953 & $5.47 \%$ \\
\hline
\end{tabular}


O mesmo foi verificado para a componente de cor G (Green). O erro máximo obtido pela comparação dos 2 métodos foi de $9.42 \%$.

Tabela 4.4: Dados comparativos para o voluntário LBG dos 36 setores para a componente B (Blue), valor de glicemia $87 \mathrm{mg} / \mathrm{dl}$

\begin{tabular}{|l|r|r|r|}
\hline Setores & $\begin{array}{c}\text { Valor } \\
\text { gerado pelo } \\
\text { Software } \\
\text { GlucoIris }\end{array}$ & $\begin{array}{c}\text { Valor obtido } \\
\text { pelo } \\
\text { software } \\
\text { desenvolvido }\end{array}$ & $\begin{array}{c}\text { Erro Obtido } \\
(\%)\end{array}$ \\
\hline $\mathrm{B} 1 \mathrm{Pu}$ & 0.6522 & 0.6489 & $0.49 \%$ \\
\hline $\mathrm{B} 1 \mathrm{Co}$ & 2.5 & 2.7716 & $10.86 \%$ \\
\hline $\mathrm{B} 1 \mathrm{Ci}$ & 5 & 5.1707 & $3.41 \%$ \\
\hline $\mathrm{B} 21 \mathrm{Pu}$ & 0.4348 & 0.4159 & $4.35 \%$ \\
\hline $\mathrm{B} 2 \mathrm{Co}$ & 1.7391 & 1.8451 & $6.09 \%$ \\
\hline $\mathrm{B} 2 \mathrm{Ci}$ & 4.1304 & 4.0504 & $1.94 \%$ \\
\hline $\mathrm{B} 3 \mathrm{Pu}$ & 0.6522 & 0.6248 & $4.20 \%$ \\
\hline $\mathrm{B} 3 \mathrm{Co}$ & 1.7391 & 1.627 & $6.45 \%$ \\
\hline $\mathrm{B} 3 \mathrm{Ci}$ & 2.8261 & 2.6922 & $4.74 \%$ \\
\hline $\mathrm{B} 4 \mathrm{Pu}$ & 0.6522 & 0.646 & $0.94 \%$ \\
\hline $\mathrm{B} 4 \mathrm{Co}$ & 1.1957 & 1.1712 & $2.05 \%$ \\
\hline $\mathrm{B} 4 \mathrm{Ci}$ & 1.7391 & 1.6325 & $6.14 \%$ \\
\hline $\mathrm{B} 5 \mathrm{Pu}$ & 0.4348 & 0.4225 & $2.83 \%$ \\
\hline $\mathrm{B} 5 \mathrm{Co}$ & 0.6522 & 0.6765 & $3.74 \%$ \\
\hline $\mathrm{B} 5 \mathrm{Ci}$ & 1.3043 & 1.232 & $5.54 \%$ \\
\hline $\mathrm{B} 6 \mathrm{Pu}$ & 0.3261 & 0.3207 & $1.63 \%$ \\
\hline $\mathrm{B} 6 \mathrm{Co}$ & 1.6304 & 1.7455 & $7.06 \%$ \\
\hline $\mathrm{B} 6 \mathrm{Ci}$ & 2.2826 & 2.3886 & $4.64 \%$ \\
\hline $\mathrm{B} 7 \mathrm{Pu}$ & 0.2174 & 0.2001 & $7.96 \%$ \\
\hline $\mathrm{B} 7 \mathrm{Co}$ & 0.8696 & 0.895 & $2.92 \%$ \\
\hline $\mathrm{B} 7 \mathrm{Ci}$ & 1.6304 & 1.5232 & $6.58 \%$ \\
\hline $\mathrm{B} 8 \mathrm{Pu}$ & 0.6522 & 0.6561 & $0.60 \%$ \\
\hline $\mathrm{B} 8 \mathrm{Co}$ & 0.9783 & 0.9194 & $6.02 \%$ \\
\hline $\mathrm{B} 8 \mathrm{Ci}$ & 1.9565 & 1.8182 & $7.07 \%$ \\
\hline $\mathrm{B} 9 \mathrm{Pu}$ & 0.3261 & 0.3442 & $5.58 \%$ \\
\hline $\mathrm{B} 9 \mathrm{Co}$ & 1.413 & 1.3834 & $2.09 \%$ \\
\hline $\mathrm{B} 9 \mathrm{Ci}$ & 1.5217 & 1.4563 & $4.30 \%$ \\
\hline $\mathrm{B} 10 \mathrm{Pu}$ & 0.5435 & 0.5653 & $4.01 \%$ \\
\hline $\mathrm{B} 10 \mathrm{Co}$ & 1.3043 & 1.2612 & $3.30 \%$ \\
\hline $\mathrm{B} 10 \mathrm{Ci}$ & 2.3913 & 2.4208 & $1.23 \%$ \\
\hline $\mathrm{B} 11 \mathrm{Pu}$ & 0.5435 & 0.5012 & $7.78 \%$ \\
\hline $\mathrm{B} 11 \mathrm{Co}$ & 1.413 & 1.4524 & $2.79 \%$ \\
\hline $\mathrm{B} 11 \mathrm{Ci}$ & 3.6957 & 3.6081 & $2.37 \%$ \\
\hline $\mathrm{B} 12 \mathrm{Pu}$ & 0.4348 & 0.4397 & $1.13 \%$ \\
\hline $\mathrm{B} 12 \mathrm{Co}$ & 2.3913 & 2.4351 & $1.83 \%$ \\
\hline & 4.6739 & 4.6769 & $0.06 \%$ \\
\hline
\end{tabular}


Para a componente de cor B (Blue) o erro máximo obtido foi de $10.86 \%$. Foi realizado a verificação para outra imagem, do mesmo voluntário (LBG), com valor de glicemia $88 \mathrm{mg} / \mathrm{dl}$. O erro máximo encontrado foi de $9.6 \%, 9.9 \%$ e 10.4\% para as componentes de cor R, G e B, respectivamente.

Depois de verificados os dados gerados pelo software GlucoÍris, a próxima etapa foi a utilização de duas arquiteturas de RNA's, MLP e RBF, para a estimação dos valores de glicemia baseado nas componentes de cores das imagens. Diferentes topologias e parâmetros de redes foram utilizados. Em todos os experimentos utilizou-se a técnica supervisionada de treinamento, com dados de entrada e saída de 24 voluntários.

\subsection{Estimação dos valores de Glicemia usando rede neural MLP}

Primeiramente os dados de todos os voluntários foram passados a uma única RNA para treinamento. O objetivo foi tentar verificar se é viável que uma única RNA aprenda a quantificar a glicemia para quaisquer pessoas de diferentes cores de olhos.

Para a estimação da glicemia, utilizou-se a rede neural perceptron multicamadas (MLP), com o algoritmo de retropropagação (backpropagation) e o algoritmo de Levenberg-Marquardt. A topologia e os parâmetros usados durante a fase treinamento da rede foram variáveis, com o intuito de encontrar os melhores parâmetros para a estabilidade da rede. Para todos os treinamentos realizados os pesos foram inicializados aleatoriamente para compor a matriz de pesos. As funções de ativações utilizadas foram a função sigmóide para ativar as saídas dos neurônios nas camadas ocultas e a função rampa para o neurônio na saída da rede. $\mathrm{O}$ valor do termo de momento empregado foi de 0.09. Para a primeira camada oculta contou-se com uma variação na quantidade de neurônios de 5 a 15, e para a camada oculta de 5 a 10 neurônios. Definiu-se apenas um neurônio para a camada de saída com o intuito da rede estimar o valor de glicemia.

$\mathrm{O}$ primeiro teste foi utilizar a base de dados geral considerando todas as características de entrada para cada voluntário (conjunto de íris direita e esquerda). A RNA contou com 432 dados de entradas. O valor 432 refere-se aos 3 setores (pupilar, colarete e ciliar), 12 setores baseados nas horas do relógio, e as componentes $\mathrm{R}, \mathrm{G}, \mathrm{B}$, H, S e I, portanto $3 \times 12$ × 6 (componentes) x 2 (íris direita e íris esquerda) $=432$.

Com os resultados obtidos desse treinamento conclui-se que a rede é capaz de aprender, mas possui uma reduzida capacidade de generalização para o conjunto teste. Nota-se que a rede está muito dimensionada, ou seja, possui uma grande quantidade de 
características para os dados de entrada e uma reduzida quantidade de amostras, isso faz com que a rede memorize os dados do conjunto de treinamento, e compromete a sua capacidade de generalização.

Testes foram realizados na tentativa de selecionar as características que melhor determinam a glicemia, utilizando-se, para tanto, os valores dos coeficentes de correlação linear entre cada componente $(\mathrm{R}, \mathrm{G}, \mathrm{B}, \mathrm{H}, \mathrm{S}, \mathrm{I})$ que apresentavam as maiores correlações positivas e negativas, com o objetivo de reduzir a quantidade de características dos padrões de entrada para a rede. Portanto, para cada voluntário foi definida uma RNA a ser treinada com os seus respectivos dados de coloração de íris $\mathrm{x}$ glicemia. Valores referentes ao máximo e mínímo do coeficiente de correlação para a íris direita e esquerda foram utilizados como entrada para a rede neural. Esses dados são fornecidos pelo software GlucoÍris.

O valor do nível de glicemia e as componentes de cor normalizadas para cada região de interesse, previamente determinados para cada imagem do conjunto, são usados para calcular o valor do coeficiente de correlação linear (GONÇALVES, 2005).

$\mathrm{O}$ coeficiente de correlação linear é um número que varia entre -1.0 e +1.0 . Quando seu valor é +1.0 há correlação linear perfeita e direta entre o nível da glicemia e a componente da cor, isto é, quando o nível de glicemia aumenta, a componente da cor aumenta de forma perfeitamente proporcional. Quando o valor do coeficiente de correlação é igual a -1.0, também há correlação linear perfeita, porém inversa, o que significa que o aumento do nível de glicemia provoca redução perfeitamente proporcional na componente da cor. Se o coeficiente de correlação linear é 0.0 , não há nenhum tipo de correlação linear entre o nível de glicemia e a componente da cor, indicando que as variações destas grandezas não tem nenhuma ligação que possa ser descrita por uma equação linear. A identificação de regiões de interesse que apresentem coeficientes de correlação linear, cujo valor absoluto está na faixa entre 0.8 e 1.0 , são excelentes resultados, não importando se são valores positivos ou negativos (GONÇALVES JR., 2005).

O programa GlucoÍris registra uma síntese dos resultados contendo a informação da região de interesse regular onde foi registrado o valor do máximo e do mínimo coeficiente de correlação.

Para compor a matriz de treinamento utilizou-se dois terços das amostras, e para o conjunto de teste o um terço restante. Isso é necessário para monitorar a capacidade de generalização da rede. Como já mencionado, para quantificação do nível de glicemia 
no sangue através de informações sobre componentes de cores, saturação, intensidade e brilho, referentes às irides dos olhos direito e esquerdo, utilizou-se a rede neural perceptron multicamadas (MLP), aplicando-se os algoritmos de treinamento LevenbergMarquardt. A topologia e os parâmetros usados durante a fase de treinamento da rede são descritos na Tabela 4.5 .

Tabela 4.5 - Topologias e os parâmetros utilizados durante a fase de treinamento da rede MLP

\begin{tabular}{|c|c|c|c|c|c|}
\hline \multirow{2}{*}{$\mathrm{N}^{\mathrm{o}}$} & \multicolumn{2}{|c|}{ Topologias } & \multirow{2}{*}{$\begin{array}{c}\text { Taxa de } \\
\text { Aprendizagem }\end{array}$} & \multirow{2}{*}{$\begin{array}{l}\mathrm{N}^{0} \text { de épocas } \\
\text { de treinamento }\end{array}$} & \multirow{2}{*}{$\begin{array}{l}\text { Erro Quadrático } \\
\text { Médio(MSE) }\end{array}$} \\
\hline & $1^{\mathrm{a}}$ camada Oculta & $2^{\mathrm{a}}$ camada Oculta & & & \\
\hline 1 & 10 & 5 & 0.01 & $70-450$ & $10^{-8}$ \\
\hline 2 & 6 & 3 & 0.01 & $25-320$ & $10^{-5}$ \\
\hline
\end{tabular}

Para a obtenção desses valores, realizou-se uma grande quantidade de testes que evidenciaram ser os melhores parâmetros para a função de ativação utilizada, ou seja, que conduzia aos melhores resultados.

Os dados do conjunto de treinamento e de teste tiveram que ser normalizados devido à função de ativação empregada, devendo estar entre 0 e 1 . Primeiramente utilizou-se como dados de entradas o maior e o menor valor de correlação da íris direita e esquerda, totalizando 4 entradas. Outro treinamento foi realizado considerando-se os dois maiores valores de correlação positiva e os dois maiores valores de correlação negativa da íris direita e esquerda, obtendo-se 8 padrões de entrada.

Tabela A1, Tabela A2, Tabela A3 e Tabela A4, do Anexo A, referem-se aos valores obtidos pela rede MLP utilizando as topologia 1 e 2 descritas na Tabela 4.5, considerando-se 4 e 8 características como entrada para a rede. A partir da tabela podem-se obter gráficos para melhor representação dos resultados, para os voluntários BCP e HIH, pois estes apresentam uma quantidade de coleta de dados maior do que os demais. Conforme Figura 4.6 e Figura 4.7 respectivamente. O primeiro parâmetro da legenda do gráfico indica a arquitetura de rede utilizada, no caso MLP, o segundo parâmetro refere-se aos tipos de topologias utilizadas (1 ou 2) conforme descritas na Tabela 4.5. E o último parâmetro refere-se a quantidade de características utilizadas como dados de entrada para a rede (4 ou 8). 


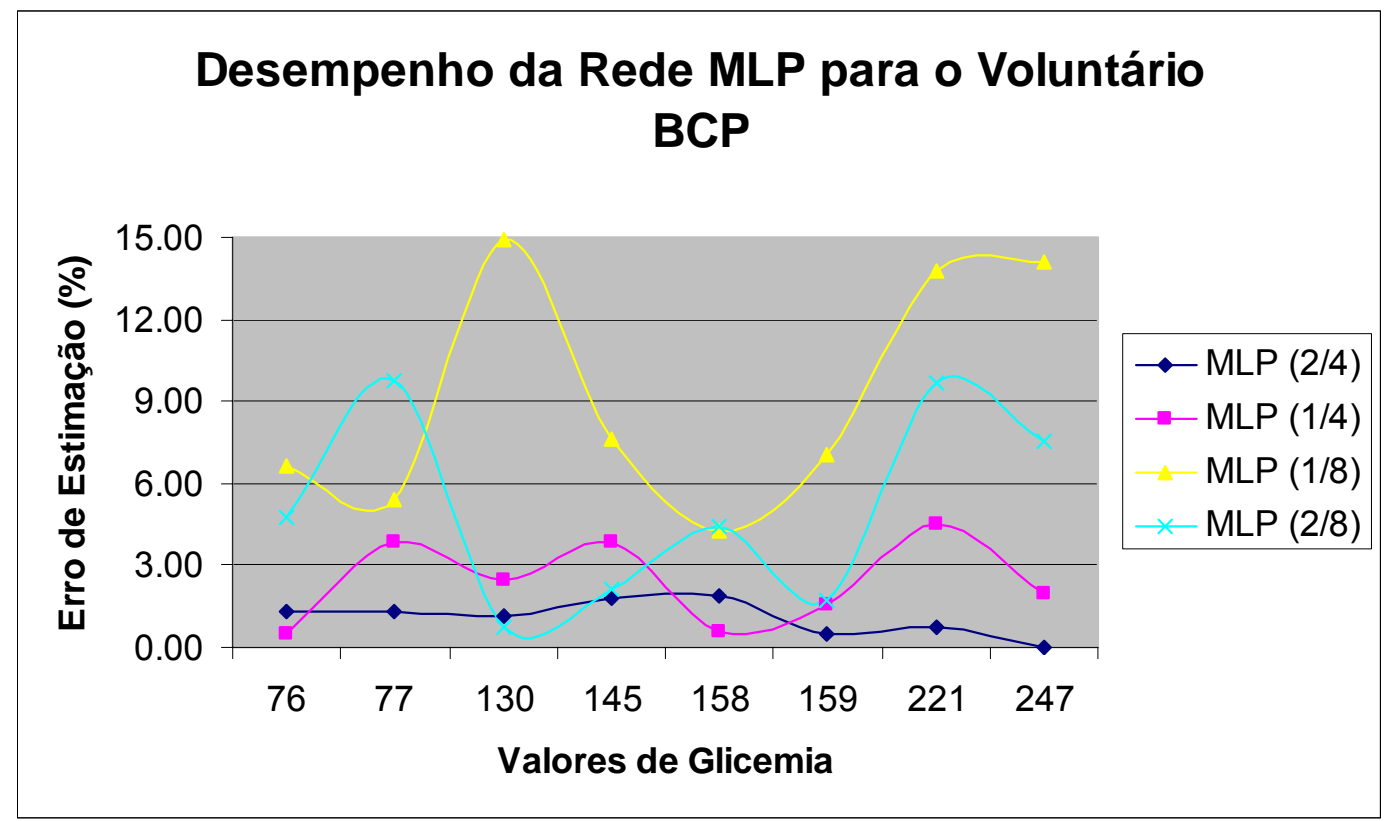

Figura 4.6 - Gráfico para o voluntário BCP

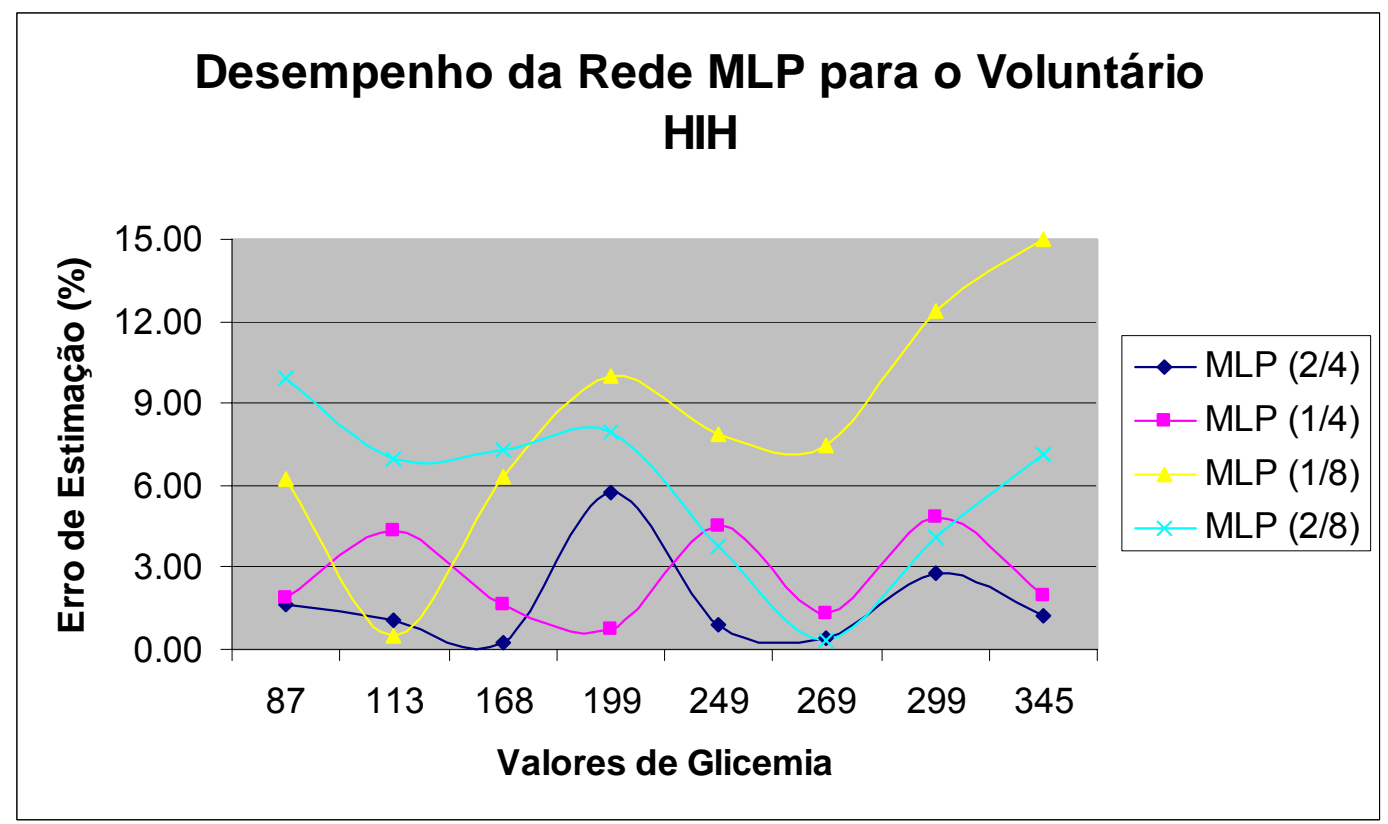

Figura 4.7 - Gráfico para o voluntário HIH 


\subsection{Estimação dos valores de Glicemia usando rede neural RBF}

Outra arquitetura de rede que também foi utilizada para estimação dos valores de glicemia é a RBF. Conforme já descrito, essa rede possui apenas uma camada oculta. Para o mesmo grau de precisão a rede RBF requer um número maior de parâmetros que um MLP. A RBF apresentam boas propriedades aproximativas equiparáveis as do MLP.

A topologia e os parâmetros usados durante a fase de treinamento da rede para essa arquitetura de rede são descritos na Tabela 4.6.

Tabela 4.6 - Topologias e parâmetros utilizados durante a fase de treinamento da rede $\mathrm{RBF}$

\begin{tabular}{|c|c|c|c|}
\hline \multirow{2}{*}{$\mathrm{N}^{\circ}$} & Topologias & $\begin{array}{c}\text { Taxa de } \\
\text { Aprendizagem }\end{array}$ & $\begin{array}{c}\text { Erro Quadrático } \\
\text { Médio(MSE) }\end{array}$ \\
\hline & Camada Oculta & 0.01 & $10^{-8}$ \\
\hline 1 & 6 & 0.01 & $10^{-5}$ \\
\hline 2 & 3 & & \\
\hline
\end{tabular}

Os valores foram obtidos após realização de alguns testes que evidenciaram ser os melhores parâmetros para a função de ativação utilizada, ou seja, que conduzia aos melhores resultados.

As Tabela A5, Tabela A6, Tabela A7 e Tabela A8, do Anexo A, referem-se aos valores obtidos pela rede RBF utilizando as topologia 1 e 2 descritas na Tabela 4.6, considerando-se 4 e 8 características como entrada para a rede. A partir da tabela podese obteve-se um gráfico para melhor representar o resultado, para os voluntários BCP e HIH. Conforme a Figura 4.8 e Figura 4.9, respectivamente. O primeiro parâmetro da legenda indica a arquitetura de rede utilizada, no caso RBF, o segundo parâmetro referese aos tipos de topologias utilizadas (1 ou 2) conforme descritas na Tabela 4.6. E o último parâmetro refere-se a quantidade de características utilizadas como dados de entrada para a rede (4 ou 8). 


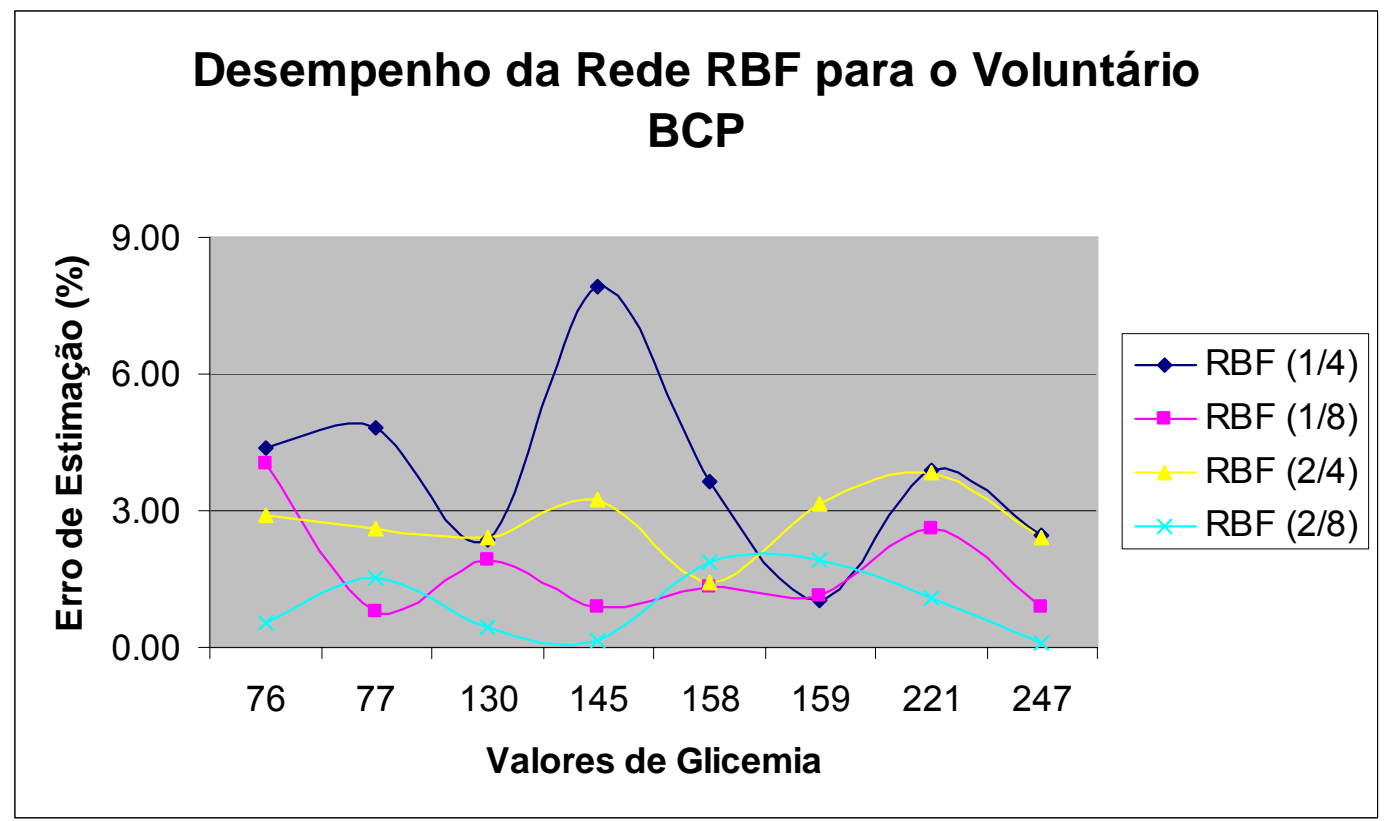

Figura 4.8 - Gráfico para o voluntário BCP

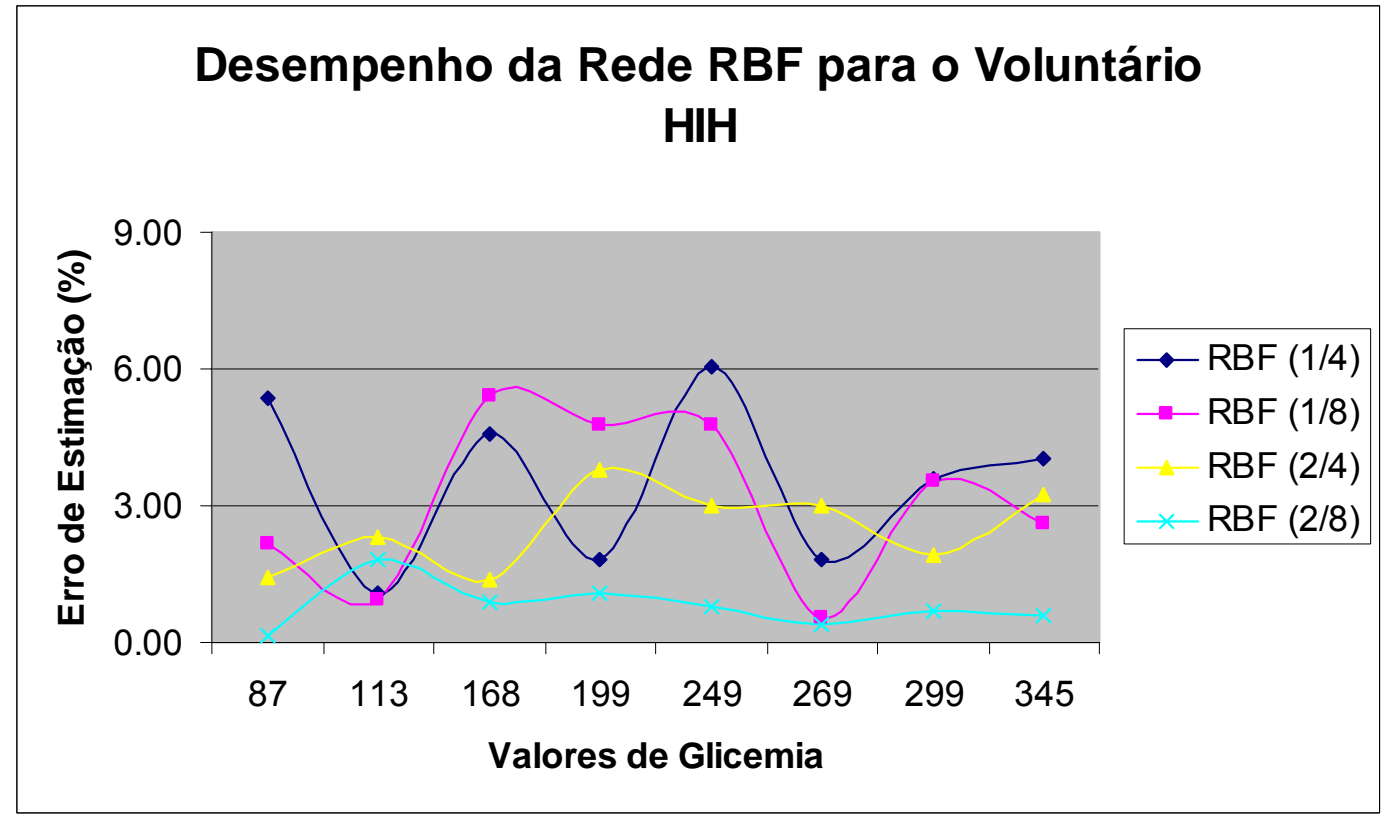

Figura 4.9 - Gráfico para o voluntário BCP

O próximo capítulo trata da análise dos resultados alcançados e das propostas futuras de trabalho. 


\section{Conclusões e sugestões para trabalhos futuros}

Nesse trabalho foi desenolvido um algoritmo para realizar a normalização pelo RGB médio, calculando-se a intensidade média resultante das 36 regiões regulares da íris, para verificar os resultados gerados pelo software GlucoÍris.

Como dados de entradas foi utilizado um banco de imagens contendo aproximadamente 500 imagens da íris humana.

Considerando-se os resultados e discussões apresentadas no capítulo anterior, conclui-se que:

a) Para a etapa de validação dos resultados gerados pelo software GlucoÍris, obteve-se resultados satisfatórios para as imagens do banco de dados em questão, pois o algoritmo de verificação conseguiu reproduzir de maneira coerente os dados gerados pelo software GlucoÍris.

b) Com base nos resultados expostos anteriormente, conclui-se que a RNA é capaz de aprender, com poucos neurônios intermediários e poucas épocas, para o conjunto de treinamento, porém, há uma redução na capacidade de generalização para o conjuntos teste.

c) Através dos gráficos das Figura 4.6 e Figura 4.7, para a rede MLP, verifica-se que a rede de topologia 2 e com 4 características de entrada apresentou o melhor desempenho, para o estudo em questão. Esse mesmo resultado pode ser verificado para os demais voluntários.

d) Os gráficos das Figura 4.8 e Figura 4.9 permitem concluir que a rede RBF de topologia 2 e com 8 características de entrada, apresentou o melhor resultado para a estimação dos valores de glicemia baseado na íris humana. 
Até o presente momento o trabalho tem apresentado resultados satisfatórios após o treinamento de uma RNA. Pode-se concluir que as etapas do trabalho realizadas até a presente data obtiveram sucesso quanto a atingir os objetivos propostos, mas ainda há limitações, pois as redes neurais artificiais, para melhorem seus resultados, dependem de uma quantidade muito grande de amostras.

O primeiro problema encontrado para realizar o treinamento da RNA foi a grande quantidade de parâmetros fornecidos para a rede. Na primeira fase, considerando os 432 (íris direita e esquerda) parâmetros referentes às componentes de cores R, G, B, H, S, I para cada voluntário, a rede foi incapaz de generalizar e produzir bons resultados. Erros além do esperado foram obitdos. Outro detalhe que dificultou obter um melhor resultado é que cada voluntário apresenta uma resposta à glicemia em regiões e setores diferentes na íris. Esse foi um dos grande problemas para se escolher as melhores características para servirem de entrada à RNA. Por isso, optou-se em fazer um treinamento para cada usuário em particular.

Para sanar este problema, uma nova fase de teste foi iniciada, em que considerou-se como parâmetros de entrada para a RNA apenas as componentes de cor que apresentavam o maior e o menor coeficiente de correlação. Novos treinamentos foram realizados separadamente para cada voluntário, e os resultados obtidos são de certa forma promissor. Contudo, resultados melhores podem ser alcançados com uma quantidade maior de amostras.

\subsection{Contribuições}

Este trabalho foi uma contribuição para o desenvolvimento do sistema de medição de glicemia de forma não-invasiva, o GlucoÍris. O objetivo geral foi utilizar novas arquiteturas e topologias de redes neurais para automatizar o processo de medir glicemia baseado nas análises de imagens da íris humana.

A obtenção de resultados melhores foi limitada pela quantidade de amostras individuais de cada voluntário.

Os estudos realizados, com as arquiteturas de rede em questão, mostraram que a medição da glicemia através da íris é possível, porém são necessárias ainda mais pesquisas e mais dados para o aprimoramento do sistema. 


\subsection{Propostas para trabalhos futuros}

O sistema GlucoÍris é um dispositivo portátil de monitoração da glicemia. Os resultados atingidos, em trabalhos anteriores, mostraram que medir a glicemia através da íris é viável, porém muitas pesquisas precisam ser ainda realizadas.

Uma proposta de melhoria para esse trabalho seria a utilização de outras técnicas de inteligência artificial que permitam obter resultados melhores. As redes neurais artificiais estão sendo treinadas para cada indivíduo separadamente, podendo-se, portanto, estudar outros métodos que permitam utilizar uma mesma rede neural para estimar a glicemia de diferentes indivíduos.

A avaliação da correlação da glicemia, com variações na coloração da íris humana ainda é recente. Existe, porém, uma esperança para as pessoas diabéticas que, num futuro não muito distante, possam a vir medir a glicemia de maneira mais simples, indolor e por custo mínimo. 


\section{REFERÊNCIAS BIBLIOGRÁFICAS}

ALBERTI, K. G. M. M.; ZIMMET, P. Z.; CONSULTATION, W. (2004). "Definition, diagnosis and classification of diabetes mellitus and its complications. Part 1: diagnosis and classification of diabetes mellitus. Provisional report of a WHO Consultation", Diabetic Medicine, v.15, n.7, p.539-553.

ASSUNÇÃO, M. C. F.; SANTOS, I. S.; COSTA, J. S. D. (2002). Avaliação do Processo da Atenção Médica: Adequação do Tratamento de Pacientes com diabetes Mellitus, Pelotas, Rio Grande do Sul, Brasil, Caderno Saúde Pública, v.18, p.205-211.

BATELlO, C. (1999). Iridologia e Irisdiagnose: O que os Olhos Podem Revelar. São Paulo, SP:Ground.

CARVAlHO, A. C. P. L. F.; BRAGA, A. P.; LUBERMIR, T. B. (1998). Fundamentos de Redes Neurais Artificiais. Rio de Janeiro, RJ:DCC/IM.

CHENG, S. C.; HUANG, Y. M. (2003). "A novel Approach to Diagnose Diabetes Based on the Fractal Characteristics of Retinal Images", IEEE Transactions on Information Technology in Biomedicine, v.7, n.3, p.163-170.

COTÉ, G. L.; FOX, M. D.; NORTHROP, R. B. (1992). "Noninvasive optical polarimetric glucose sensing using a true phasemeasurement technique", IEEE Transactions on Biomedical Engineering, v.39, n.7, p.752-756.

DIB, S. A. (2000). “Automonitoração da Glicemia no Diabetes Mellitus do Tipo 1: Um Investimento com Retorno Garantido", Arquivos Brasileiros de Endocrinologia \& Metabologia, v.44, n.3, p.193-194.

FERNANDES, A. P. M.; PACE, A. E.; ZANETTI, M. L.; FOSS, M. C.; DONADI, E. A. (2005). Fatores imunogenéticos associados ao diabetes mellitus do tipo 1, Revista Latino-Americana de Enfermagem, v.13, p.743-749.

GARCIA, E. V.;MARQUES, J. L. B. Estudo para a Detecção Não-invasiva de Hipoglicemia Baseada na Análise do Eletrocardiograma. In: Anais do II Congresso Latino-Americano de Engenharia Biomédica, Havana, 2001. CDROM.

GONÇALVES JR., A.A. (2005). Sistema Não-Invasivo para Determinação da Glicemia em Seres Humanos a partir de Imagens da Íris Fase IV. Projeto ...Florianópolis: Imprensa Oficial, 2005. $10 \mathrm{p}$. 
GONÇALVES, C. P. (1975). Oftalmologia. Rio de Janeiro, RJ:Atheneu.

GRAZIANO, R. M.; LEONE, C. R. (2005). "Frequent ophthalmologic problems and visual development of preterm newborn infants", Jornal de Pediatria, v.81, n.1, p.S95-S100.

GROSS, J. L.; SILVEIRO, S. P.; CAMARGO, J. L.; REICHELT, A. J.; AZEVEDO, M. J. (2002). Diabetes Melito: Diagnóstico, Classificação e Avaliação do Controle Glicêmico, Arquivos Brasileiros de Endocrinologia \& Metabologia, v.46, p.1626.

GUYTON, A. C. (1988). Fisiologia Humana. Rio de Janeiro, RJ:Guanabara Koogan.

HAGAN, M.; MENHAJ, M. (1994). "Training feedforward networks with the Marquardt algorithm”, IEEE Transactions on Neural Networks, v.5, n.6, p.989993.

HAM, F. M.; KOSTANIC, I. N.; COHEN, G. M.; GOOCH, B. R. (1997). "Determination of Glucose Concentrations in a Aqueous Matrix from NIR Spectra using optimal Time-Domin Filtering and Partial Least-Squares Regression”, IEEE Transactions on Biomedical Engineering, v.44, n.6, p.475485.

HARRIS, M. I.; KLEIN, R.; WELBORN, T. A.; KNUIMAN, M. W. (1992). “Onset of NIDDM Occurs at least 4-7 yr before Clinical diagnosis", Diabetes Care, v.15, p.815-824.

HAYKIN, S. (2001). Redes Neurais: princípios e práticas. Porto Alegre, RS:Bookman.

JENSEN, B. (1980). Iridology Simplified: An Introduction to the science of Iridology and its relation to nutrition. California, USA:Iridologists International.

JENSEN, B.; BODDEN, D. V. (1992). Visions of Health: Understanding Iridology. New York, NY:Avery.

KERMANI, B. G.; SCHIFFMAN, S. S.; NAGLE, H. T. (1999). "Using Neural Networks and Genetic Algorithms to Enhance Performance in an Electronic Nose", IEEE transactions on Biomedical Engineering, v.46, n.4, p.429-439.

KING, H.; AUBERT, R. E.; HERMAN, W. H. (1995). “Global Burden of Diabetes”, Diabetes Care, v.21, p.1414-1431.

KOVÁCS, Z. L. (1996). Redes Neurais Artificiais: Fundamentos e Aplicações. São Paulo, SP:collegium cognitio. 
LEMOS-MARINI, S. H. V.; LIMA, M. C. d.; JR, G. G.; M, M. F. V.; MINICUCCI, W. J. (2000). “A importância dos controles domiciliares na redução de internações em portadores de diabetes mellitus do tipo 1", Arquivos Brasileiros de Endocrinologia \& Metabologia, v.44, n.3, p.215-219.

MAIA, F. F. R.; ARAUJO, L. R. (2005). “Acurácia, utilidade e complicações da monitorização subcutânea da glicose (CGMS) em pacientes pediátricos com diabetes tipo 1", Jornal de Pediatria, v.81, n.4, p.293-297.

MAPA.JPG (2005). Altura: 627 pixels. Largura: 497 pixels. 150 dpi. 8B RGB. 72 Kb. Formato JPG. Compactado. Disponível em: < http://www1.folha.uol.com.br/folha/equilibrio/equi20000726_iris.shtml >. Acesso em: 07 dezembro. 2005.

MARQUES FILHO, O.; VIEIRA NETO, H. (1999). Processamento Digital de Imagens. Rio de Janeiro:Brasport.

MENEZES, J. R. (2004). Desenvolvimento e Avaliação Preliminar de um Sistema para a Quantificação da Glicose no Sangue por meio de Imagens da Íris Humana. 114p. Dissertação (Mestrado) - Universidade Federal de Santa Catarina, Florianópolis. 2004.

MINISTÉRIO DA SAÚDE. Secretaria de Assistência à Saúde. Departamento de Assistência e Promoção à Saúde. (1993). Manual de Diabetes. 2.ed. Brasília.

OLHO.JPG (2006). Altura: 459 pixels. Largura: 382 pixels. 300 dpi. 8B RGB. $41 \mathrm{~Kb}$.

Formato JPG. Compactado. Disponível em: <satelite.cptec.inpe.br/uv/RUV_e_olho.html $>$. Acesso em: 15 fevereiro. 2006.

ORTIZ, B. O.; PIÑERO, X.; BLANCO, J. (2004) . Instrumentation anbMeasurements in the Human Body. In: CONGRESS ON BIOFLUID DYNAMICS OF HUMAN BODY SYSTEMS AT UNIVERSITY OF PUERTO RICO MAYAGUEZ, 7., 2004, Porto Rico. Anais Eletrônicos ... Porto Rico. Disponível em:

http://www.uprm.edu/ mgoyal/fluidsjuly2004/instrumentation.pdf $>$. Acesso em: 27 abr. 2004.

OSÓRIO, F. ; BITTENCOURT, J. R. Sistemas inteligentes baseados em RNAs aplicados ao processamento de imagens. In: Workshop de Inteligência Artificial, Santa Cruz do Sul: UNISC, 2000.

PACCOLA, G. M. F. G.; FARIA, C. M.; SALES, A. P. M.; MONTENEGRO, A. P. D. R.; JORGE, S. M.; DUARTE, G.; FOSS, M. C. (2001). “Evolução materno-fetal 
de gestantes diabéticas seguidas no HC-FMRP-USP no período de 1992-1999”, Arquivos Brasileiros de Endocrinologia \& Metabologia, v.45, n.5, p.467-474.

PÉRES, D. S.; FRANCO, L. J.; SANTOS, M. A. (2006). Comportamento alimentar em mulheres portadoras de diabetes tipo 2, Revista Saúde Pública, v.40, p.310-317.

PICA, C. Q. (2002). Aperfeiçoamento e Avaliação de Sistema para Quantificação da Glicemia Através de Análises de Imagens da Íris Humana. 108p. Dissertação (Mestrado) - Universidade Federal de Santa Catarina, Florianópolis. 2002.

PIMENTA, W. P.; TEIXEIRA, A. S.; ARAGON, F. F.; BAPTISTELli, E. E.; MOREIRA, A. G.; CASTRO, A. V. B.; PADOVANI, C. R. (2002). “A ultrasonografia do pâncreas é eficaz em diagnosticar o diabete melito tipo 1 e tipo 2?", Radiologia Brasileira, v.35, n.4, p.209-212.

RHEE, M. K.; COOK, C. B.; KEBBI, I. E.; LYLES, R. H.; DUNBAR, V. G.; PANAYIOTO, R. M.; BERKOWITZ, K. J.; BOYD, B.; BROUSSARD, S.; GEORGE, C. D. (2005). Barriers to Diabetes Education in Urban Patients, The Diabetes EDUCATOR, v.31, p.410-417.

ROZMAN, J.; BUNC, M.; ZORKO, B. (2004). "Modulation of hormone secretion by functional electrical stimulation of the intact and incompletely dysfunctional dog pancreas", Brazilian Journal of Medical and Biological Research, v.37, n.3, p.363-370.

TAMADA, J. A.; LESHO, M.; TIERNEY, M. J. (2002). Keeping Watch on Glucose, IEEE Spectrum, v.34, p.52-57.

TAMBASCIA, M. A. (2004). "Hiperglicemia Pós Prandial”, Diabetes New, v.1, n.2, p.14-17.

WAREHAM, N. J.; GRIFFIN, S. J. (2001). "Should we screen for type 2 diabetes? Evaluation against National Screening Committee criteria”, BMJ, v.322, p.986988. 


\section{APÊNDICE A - Dados obtidos das simulações da rede MLP}

Tabela A1: Valores obtidos pela RNA para cada voluntário utilizando a rede MLP/topologia 2 com 4 características

\begin{tabular}{|c|c|c|c|}
\hline Voluntário & $\begin{array}{c}\text { Glicemia } \\
\text { (glicosímetro) }\end{array}$ & $\begin{array}{c}\text { Valor Obtido } \\
\text { pela rede }\end{array}$ & Erro (\%) \\
\hline AR & 77 & 85.025 & 10.42 \\
\hline AR & 85 & 77.458 & 8.87 \\
\hline $\mathrm{AB}$ & 90 & 87.810 & 2.43 \\
\hline $\mathrm{AB}$ & 213 & 213.000 & 0.00 \\
\hline $\mathrm{BCP}$ & 158 & 165.000 & 5.95 \\
\hline $\mathrm{BCP}$ & 247 & 246.895 & 0.04 \\
\hline $\mathrm{BCP}$ & 77 & 76.000 & 1.30 \\
\hline $\mathrm{BCP}$ & 130 & 128.563 & 1.11 \\
\hline $\mathrm{BCP}$ & 145 & 142.362 & 1.82 \\
\hline $\mathrm{BCP}$ & 221 & 222.580 & 0.71 \\
\hline $\mathrm{BCP}$ & 76 & 75.025 & 1.28 \\
\hline $\mathrm{BCP}$ & 159 & 158.251 & 0.47 \\
\hline $\mathrm{BR}$ & 170 & 168.996 & 0.59 \\
\hline $\mathrm{BR}$ & 136 & 135.778 & 0.16 \\
\hline CASC & 98 & 97.989 & 0.01 \\
\hline CASC & 93 & 93.241 & 0.26 \\
\hline ECC & 258 & 259.833 & 0.71 \\
\hline ECC & 208 & 213.816 & 2.80 \\
\hline $\mathrm{EC}$ & 219 & 206.878 & 5.54 \\
\hline $\mathrm{EC}$ & 238 & 238.000 & 0.00 \\
\hline $\mathrm{F}$ & 155 & 154.387 & 0.40 \\
\hline $\mathrm{F}$ & 124 & 133.719 & 7.84 \\
\hline $\mathrm{HIH}$ & 345 & 307.419 & 10.89 \\
\hline $\mathrm{HIH}$ & 249 & 246.842 & 0.87 \\
\hline $\mathrm{HIH}$ & 168 & 168.365 & 0.22 \\
\hline $\mathrm{HIH}$ & 269 & 281.121 & 4.51 \\
\hline $\mathrm{HIH}$ & 299 & 307.419 & 2.82 \\
\hline $\mathrm{HIH}$ & 199 & 210.419 & 5.74 \\
\hline $\mathrm{HIH}$ & 87 & 88.409 & 1.62 \\
\hline $\mathrm{HIH}$ & 113 & 111.822 & 1.04 \\
\hline JNS & 248 & 231.441 & 6.68 \\
\hline JNS & 217 & 218.155 & 0.53 \\
\hline JS & 94 & 95.867 & 1.99 \\
\hline JS & 124 & 123.999 & 0.00 \\
\hline LBG & 87 & 87.000 & 0.00 \\
\hline LBG & 107 & 104.778 & 2.08 \\
\hline MTC & 89 & 88.475 & 0.59 \\
\hline MTC & 145 & 146.002 & 0.69 \\
\hline MGF & 123 & 122.147 & 0.69 \\
\hline MGF & 127 & 126.800 & 0.16 \\
\hline MF & 193 & 185.068 & 4.11 \\
\hline MF & 112 & 133.000 & 18.75 \\
\hline MJS & 146 & 143.448 & 1.75 \\
\hline MJS & 100 & 99.431 & 0.57 \\
\hline NRG & 78 & 78.0225 & 0.03 \\
\hline NRG & 76 & 76.1203 & 0.16 \\
\hline RMM & 119 & 119.6831 & 0.57 \\
\hline RMM & 109 & 112.0693 & 2.82 \\
\hline SJT & 227 & 224.2202 & 1.22 \\
\hline SJT & 155 & 152.0232 & 1.92 \\
\hline SRSM & 131 & 127.3039 & 2.82 \\
\hline SRSM & 118 & 118 & 0.00 \\
\hline VMBL & 125 & 135.4861 & 8.39 \\
\hline VMBL & 276 & 254.7051 & 7.72 \\
\hline VIPG & 176 & 173.2478 & 1.56 \\
\hline VIPG & 150 & 145.0523 & 3.30 \\
\hline
\end{tabular}


Tabela A2: Valores obtidos pela RNA para cada voluntário utilizando a rede MLP/topologia 1 com 4 características

\begin{tabular}{|c|c|c|c|}
\hline Voluntário & $\begin{array}{c}\text { Glicemia } \\
\text { (glicosímetro) }\end{array}$ & $\begin{array}{l}\text { Valor Obtido } \\
\text { pela rede }\end{array}$ & Erro (\%) \\
\hline AR & 77 & 73.485 & 4.56 \\
\hline $\mathrm{AR}$ & 85 & 84.507 & 0.58 \\
\hline $\mathrm{AB}$ & 90 & 86.578 & 3.80 \\
\hline $\mathrm{AB}$ & 213 & 220.933 & 3.72 \\
\hline $\mathrm{BCP}$ & 158 & 157.130 & 0.55 \\
\hline $\mathrm{BCP}$ & 247 & 242.235 & 1.93 \\
\hline $\mathrm{BCP}$ & 77 & 79.950 & 3.83 \\
\hline $\mathrm{BCP}$ & 130 & 126.759 & 2.49 \\
\hline $\mathrm{BCP}$ & 145 & 139.439 & 3.83 \\
\hline $\mathrm{BCP}$ & 221 & 211.127 & 4.47 \\
\hline $\mathrm{BCP}$ & 76 & 75.621 & 0.50 \\
\hline $\mathrm{BCP}$ & 159 & 156.544 & 1.54 \\
\hline BR & 170 & 171.010 & 0.59 \\
\hline BR & 136 & 136.809 & 0.60 \\
\hline CASC & 98 & 98.560 & 0.57 \\
\hline CASC & 93 & 96.608 & 3.88 \\
\hline ECC & 258 & 252.114 & 2.28 \\
\hline ECC & 208 & 216.476 & 4.08 \\
\hline EC & 219 & 220.997 & 0.91 \\
\hline $\mathrm{EC}$ & 238 & 249.290 & 4.74 \\
\hline $\mathrm{F}$ & 155 & 154.684 & 0.20 \\
\hline $\mathrm{F}$ & 124 & 119.794 & 3.39 \\
\hline $\mathrm{HIH}$ & 345 & 338.221 & 1.97 \\
\hline HIH & 249 & 260.162 & 4.48 \\
\hline $\mathrm{HIH}$ & 168 & 165.274 & 1.62 \\
\hline HIH & 269 & 272.542 & 1.32 \\
\hline HIH & 299 & 284.558 & 4.83 \\
\hline $\mathrm{HIH}$ & 199 & 197.553 & 0.73 \\
\hline $\mathrm{HIH}$ & 87 & 85.331 & 1.92 \\
\hline $\mathrm{HIH}$ & 113 & 108.063 & 4.37 \\
\hline JNS & 248 & 250.534 & 1.02 \\
\hline JNS & 217 & 218.103 & 0.51 \\
\hline JS & 94 & 98.205 & 4.47 \\
\hline JS & 124 & 120.205 & 3.06 \\
\hline LBG & 87 & 84.185 & 3.24 \\
\hline LBG & 107 & 102.138 & 4.54 \\
\hline MTC & 89 & 86.555 & 2.75 \\
\hline MTC & 145 & 140.789 & 2.90 \\
\hline MGF & 123 & 122.422 & 0.47 \\
\hline MGF & 127 & 121.919 & 4.00 \\
\hline MF & 193 & 186.062 & 3.59 \\
\hline MF & 112 & 109.320 & 2.39 \\
\hline MJS & 146 & 141.404 & 3.15 \\
\hline MJS & 100 & 96.193 & 3.81 \\
\hline NRG & 78 & 79.271 & 1.63 \\
\hline NRG & 76 & 77.011 & 1.33 \\
\hline RMM & 119 & 118.467 & 0.45 \\
\hline RMM & 109 & 109.811 & 0.74 \\
\hline SJT & 227 & 221.179 & 2.56 \\
\hline SJT & 155 & 155.754 & 0.49 \\
\hline SRSM & 131 & 137.060 & 4.63 \\
\hline SRSM & 118 & 121.718 & 3.15 \\
\hline VMBL & 125 & 127.122 & 1.70 \\
\hline VMBL & 276 & 271.592 & 1.60 \\
\hline VIPG & 176 & 172.396 & 2.05 \\
\hline VIPG & 150 & 147.865 & 1.42 \\
\hline
\end{tabular}


Tabela A3: Valores obtidos pela RNA para cada voluntário utilizando a rede MLP/topologia 1 com 8 características

\begin{tabular}{|c|c|c|c|}
\hline Voluntário & $\begin{array}{c}\text { Glicemia } \\
\text { (glicosímetro) }\end{array}$ & $\begin{array}{c}\text { Valor Obtido } \\
\text { pela rede }\end{array}$ & Erro $(\%)$ \\
\hline AR & 77 & 71.520 & 7.12 \\
\hline $\mathrm{AR}$ & 85 & 89.885 & 5.75 \\
\hline $\mathrm{AB}$ & 90 & 81.905 & 8.99 \\
\hline $\mathrm{AB}$ & 213 & 189.212 & 11.17 \\
\hline $\mathrm{BCP}$ & 158 & 151.324 & 4.23 \\
\hline $\mathrm{BCP}$ & 247 & 281.764 & 14.07 \\
\hline BCP & 77 & 72.853 & 5.39 \\
\hline $\mathrm{BCP}$ & 130 & 110.630 & 14.90 \\
\hline $\mathrm{BCP}$ & 145 & 133.943 & 7.63 \\
\hline $\mathrm{BCP}$ & 221 & 251.367 & 13.74 \\
\hline $\mathrm{BCP}$ & 76 & 70.929 & 6.67 \\
\hline $\mathrm{BCP}$ & 159 & 170.192 & 7.04 \\
\hline BR & 170 & 145.301 & 14.53 \\
\hline $\mathrm{BR}$ & 136 & 118.183 & 13.10 \\
\hline CASC & 98 & 97.300 & 0.71 \\
\hline CASC & 93 & 85.847 & 7.69 \\
\hline ECC & 258 & 287.461 & 11.42 \\
\hline ECC & 208 & 228.360 & 9.79 \\
\hline EC & 219 & 200.975 & 8.23 \\
\hline $\mathrm{EC}$ & 238 & 269.897 & 13.40 \\
\hline $\mathrm{F}$ & 155 & 162.373 & 4.76 \\
\hline $\mathrm{F}$ & 124 & 129.064 & 4.08 \\
\hline $\mathrm{HIH}$ & 345 & 396.735 & 15.00 \\
\hline $\mathrm{HIH}$ & 249 & 229.390 & 7.88 \\
\hline $\mathrm{HIH}$ & 168 & 178.614 & 6.32 \\
\hline $\mathrm{HIH}$ & 269 & 248.815 & 7.50 \\
\hline $\mathrm{HIH}$ & 299 & 335.907 & 12.34 \\
\hline $\mathrm{HIH}$ & 199 & 179.090 & 10.00 \\
\hline $\mathrm{HIH}$ & 87 & 92.422 & 6.23 \\
\hline $\mathrm{HIH}$ & 113 & 112.476 & 0.46 \\
\hline JNS & 248 & 247.280 & 0.29 \\
\hline JNS & 217 & 243.668 & 12.29 \\
\hline JS & 94 & 99.453 & 5.80 \\
\hline JS & 124 & 122.756 & 1.00 \\
\hline LBG & 87 & 92.685 & 6.53 \\
\hline LBG & 107 & 92.283 & 13.75 \\
\hline MTC & 89 & 82.296 & 7.53 \\
\hline MTC & 145 & 140.367 & 3.20 \\
\hline MGF & 123 & 107.536 & 12.57 \\
\hline MGF & 127 & 121.791 & 4.10 \\
\hline MF & 193 & 164.492 & 14.77 \\
\hline MF & 112 & 99.163 & 11.46 \\
\hline MJS & 146 & 130.469 & 10.64 \\
\hline MJS & 100 & 94.741 & 5.26 \\
\hline NRG & 78 & 84.884 & 8.83 \\
\hline NRG & 76 & 80.328 & 5.70 \\
\hline RMM & 119 & 110.688 & 6.98 \\
\hline RMM & 109 & 104.724 & 3.92 \\
\hline SJT & 227 & 207.878 & 8.42 \\
\hline SJT & 155 & 176.545 & 13.90 \\
\hline SRSM & 131 & 123.708 & 5.57 \\
\hline SRSM & 118 & 117.090 & 0.77 \\
\hline VMBL & 125 & 111.810 & 10.55 \\
\hline VMBL & 276 & 261.604 & 5.22 \\
\hline VIPG & 176 & 156.508 & 11.07 \\
\hline VIPG & 150 & 131.884 & 12.08 \\
\hline
\end{tabular}


Tabela A4: Valores obtidos pela RNA para cada voluntário utilizando a rede MLP/topologia 2 com 8 características

\begin{tabular}{|c|c|c|c|}
\hline Voluntário & $\begin{array}{c}\text { Glicemia } \\
\text { (glicosímetro) }\end{array}$ & $\begin{array}{c}\text { Valor Obtido } \\
\text { pela rede }\end{array}$ & Erro $(\%)$ \\
\hline AR & 77 & 74.742 & 2.93 \\
\hline $\mathrm{AR}$ & 85 & 79.138 & 6.90 \\
\hline $\mathrm{AB}$ & 90 & 81.770 & 9.14 \\
\hline $\mathrm{AB}$ & 213 & 201.711 & 5.30 \\
\hline $\mathrm{BCP}$ & 158 & 164.929 & 4.39 \\
\hline $\mathrm{BCP}$ & 247 & 228.279 & 7.58 \\
\hline BCP & 77 & 84.489 & 9.73 \\
\hline $\mathrm{BCP}$ & 130 & 129.019 & 0.75 \\
\hline $\mathrm{BCP}$ & 145 & 141.890 & 2.14 \\
\hline $\mathrm{BCP}$ & 221 & 242.432 & 9.70 \\
\hline $\mathrm{BCP}$ & 76 & 72.384 & 4.76 \\
\hline $\mathrm{BCP}$ & 159 & 156.320 & 1.69 \\
\hline BR & 170 & 180.240 & 6.02 \\
\hline $\mathrm{BR}$ & 136 & 149.064 & 9.61 \\
\hline CASC & 98 & 91.620 & 6.51 \\
\hline CASC & 93 & 96.729 & 4.01 \\
\hline ECC & 258 & 268.093 & 3.91 \\
\hline ECC & 208 & 211.507 & 1.69 \\
\hline EC & 219 & 240.584 & 9.86 \\
\hline $\mathrm{EC}$ & 238 & 244.126 & 2.57 \\
\hline $\mathrm{F}$ & 155 & 164.072 & 5.85 \\
\hline $\mathrm{F}$ & 124 & 118.512 & 4.43 \\
\hline $\mathrm{HIH}$ & 345 & 320.451 & 7.12 \\
\hline $\mathrm{HIH}$ & 249 & 258.285 & 3.73 \\
\hline $\mathrm{HIH}$ & 168 & 180.287 & 7.31 \\
\hline $\mathrm{HIH}$ & 269 & 269.856 & 0.32 \\
\hline $\mathrm{HIH}$ & 299 & 311.288 & 4.11 \\
\hline $\mathrm{HIH}$ & 199 & 214.796 & 7.94 \\
\hline $\mathrm{HIH}$ & 87 & 78.400 & 9.89 \\
\hline $\mathrm{HIH}$ & 113 & 120.898 & 6.99 \\
\hline JNS & 248 & 265.304 & 6.98 \\
\hline JNS & 217 & 215.242 & 0.81 \\
\hline JS & 94 & 95.548 & 1.65 \\
\hline JS & 124 & 132.635 & 6.96 \\
\hline LBG & 87 & 85.326 & 1.92 \\
\hline LBG & 107 & 104.584 & 2.26 \\
\hline MTC & 89 & 86.832 & 2.44 \\
\hline MTC & 145 & 155.376 & 7.16 \\
\hline MGF & 123 & 131.551 & 6.95 \\
\hline MGF & 127 & 127.743 & 0.59 \\
\hline MF & 193 & 187.384 & 2.91 \\
\hline MF & 112 & 119.566 & 6.76 \\
\hline MJS & 146 & 157.225 & 7.69 \\
\hline MJS & 100 & 99.023 & 0.98 \\
\hline NRG & 78 & 73.297 & 6.03 \\
\hline NRG & 76 & 71.282 & 6.21 \\
\hline RMM & 119 & 107.422 & 9.73 \\
\hline RMM & 109 & 109.379 & 0.35 \\
\hline SJT & 227 & 205.217 & 9.60 \\
\hline SJT & 155 & 140.228 & 9.53 \\
\hline SRSM & 131 & 140.974 & 7.61 \\
\hline SRSM & 118 & 116.930 & 0.91 \\
\hline VMBL & 125 & 112.528 & 9.98 \\
\hline VMBL & 276 & 250.866 & 9.11 \\
\hline VIPG & 176 & 166.087 & 5.63 \\
\hline VIPG & 150 & 161.435 & 7.62 \\
\hline
\end{tabular}


Tabela A5: Valores obtidos pela RNA para cada voluntário utilizando a rede RBF/topologia 1 com 4 características

\begin{tabular}{|c|c|c|c|}
\hline Voluntário & $\begin{array}{c}\text { Glicemia } \\
\text { (glicosímetro) }\end{array}$ & $\begin{array}{c}\text { Valor Obtido } \\
\text { pela rede }\end{array}$ & Erro (\%) \\
\hline AR & 77 & 78.669 & 2.17 \\
\hline AR & 85 & 87.785 & 3.28 \\
\hline $\mathrm{AB}$ & 90 & 86.356 & 4.05 \\
\hline $\mathrm{AB}$ & 213 & 208.776 & 1.98 \\
\hline BCP & 158 & 152.265 & 3.63 \\
\hline BCP & 247 & 240.918 & 2.46 \\
\hline $\mathrm{BCP}$ & 77 & 73.305 & 4.80 \\
\hline $\mathrm{BCP}$ & 130 & 126.910 & 2.38 \\
\hline $\mathrm{BCP}$ & 145 & 133.499 & 7.93 \\
\hline $\mathrm{BCP}$ & 221 & 212.445 & 3.87 \\
\hline $\mathrm{BCP}$ & 76 & 72.688 & 4.36 \\
\hline $\mathrm{BCP}$ & 159 & 157.368 & 1.03 \\
\hline $\mathrm{BR}$ & 170 & 171.465 & 0.86 \\
\hline $\mathrm{BR}$ & 136 & 131.085 & 3.61 \\
\hline CASC & 98 & 91.253 & 6.88 \\
\hline CASC & 93 & 92.768 & 0.25 \\
\hline $\mathrm{ECC}$ & 258 & 253.056 & 1.92 \\
\hline $\mathrm{ECC}$ & 208 & 191.378 & 7.99 \\
\hline $\mathrm{EC}$ & 219 & 218.932 & 0.03 \\
\hline $\mathrm{EC}$ & 238 & 231.146 & 2.88 \\
\hline $\mathrm{F}$ & 155 & 155.113 & 0.07 \\
\hline $\mathrm{F}$ & 124 & 129.578 & 4.50 \\
\hline $\mathrm{HIH}$ & 345 & 331.026 & 4.05 \\
\hline $\mathrm{HIH}$ & 249 & 233.906 & 6.06 \\
\hline $\mathrm{HIH}$ & 168 & 160.324 & 4.57 \\
\hline $\mathrm{HIH}$ & 269 & 264.066 & 1.83 \\
\hline $\mathrm{HIH}$ & 299 & 288.253 & 3.59 \\
\hline $\mathrm{HIH}$ & 199 & 202.593 & 1.81 \\
\hline $\mathrm{HIH}$ & 87 & 82.316 & 5.38 \\
\hline $\mathrm{HIH}$ & 113 & 114.232 & 1.09 \\
\hline JNS & 248 & 242.882 & 2.06 \\
\hline JNS & 217 & 201.318 & 7.23 \\
\hline JS & 94 & 88.400 & 5.96 \\
\hline JS & 124 & 121.130 & 2.31 \\
\hline LBG & 87 & 81.162 & 6.71 \\
\hline LBG & 107 & 107.160 & 0.15 \\
\hline MTC & 89 & 85.498 & 3.94 \\
\hline MTC & 145 & 151.354 & 4.38 \\
\hline MGF & 123 & 126.638 & 2.96 \\
\hline MGF & 127 & 124.762 & 1.76 \\
\hline MF & 193 & 195.027 & 1.05 \\
\hline MF & 112 & 108.997 & 2.68 \\
\hline MJS & 146 & 149.300 & 2.26 \\
\hline MJS & 100 & 97.993 & 2.01 \\
\hline NRG & 78 & 74.736 & 4.18 \\
\hline NRG & 76 & 72.236 & 4.95 \\
\hline RMM & 119 & 123.641 & 3.90 \\
\hline RMM & 109 & 101.721 & 6.68 \\
\hline SJT & 227 & 223.755 & 1.43 \\
\hline SJT & 155 & 162.671 & 4.95 \\
\hline SRSM & 131 & 124.710 & 4.80 \\
\hline SRSM & 118 & 115.232 & 2.35 \\
\hline VMBL & 125 & 129.434 & 3.55 \\
\hline VMBL & 276 & 273.348 & 0.96 \\
\hline VIPG & 176 & 184.631 & 4.90 \\
\hline VIPG & 150 & 149.783 & 0.14 \\
\hline
\end{tabular}


Tabela A6: Valores obtidos pela RNA para cada voluntário utilizando a rede RBF/topologia 1 com 8 características

\begin{tabular}{|c|c|c|c|}
\hline Voluntário & $\begin{array}{c}\text { Glicemia } \\
\text { (glicosímetro) }\end{array}$ & $\begin{array}{c}\text { Valor Obtido } \\
\text { pela rede }\end{array}$ & Erro (\%) \\
\hline AR & 77 & 75.899 & 1.43 \\
\hline AR & 85 & 84.749 & 0.30 \\
\hline $\mathrm{AB}$ & 90 & 84.676 & 5.92 \\
\hline $\mathrm{AB}$ & 213 & 205.610 & 3.47 \\
\hline BCP & 158 & 160.072 & 1.31 \\
\hline BCP & 247 & 244.817 & 0.88 \\
\hline BCP & 77 & 76.386 & 0.80 \\
\hline $\mathrm{BCP}$ & 130 & 127.521 & 1.91 \\
\hline $\mathrm{BCP}$ & 145 & 143.695 & 0.90 \\
\hline $\mathrm{BCP}$ & 221 & 215.241 & 2.61 \\
\hline $\mathrm{BCP}$ & 76 & 72.947 & 4.02 \\
\hline $\mathrm{BCP}$ & 159 & 157.230 & 1.11 \\
\hline $\mathrm{BR}$ & 170 & 170.192 & 0.11 \\
\hline $\mathrm{BR}$ & 136 & 134.900 & 0.81 \\
\hline CASC & 98 & 92.553 & 5.56 \\
\hline CASC & 93 & 92.708 & 0.31 \\
\hline $\mathrm{ECC}$ & 258 & 247.720 & 3.98 \\
\hline $\mathrm{ECC}$ & 208 & 196.902 & 5.34 \\
\hline $\mathrm{EC}$ & 219 & 214.071 & 2.25 \\
\hline $\mathrm{EC}$ & 238 & 232.892 & 2.15 \\
\hline $\mathrm{F}$ & 155 & 156.452 & 0.94 \\
\hline $\mathrm{F}$ & 124 & 119.956 & 3.26 \\
\hline $\mathrm{HIH}$ & 345 & 335.928 & 2.63 \\
\hline $\mathrm{HIH}$ & 249 & 237.143 & 4.76 \\
\hline $\mathrm{HIH}$ & 168 & 158.914 & 5.41 \\
\hline $\mathrm{HIH}$ & 269 & 270.406 & 0.52 \\
\hline $\mathrm{HIH}$ & 299 & 288.356 & 3.56 \\
\hline $\mathrm{HIH}$ & 199 & 189.545 & 4.75 \\
\hline $\mathrm{HIH}$ & 87 & 85.111 & 2.17 \\
\hline $\mathrm{HIH}$ & 113 & 111.974 & 0.91 \\
\hline JNS & 248 & 241.006 & 2.82 \\
\hline JNS & 217 & 219.146 & 0.99 \\
\hline JS & 94 & 89.199 & 5.11 \\
\hline JS & 124 & 118.735 & 4.25 \\
\hline LBG & 87 & 84.378 & 3.01 \\
\hline LBG & 107 & 104.909 & 1.95 \\
\hline MTC & 89 & 85.104 & 4.38 \\
\hline MTC & 145 & 137.380 & 5.26 \\
\hline MGF & 123 & 119.903 & 2.52 \\
\hline MGF & 127 & 128.767 & 1.39 \\
\hline MF & 193 & 189.909 & 1.60 \\
\hline MF & 112 & 105.438 & 5.86 \\
\hline MJS & 146 & 139.394 & 4.52 \\
\hline MJS & 100 & 94.655 & 5.35 \\
\hline NRG & 78 & 76.189 & 2.32 \\
\hline NRG & 76 & 74.464 & 2.02 \\
\hline RMM & 119 & 117.096 & 1.60 \\
\hline RMM & 109 & 104.095 & 4.50 \\
\hline SJT & 227 & 217.612 & 4.14 \\
\hline SJT & 155 & 153.703 & 0.84 \\
\hline SRSM & 131 & 126.598 & 3.36 \\
\hline SRSM & 118 & 117.011 & 0.84 \\
\hline VMBL & 125 & 122.470 & 2.02 \\
\hline VMBL & 276 & 267.073 & 3.23 \\
\hline VIPG & 176 & 169.640 & 3.61 \\
\hline VIPG & 150 & 149.680 & 0.21 \\
\hline
\end{tabular}


Tabela A7: Valores obtidos pela RNA para cada voluntário utilizando a rede RBF/topologia 2 com 4 características

\begin{tabular}{|c|c|c|c|}
\hline Voluntário & $\begin{array}{c}\text { Glicemia } \\
\text { (glicosímetro) }\end{array}$ & $\begin{array}{c}\text { Valor Obtido } \\
\text { pela rede }\end{array}$ & Erro (\%) \\
\hline AR & 77 & 76.808 & 0.25 \\
\hline $\mathrm{AR}$ & 85 & 87.824 & 3.32 \\
\hline $\mathrm{AB}$ & 90 & 90.813 & 0.90 \\
\hline $\mathrm{AB}$ & 213 & 211.559 & 0.68 \\
\hline $\mathrm{BCP}$ & 158 & 155.702 & 1.45 \\
\hline $\mathrm{BCP}$ & 247 & 241.043 & 2.41 \\
\hline BCP & 77 & 74.994 & 2.61 \\
\hline $\mathrm{BCP}$ & 130 & 133.157 & 2.43 \\
\hline $\mathrm{BCP}$ & 145 & 149.738 & 3.27 \\
\hline $\mathrm{BCP}$ & 221 & 229.451 & 3.82 \\
\hline $\mathrm{BCP}$ & 76 & 78.207 & 2.90 \\
\hline $\mathrm{BCP}$ & 159 & 163.985 & 3.13 \\
\hline BR & 170 & 169.882 & 0.07 \\
\hline $\mathrm{BR}$ & 136 & 137.022 & 0.75 \\
\hline CASC & 98 & 94.446 & 3.63 \\
\hline CASC & 93 & 91.124 & 2.02 \\
\hline ECC & 258 & 263.729 & 2.22 \\
\hline ECC & 208 & 208.922 & 0.44 \\
\hline EC & 219 & 216.023 & 1.36 \\
\hline $\mathrm{EC}$ & 238 & 238.441 & 0.19 \\
\hline $\mathrm{F}$ & 155 & 156.659 & 1.07 \\
\hline $\mathrm{F}$ & 124 & 119.351 & 3.75 \\
\hline $\mathrm{HIH}$ & 345 & 333.768 & 3.26 \\
\hline $\mathrm{HIH}$ & 249 & 241.513 & 3.01 \\
\hline $\mathrm{HIH}$ & 168 & 165.709 & 1.36 \\
\hline $\mathrm{HIH}$ & 269 & 260.872 & 3.02 \\
\hline $\mathrm{HIH}$ & 299 & 293.324 & 1.90 \\
\hline $\mathrm{HIH}$ & 199 & 206.582 & 3.81 \\
\hline $\mathrm{HIH}$ & 87 & 85.757 & 1.43 \\
\hline $\mathrm{HIH}$ & 113 & 115.633 & 2.33 \\
\hline JNS & 248 & 252.842 & 1.95 \\
\hline JNS & 217 & 213.994 & 1.39 \\
\hline JS & 94 & 96.577 & 2.74 \\
\hline JS & 124 & 128.894 & 3.95 \\
\hline LBG & 87 & 87.753 & 0.87 \\
\hline LBG & 107 & 102.837 & 3.89 \\
\hline MTC & 89 & 87.015 & 2.23 \\
\hline MTC & 145 & 142.161 & 1.96 \\
\hline MGF & 123 & 120.984 & 1.64 \\
\hline MGF & 127 & 129.353 & 1.85 \\
\hline MF & 193 & 196.068 & 1.59 \\
\hline MF & 112 & 114.614 & 2.33 \\
\hline MJS & 146 & 148.177 & 1.49 \\
\hline MJS & 100 & 96.553 & 3.45 \\
\hline NRG & 78 & 75.854 & 2.75 \\
\hline NRG & 76 & 78.228 & 2.93 \\
\hline RMM & 119 & 115.290 & 3.12 \\
\hline RMM & 109 & 107.841 & 1.06 \\
\hline SJT & 227 & 226.573 & 0.19 \\
\hline SJT & 155 & 157.480 & 1.60 \\
\hline SRSM & 131 & 131.450 & 0.34 \\
\hline SRSM & 118 & 115.037 & 2.51 \\
\hline VMBL & 125 & 125.164 & 0.13 \\
\hline VMBL & 276 & 267.181 & 3.20 \\
\hline VIPG & 176 & 181.358 & 3.04 \\
\hline VIPG & 150 & 151.752 & 1.17 \\
\hline
\end{tabular}


Tabela A8: Valores obtidos pela RNA para cada voluntário utilizando a rede RBF/topologia 2 com 8 características

\begin{tabular}{|c|c|c|c|}
\hline Voluntário & $\begin{array}{c}\text { Glicemia } \\
\text { (glicosímetro) }\end{array}$ & $\begin{array}{c}\text { Valor Obtido } \\
\text { pela rede }\end{array}$ & Erro $(\%)$ \\
\hline AR & 77 & 78.058 & 1.37 \\
\hline $\mathrm{AR}$ & 85 & 83.431 & 1.85 \\
\hline $\mathrm{AB}$ & 90 & 91.263 & 1.40 \\
\hline $\mathrm{AB}$ & 213 & 216.571 & 1.68 \\
\hline $\mathrm{BCP}$ & 158 & 155.046 & 1.87 \\
\hline $\mathrm{BCP}$ & 247 & 246.693 & 0.12 \\
\hline BCP & 77 & 75.830 & 1.52 \\
\hline $\mathrm{BCP}$ & 130 & 129.442 & 0.43 \\
\hline $\mathrm{BCP}$ & 145 & 144.789 & 0.15 \\
\hline $\mathrm{BCP}$ & 221 & 218.662 & 1.06 \\
\hline $\mathrm{BCP}$ & 76 & 75.592 & 0.54 \\
\hline $\mathrm{BCP}$ & 159 & 155.929 & 1.93 \\
\hline BR & 170 & 166.965 & 1.79 \\
\hline $\mathrm{BR}$ & 136 & 138.205 & 1.62 \\
\hline CASC & 98 & 97.755 & 0.25 \\
\hline CASC & 93 & 94.140 & 1.23 \\
\hline ECC & 258 & 259.053 & 0.41 \\
\hline ECC & 208 & 207.533 & 0.22 \\
\hline EC & 219 & 217.684 & 0.60 \\
\hline $\mathrm{EC}$ & 238 & 235.924 & 0.87 \\
\hline $\mathrm{F}$ & 155 & 154.815 & 0.12 \\
\hline $\mathrm{F}$ & 124 & 121.648 & 1.90 \\
\hline $\mathrm{HIH}$ & 345 & 347.100 & 0.61 \\
\hline $\mathrm{HIH}$ & 249 & 247.019 & 0.80 \\
\hline $\mathrm{HIH}$ & 168 & 166.492 & 0.90 \\
\hline $\mathrm{HIH}$ & 269 & 270.051 & 0.39 \\
\hline $\mathrm{HIH}$ & 299 & 301.080 & 0.70 \\
\hline $\mathrm{HIH}$ & 199 & 201.177 & 1.09 \\
\hline $\mathrm{HIH}$ & 87 & 87.132 & 0.15 \\
\hline $\mathrm{HIH}$ & 113 & 110.920 & 1.84 \\
\hline JNS & 248 & 252.343 & 1.75 \\
\hline JNS & 217 & 218.224 & 0.56 \\
\hline JS & 94 & 93.281 & 0.77 \\
\hline JS & 124 & 126.286 & 1.84 \\
\hline LBG & 87 & 86.953 & 0.05 \\
\hline LBG & 107 & 108.155 & 1.08 \\
\hline MTC & 89 & 87.881 & 1.26 \\
\hline MTC & 145 & 144.973 & 0.02 \\
\hline MGF & 123 & 123.496 & 0.40 \\
\hline MGF & 127 & 127.645 & 0.51 \\
\hline MF & 193 & 189.974 & 1.57 \\
\hline MF & 112 & 111.198 & 0.72 \\
\hline MJS & 146 & 147.600 & 1.10 \\
\hline MJS & 100 & 99.378 & 0.62 \\
\hline NRG & 78 & 79.207 & 1.55 \\
\hline NRG & 76 & 75.628 & 0.49 \\
\hline RMM & 119 & 119.603 & 0.51 \\
\hline RMM & 109 & 107.515 & 1.36 \\
\hline SJT & 227 & 223.122 & 1.71 \\
\hline SJT & 155 & 154.289 & 0.46 \\
\hline SRSM & 131 & 129.733 & 0.97 \\
\hline SRSM & 118 & 115.876 & 1.80 \\
\hline VMBL & 125 & 126.897 & 1.52 \\
\hline VMBL & 276 & 276.234 & 0.08 \\
\hline VIPG & 176 & 173.933 & 1.17 \\
\hline VIPG & 150 & 152.867 & 1.91 \\
\hline
\end{tabular}




\section{ANEXO A - Dados dos voluntários}

1- AR:

- Data de nascimento: 17/01/1970

- Sexo: Feminino

- Cor: Branca

- Procedência: Florianópolis

- Profissão: Administrativa (funcionária Oftalmologia Hospital Celso Ramos)

- Diabético (a): NÃO

- Apresenta outras enfermidades?: Ñão

- Exame oftalmológico: O.D.= Miopia e astigmatismo / O.E.= Miopia (20/20 A.O.) /

Biomicroscopia normal A.O. / Fundo de olho normal A.O / Tonometria normal A.O.

-Taxas glicemia capilar:

\begin{tabular}{|l|l|l|l|}
\hline $\begin{array}{l}\text { DATA } \\
\text { COLETA }\end{array}$ & $\begin{array}{l}\text { GLICEMIA } \\
\text { CAPILAR }\end{array}$ & JEJUM & ARQUIVOS ID/IE \\
\hline $10 / 06 / 2003$ & 77 & NÃO & \\
\hline $17 / 06 / 2003$ & 70 & SIM & \\
\hline $01 / 07 / 2003$ & 121 & NÃO & \\
\hline $08 / 07 / 2003$ & 84 & SIM & \\
\hline $15 / 07 / 2003$ & 75 & SIM & \\
\hline $22 / 07 / 2003$ & 80 & - & \\
\hline $29 / 07 / 2003$ & 76 & SIM & \\
\hline $05 / 08 / 2003$ & 120 & NÃO & \\
\hline $12 / 08 / 2003$ & 77 & NÃO & \\
\hline $19 / 08 / 2003$ & $65 / 85$ & NÃO & \\
\hline
\end{tabular}

Íris Direita

\begin{tabular}{|l|l|l|l|l|l|l|l|l|l|}
\hline $\begin{array}{l}\text { Pos } \\
\text { mín }\end{array}$ & mín & $\begin{array}{l}\text { Pos } \\
\text { máx }\end{array}$ & máx & R med & G med & B med & H med & S med & I med \\
\hline R4Co & -0.568 & B10Pu & 0.786 & 0.248 & 0.187 & 0.183 & 0.227 & 0.185 & 0.176 \\
\hline
\end{tabular}

Íris Esquerda

\begin{tabular}{|l|l|l|l|l|l|l|l|l|l|}
\hline $\begin{array}{l}\text { Pos } \\
\text { mín }\end{array}$ & mín & $\begin{array}{l}\text { Pos } \\
\text { máx }\end{array}$ & máx & R med & G med & B med & H med & S med & I med \\
\hline $\mathrm{H} 4 \mathrm{Ci}$ & -0.739 & G5Ci & 0.561 & 0.214 & 0.166 & 0.215 & 0.288 & 0.252 & 0.220 \\
\hline
\end{tabular}


2- AB:

- Data de nascimento: 23/09/1948

- Sexo: Masculino

- Cor: Branca

- Procedência: São José

- Profissão:Policial Rodoviário (aposentado)

- Diabético (a): SIM

- Diabético (a) há quanto tempo?: Há 5 anos

- Apresenta outras enfermidades?: HAS (Hipertensão Arterial Sistêmica)

- Tratamentos que realiza:

- Diabetes: Metformin 500 3x, Diamicron- 1 antes café

- H.A.S: Vasopril Plus 20-12.5 mg- 1 antes café, Atenolol $50 \mathrm{mg} 1$ no café.

- Exame oftalmológico: A.O.= hipermetropia e presbiopia (20/20 e J1 A.O.) /

Biomicroscopia normal A.O. / Fundo de olho normal A.O / Tonometria normal A.O.

-Taxas glicemia capilar:

\begin{tabular}{|l|l|l|l|}
\hline DATA COLETA & $\begin{array}{l}\text { GLICEMIA } \\
\text { CAPILAR }\end{array}$ & JEJUM & $\begin{array}{l}\text { GLICEMIA } \\
\text { VENOSA }\end{array}$ \\
\hline $08 / 07 / 2003$ & 175 & SIM & \\
\hline $15 / 07 / 2003$ & 122 & SIM & \\
\hline $22 / 07 / 2003$ & 111 & - & \\
\hline $29 / 07 / 2003$ & 192 & SIM & \\
\hline $12 / 08 / 2003$ & 126 & SIM & 132 \\
\hline $19 / 08 / 2003$ & 124 & SIM & \\
\hline $26 / 08 / 2003$ & 167 & NÃO & \\
\hline $02 / 09 / 2003$ & 109 & SIM & \\
\hline $09 / 09 / 2003$ & 90 & SIM & \\
\hline $23 / 09 / 2003$ & 213 & NAO & \\
\hline
\end{tabular}

Íris Direita

\begin{tabular}{|l|l|l|l|l|l|l|l|l|l|}
\hline $\begin{array}{l}\text { Pos } \\
\text { mín }\end{array}$ & mín & $\begin{array}{l}\text { Pos } \\
\text { máx }\end{array}$ & máx & R med & G med & B med & H med & S med & I med \\
\hline G7Pu & -0.704 & I7Co & 0.788 & 0.239 & 0.316 & 0.246 & 0.191 & 0.231 & 0.280 \\
\hline
\end{tabular}

Íris Esquerda

\begin{tabular}{|l|l|l|l|l|l|l|l|l|l|}
\hline $\begin{array}{l}\text { Pos } \\
\text { mín }\end{array}$ & mín & $\begin{array}{l}\text { Pos } \\
\text { máx }\end{array}$ & máx & R med & G med & B med & H med & S med & I med \\
\hline R1Pu & -0.662 & R4Co & 0.796 & 0.279 & 0.299 & 0.268 & 0.292 & 0.271 & 0.289 \\
\hline
\end{tabular}


3- BC:

- Data de nascimento: 10/10/1957

- Sexo: Masculino

- Cor: Branca

- Procedência: Florianópolis

- Profissão: Cozinheiro

- Diabético (a): SIM

- Diabético (a) há quanto tempo?: Há 10 anos

- Apresenta outras enfermidades?: Não

- Tratamentos que realiza:

- Diabetes: Insulina NPH e R

- Exame oftalmológico: A.O.= presbiopia (20/20 e J1 A.O.) / Biomicroscopia O.D.= pinguécula / O.E.= pterígio nasal / Fundo de olho A.O.= RDNP moderada + marcas de laser / Tonometria normal A.O.

-Taxas glicemia capilar:

\begin{tabular}{|l|l|l|l|}
\hline DATA COLETA & $\begin{array}{l}\text { GLICEMIA } \\
\text { CAPILAR }\end{array}$ & JEJUM & $\begin{array}{l}\text { GLICEMIA } \\
\text { VENOSA }\end{array}$ \\
\hline $10 / 06 / 2003$ & 158 & - & \\
\hline $17 / 06 / 2003$ & 247 & - & \\
\hline $01 / 07 / 2003$ & 189 & - & \\
\hline $08 / 07 / 2003$ & 77 & NÃO & \\
\hline $15 / 07 / 2003$ & 130 & NAO & \\
\hline $22 / 07 / 2003$ & 76 & - & \\
\hline $29 / 07 / 2003$ & 89 & NÃO & \\
\hline $05 / 08 / 2003$ & 159 & NÃO & \\
\hline $12 / 08 / 2003$ & 145 & NÃO & 241 \\
\hline $19 / 08 / 2003$ & 221 & NAO & \\
\hline
\end{tabular}

Íris Direita

\begin{tabular}{|l|l|l|l|l|l|l|l|l|l|}
\hline $\begin{array}{l}\text { Pos } \\
\text { mín }\end{array}$ & mín & $\begin{array}{l}\text { Pos } \\
\text { máx }\end{array}$ & máx & R med & G med & B med & H med & S med & I med \\
\hline H11Co & -0.635 & S8Pu & 0.856 & 0.258 & 0.231 & 0.292 & 0.372 & 0.337 & 0.271 \\
\hline
\end{tabular}

Íris Esquerda

\begin{tabular}{|l|l|l|l|l|l|l|l|l|l|}
\hline $\begin{array}{l}\text { Pos } \\
\text { mín }\end{array}$ & mín & $\begin{array}{l}\text { Pos } \\
\text { máx }\end{array}$ & máx & R med & G med & B med & H med & S med & I med \\
\hline I11Co & -0.816 & I2Ci & 0.871 & 0.427 & 0.444 & 0.348 & 0.275 & 0.372 & 0.338 \\
\hline
\end{tabular}


4 - BR:

- Data de nascimento: $16 / 04 / 1956$

- Sexo: Feminino

- Cor: Branca

- Procedência: Florianópolis

- Profissão: Gerente de locadora

- Diabético (a): SIM

- Diabético (a) há quanto tempo?: Há 10 anos

- Apresenta outras enfermidades?: Não

- Tratamentos que realiza:

- Diabetes: Glifage 500 3x ao dia, após refeições.

- Exame oftalmológico: A.O.= hipermetropia, astigmatismo e presbiopia (O.D. $<20 / 400$

/ O.E. $=20 / 20$ e J1 O.E.) / Biomicroscopia normal A.O. / Fundo de olho: OD= placa cicatricial de coriorretinite macular / O.E $=\mathrm{sp} /$ Tonometria normal A.O.

-Taxas glicemia capilar:

\begin{tabular}{|l|l|l|l|}
\hline DATA COLETA & $\begin{array}{l}\text { GLICEMIA } \\
\text { CAPILAR }\end{array}$ & JEJUM & $\begin{array}{l}\text { GLICEMIA } \\
\text { VENOSA }\end{array}$ \\
\hline $01 / 07 / 2003$ & 298 & NÃO & \\
\hline $08 / 07 / 2003$ & 256 & SIM & \\
\hline $15 / 07 / 2003$ & 245 & SIM & \\
\hline $22 / 07 / 2003$ & 256 & - & \\
\hline $29 / 07 / 2003$ & 295 & SIM & \\
\hline $05 / 08 / 2003$ & 269 & SIM & \\
\hline $12 / 08 / 2003$ & 229 & SIM & 187 \\
\hline $19 / 08 / 2003$ & 176 & SIM & \\
\hline $26 / 08 / 2003$ & 117 & SIM & \\
\hline $02 / 09 / 2003$ & 170 & SIM & \\
\hline $09 / 09 / 2003$ & 136 & SIM & \\
\hline
\end{tabular}

Íris Direita

\begin{tabular}{|l|l|l|l|l|l|l|l|l|l|}
\hline $\begin{array}{l}\text { Pos } \\
\text { mín }\end{array}$ & mín & $\begin{array}{l}\text { Pos } \\
\text { máx }\end{array}$ & máx & R med & G med & B med & H med & S med & I med \\
\hline H11Co & -0.900 & H7Co & 0.854 & 0.416 & 0.417 & 0.523 & 0.452 & 0.411 & 0.556 \\
\hline
\end{tabular}

Íris Esquerda

\begin{tabular}{|l|l|l|l|l|l|l|l|l|l|}
\hline $\begin{array}{l}\text { Pos } \\
\text { mín }\end{array}$ & mín & $\begin{array}{l}\text { Pos } \\
\text { máx }\end{array}$ & máx & R med & G med & B med & H med & S med & I med \\
\hline S3Co & -0.769 & G9Pu & 0.787 & 0.337 & 0.364 & 0.340 & 0.158 & 0.321 & 0.326 \\
\hline
\end{tabular}


5- CASC:

- Data de nascimento: 15/08/1942

- Sexo: Masculino

- Cor: Branca

- Procedência: Florianópolis

- Profissão: vendedor

- Diabético (a): SIM

- Diabético (a) há quanto tempo?: Há 2 anos

- Apresenta outras enfermidades?: HAS

- Tratamentos que realiza:

- Diabetes: Glucoformin 8501 cpr após almoço e 1 cpr após jantar.

- HAS: Diovan 160 mg 1 cpr no café / Lasix meio cpr café e meio cpr à tarde /

Aspirina $100 \mathrm{mg} 2$ cpr após almoço.

- Colesterol: Provastatina $10 \mathrm{mg} 1 \mathrm{cpr}$ após jantar.

Exame oftalmológico: A.O.= hipermetropia, astigmatismo e presbiopia (20/20 e J1

A.O.) / Biomicroscopia normal A.O. / Fundo de olho normal A.O. / Tonometria normal A.O.

-Taxas glicemia capilar:

\begin{tabular}{|l|l|l|l|}
\hline DATA COLETA & $\begin{array}{l}\text { GLICEMIA } \\
\text { CAPILAR }\end{array}$ & JEJUM & $\begin{array}{l}\text { GLICEMIA } \\
\text { VENOSA }\end{array}$ \\
\hline $12 / 08 / 2003$ & 104 & NAO & \\
\hline $19 / 08 / 2003$ & 104 & NAO & 104 \\
\hline $26 / 08 / 2003$ & 95 & NÃO & \\
\hline $09 / 09 / 2003$ & 129 & NÃO & \\
\hline $23 / 09 / 2003$ & 101 & NÃO & \\
\hline $30 / 09 / 2003$ & 110 & NÃO & \\
\hline $07 / 10 / 2003$ & 97 & NÃO & \\
\hline $14 / 10 / 2003$ & 98 & NÃO & \\
\hline $21 / 10 / 2003$ & 93 & NAO & \\
\hline $04 / 11 / 2003$ & 123 & NAO & \\
\hline
\end{tabular}

Íris Direita

\begin{tabular}{|l|l|l|l|l|l|l|l|l|l|}
\hline $\begin{array}{l}\text { Pos } \\
\text { mín }\end{array}$ & mín & $\begin{array}{l}\text { Pos } \\
\text { máx }\end{array}$ & máx & R med & G med & B med & H med & S med & I med \\
\hline $\mathrm{H} 10 \mathrm{Pu}$ & -0.883 & $\mathrm{H} 10 \mathrm{Ci}$ & 0.915 & 0.296 & 0.292 & 0.226 & 0.316 & 0.233 & 0.274 \\
\hline
\end{tabular}

Íris Esquerda

\begin{tabular}{|l|l|l|l|l|l|l|l|l|l|}
\hline $\begin{array}{l}\text { Pos } \\
\text { mín }\end{array}$ & mín & $\begin{array}{l}\text { Pos } \\
\text { máx }\end{array}$ & máx & R med & G med & B med & H med & S med & I med \\
\hline B8Pu & -0.857 & S10Pu & 0.826 & 0.227 & 0.229 & 0.206 & 0.228 & 0.246 & 0.173 \\
\hline
\end{tabular}


6- ECC:

- Data de nascimento: 30/11/1926

- Sexo: Masculino

- Cor: Branca

- Procedência: Florianópolis

- Profissão: Professor

- Diabético (a): SIM

- Diabético (a) há quanto tempo?: Há 11 anos

- Apresenta outras enfermidades?: Não

- Tratamentos que realiza:

- Diabetes: Diamicron 1 cpr antes café / Prandin 1 cpr antes café / Micoformina 8501 cpr após jantar.

- HAS: Captopril 1 cpr antes almoço

- Exame oftalmológico: A.O.= hipermetropia, astigmatismo e presbiopia (20/20 e J1 A.O.) / Biomicroscopia A.O.= catarata incipiente / Fundo de olho: A.O.= RDNP moderada + marcas laser / Tonometria normal A.O.

-Taxas glicemia capilar:

\begin{tabular}{|l|l|l|l|}
\hline DATA COLETA & $\begin{array}{l}\text { GLICEMIA } \\
\text { CAPILAR }\end{array}$ & JEJUM & $\begin{array}{l}\text { GLICEMIA } \\
\text { VENOSA }\end{array}$ \\
\hline $10 / 06 / 2003$ & $406 / 457$ & - & \\
\hline $17 / 06 / 2003$ & 260 & - & \\
\hline $01 / 07 / 2003$ & 222 & SIM & \\
\hline $08 / 07 / 2003$ & 248 & SIM & \\
\hline $15 / 07 / 2003$ & 187 & SIM & \\
\hline $22 / 07 / 2003$ & 243 & SIM & \\
\hline $29 / 07 / 2003$ & 235 & SIM & \\
\hline $05 / 08 / 2003$ & 223 & NÃO & \\
\hline $12 / 08 / 2003$ & 258 & NÃO & 228 \\
\hline $19 / 08 / 2003$ & 208 & NAO & \\
\hline
\end{tabular}

Íris Direita

\begin{tabular}{|l|l|l|l|l|l|l|l|l|l|}
\hline $\begin{array}{l}\text { Pos } \\
\text { mín }\end{array}$ & mín & $\begin{array}{l}\text { Pos } \\
\text { máx }\end{array}$ & máx & R med & G med & B med & H med & S med & I med \\
\hline H10Co & -0.859 & R5Ci & 0.905 & 0.452 & 0.291 & 0.356 & 0.450 & 0.297 & 0.302 \\
\hline
\end{tabular}

Íris Esquerda

\begin{tabular}{|l|l|l|l|l|l|l|l|l|l|}
\hline $\begin{array}{l}\text { Pos } \\
\text { mín }\end{array}$ & mín & $\begin{array}{l}\text { Pos } \\
\text { máx }\end{array}$ & máx & R med & G med & B med & H med & S med & I med \\
\hline G4Co & -0.938 & R11Co & 0.926 & 0.608 & 0.380 & 0.531 & 0.585 & 0.321 & 0.499 \\
\hline
\end{tabular}


7 - EC:

- Data de nascimento: 27/12/1949

- Sexo: Feminino

- Cor: Branca

- Procedência: Florianópolis

- Profissão: Costureira

- Diabético (a): SIM

- Diabético (a) há quanto tempo?: Há 18 anos

- Apresenta outras enfermidades?: Não.

- Tratamentos que realiza:

-Diabetes: Daonil meio cpr pela manhã e meio cpr à noite / Glifage $5001 \mathrm{cpr} 3$ x ao dia.

-HAS: Atenolol $50 \mathrm{mg} 1 \mathrm{x}$ pela manhã / Sustrate $1 \mathrm{cpr}$ pela manhã e $1 \mathrm{cpr}$ à noite / AAS $100 \mathrm{mg} 2 \mathrm{cpr}$ após almoço.

- Exame oftalmológico: A.O.= hipermetropia e presbiopia (20/20 e J1 A.O.) /

Biomicroscopia normal A.O. / Fundo de olho normal A.O. / Tonometria normal A.O. -Taxas glicemia capilar:

\begin{tabular}{|l|l|l|l|}
\hline DATA COLETA & $\begin{array}{l}\text { GLICEMIA } \\
\text { CAPILAR }\end{array}$ & JEJUM & $\begin{array}{l}\text { GLICEMIA } \\
\text { VENOSA }\end{array}$ \\
\hline $01 / 07 / 2003$ & 127 & NÃO & \\
\hline $08 / 07 / 2003$ & 141 & NÃO & \\
\hline $15 / 07 / 2003$ & 107 & SIM & \\
\hline $22 / 07 / 2003$ & 135 & - & \\
\hline $29 / 07 / 2003$ & 160 & NÃO & \\
\hline $05 / 08 / 2003$ & 168 & NÃO & \\
\hline $12 / 08 / 2003$ & 176 & NÃO & 172 \\
\hline $19 / 08 / 2003$ & 158 & NÃO & \\
\hline $26 / 08 / 2003$ & 219 & N ̃̃O & \\
\hline $02 / 09 / 2003$ & 238 & NÃO & \\
\hline
\end{tabular}

Íris Direita

\begin{tabular}{|l|l|l|l|l|l|l|l|l|l|}
\hline $\begin{array}{l}\text { Pos } \\
\text { mín }\end{array}$ & mín & $\begin{array}{l}\text { Pos } \\
\text { máx }\end{array}$ & máx & R med & G med & B med & H med & S med & I med \\
\hline R1Pu & -0.750 & G4Co & 0.745 & 0.425 & 0.378 & 0.180 & 0.294 & 0.249 & 0.201 \\
\hline
\end{tabular}

Íris Esquerda

\begin{tabular}{|l|l|l|l|l|l|l|l|l|l|}
\hline $\begin{array}{l}\text { Pos } \\
\text { mín }\end{array}$ & mín & $\begin{array}{l}\text { Pos } \\
\text { máx }\end{array}$ & máx & R med & $\begin{array}{l}\text { G } \\
\text { med }\end{array}$ & B med & $\begin{array}{l}\text { H } \\
\text { med }\end{array}$ & S med & I med \\
\hline G10Ci & -0.790 & B11Co & 0.877 & 0.396 & 0.327 & 0.437 & 0.308 & 0.418 & 0.393 \\
\hline
\end{tabular}


8- FRE:

- Data de nascimento: 06/09/1943

- Sexo: Masculino

- Cor: Branca

- Procedência: Florianópolis

- Profissão: Impressor UFSC (aposentado)

- Diabético (a): SIM

- Diabético (a) há quanto tempo?: Há 8 anos

- Apresenta outras enfermidades?: HAS, Aumento níveis colesterol

- Tratamentos que realiza:

- Diabetes: Neo Metmorfin 850 mg após refeições / Clibenclamida 5 mg antes café e antes jantar.

- HAS: Captopril 25 mg 1 cpr antes café e 1 antes jantar / AAS 100 mg - 1 cpr pela manhã.

- Hipercolesterolemia: Sinvastatina $10 \mathrm{mg}$ ao deitar.

- Exame oftalmológico: A.O.= hipermetropia, astigmatismo e presbiopia (20/20 e J1

A.O.) / Biomicroscopia A.O.= catarata incipiente / Fundo de olho normal A.O. /

Tonometria normal A.O.

-Taxas glicemia capilar:

\begin{tabular}{|l|l|l|l|}
\hline DATA COLETA & $\begin{array}{l}\text { GLICEMIA } \\
\text { CAPILAR }\end{array}$ & JEJUM & $\begin{array}{l}\text { GLICEMIA } \\
\text { VENOSA }\end{array}$ \\
\hline $10 / 06 / 2003$ & 138 & - & \\
\hline $17 / 06 / 2003$ & 133 & - & \\
\hline $01 / 07 / 2003$ & 122 & NÃO & \\
\hline $08 / 07 / 2003$ & 108 & SIM & \\
\hline $22 / 07 / 2003$ & 124 & NÃO & \\
\hline $29 / 07 / 2003$ & 125 & SIM & \\
\hline $05 / 08 / 2003$ & 120 & SIM & \\
\hline $12 / 08 / 2003$ & 121 & NÃO & 155 \\
\hline $19 / 08 / 2003$ & 151 & SIM & \\
\hline $26 / 08 / 2003$ & 124 & NÃO & \\
\hline
\end{tabular}

Íris Direita

\begin{tabular}{|l|l|l|l|l|l|l|l|l|l|}
\hline $\begin{array}{l}\text { Pos } \\
\text { mín }\end{array}$ & mín & $\begin{array}{l}\text { Pos } \\
\text { máx }\end{array}$ & máx & R med & G med & B med & H med & S med & I med \\
\hline H7Co & -0.825 & S2Ci & 0.820 & 0.288 & 0.383 & 0.330 & 0.279 & 0.390 & 0.356 \\
\hline
\end{tabular}

Íris Esquerda

\begin{tabular}{|l|l|l|l|l|l|l|l|l|l|}
\hline $\begin{array}{l}\text { Pos } \\
\text { mín }\end{array}$ & mín & $\begin{array}{l}\text { Pos } \\
\text { máx }\end{array}$ & máx & R med & G med & B med & H med & S med & I med \\
\hline $\mathrm{H} 7 \mathrm{Pu}$ & -0.751 & S6Co & 0.713 & 0.159 & 0.155 & 0.206 & 0.260 & 0.218 & 0.186 \\
\hline
\end{tabular}


9 - HIH:

- Data de nascimento: 27/03/1958

- Sexo: Masculino

- Cor: Branca

- Procedência: São José

- Profissão: Funcíonário público

- Diabético (a): SIM

- Diabético (a) há quanto tempo?: Há 16 anos

- Tratamentos que realiza:

- Diabetes: Insulina NPH antes café.

- HAS: Aploc Plus 1 cpr pela manhã.

- Complexo B 1 cpr pela manhã.

- Apresenta outras enfermidades?: HAS

- Exame oftalmológico: A.O.= miopia, astigmatismo e presbiopia (20/20 e J1 A.O.) /

Biomicroscopia normal A.O. / Fundo de olho A.O.= RDNP inicial / Tonometria normal

A.O.

-Taxas glicemia capilar:

\begin{tabular}{|l|l|l|l|}
\hline DATA COLETA & $\begin{array}{l}\text { GLICEMIA } \\
\text { CAPILAR }\end{array}$ & JEJUM & $\begin{array}{l}\text { GLICEMIA } \\
\text { VENOSA }\end{array}$ \\
\hline $26 / 08 / 2003$ & 345 & NÃO & 409 \\
\hline $02 / 09 / 2003$ & 269 & NÃO & \\
\hline $09 / 09 / 2003$ & 299 & NÃO & \\
\hline $23 / 09 / 2003$ & 199 & NÃO & \\
\hline $30 / 09 / 2003$ & 87 & NÃO & \\
\hline $07 / 10 / 2003$ & 113 & NÃO & \\
\hline $14 / 10 / 2003$ & 249 & NÃO & \\
\hline $21 / 10 / 2003$ & 168 & NÃO & \\
\hline $04 / 11 / 2003$ & 136 & NÃO & \\
\hline
\end{tabular}

Íris Direita

\begin{tabular}{|l|l|l|l|l|l|l|l|l|l|}
\hline $\begin{array}{l}\text { Pos } \\
\text { mín }\end{array}$ & mín & $\begin{array}{l}\text { Pos } \\
\text { máx }\end{array}$ & máx & R med & G med & B med & H med & S med & I med \\
\hline R12Pu & -0.566 & R3Co & 0.614 & 0.313 & 0.252 & 0.185 & 0.188 & 0.202 & 0.208 \\
\hline
\end{tabular}

Íris Esquerda

\begin{tabular}{|l|l|l|l|l|l|l|l|l|l|}
\hline $\begin{array}{l}\text { Pos } \\
\text { mín }\end{array}$ & mín & $\begin{array}{l}\text { Pos } \\
\text { máx }\end{array}$ & máx & R med & G med & B med & H med & S med & I med \\
\hline S4Ci & -0.651 & G7Pu & 0.760 & 0.315 & 0.329 & 0.259 & 0.232 & 0.205 & 0.272 \\
\hline
\end{tabular}


10- JNS:

- Data de nascimento: 10/01/1942

- Sexo: Masculino

- Cor: Branca

- Procedência: Florianópolis

- Profissão: Auditor de finanças (aposentado)

- Diabético (a): SIM

- Diabético (a) há quanto tempo?: Há 15 anos

- Apresenta outras enfermidades?: Não

- Tratamentos que realiza:

- Diabetes: Diamicron MR8 1 cpr antes café / Staform 10 minutos antes almoço e 10 minutos antes jantar.

- Exame oftalmológico: A.O. $=$ hipermetropia e presbiopia (O.D. $=20 / 20 /$ O.E $=<20 / 400$ e J1 O.D.) / Biomicroscopia A.O.= catarata incipiente / Fundo de olho O.D.= OVCR ramo temporal superior + marcas laser $/$ O.E. $=\mathrm{sp} /$ Tonometria normal A.O.

-Taxas glicemia capilar:

\begin{tabular}{|l|l|l|l|}
\hline DATA COLETA & $\begin{array}{l}\text { GLICEMIA } \\
\text { CAPILAR }\end{array}$ & JEJUM & $\begin{array}{l}\text { GLICEMIA } \\
\text { VENOSA }\end{array}$ \\
\hline $01 / 07 / 2003$ & 406 & - & \\
\hline $08 / 07 / 2003$ & 294 & NÃO & \\
\hline $15 / 07 / 2003$ & 415 & NÃO & \\
\hline $22 / 07 / 2003$ & 347 & NÃO & \\
\hline $29 / 07 / 2003$ & 335 & NÃO & \\
\hline $05 / 08 / 2003$ & 254 & SIM & \\
\hline $12 / 08 / 2003$ & 260 & SIM & 274 \\
\hline $19 / 08 / 2003$ & 229 & SIM & \\
\hline $26 / 08 / 2003$ & 248 & SIM & \\
\hline $02 / 09 / 2003$ & 217 & SIM & \\
\hline
\end{tabular}

Íris Direita

\begin{tabular}{|l|l|l|l|l|l|l|l|l|l|}
\hline $\begin{array}{l}\text { Pos } \\
\text { mín }\end{array}$ & mín & $\begin{array}{l}\text { Pos } \\
\text { máx }\end{array}$ & máx & R med & G med & B med & H med & S med & I med \\
\hline S7Co & -0.625 & I7Co & 0.647 & 0.175 & 0.240 & 0.289 & 0.200 & 0.290 & 0.292 \\
\hline
\end{tabular}

Íris Esquerda

\begin{tabular}{|l|l|l|l|l|l|l|l|l|l|}
\hline $\begin{array}{l}\text { Pos } \\
\text { mín }\end{array}$ & mín & $\begin{array}{l}\text { Pos } \\
\text { máx }\end{array}$ & máx & R med & G med & B med & H med & S med & I med \\
\hline G4Ci & -0.738 & R9Co & 0.839 & 0.347 & 0.340 & 0.279 & 0.229 & 0.342 & 0.300 \\
\hline
\end{tabular}


11 - JSC:

- Data de nascimento: 02/06/1981

- Sexo: Feminino

- Cor: Branca

- Procedência: Palhoça

- Profissão: Recepcionista

- Diabético (a): NÃO

Apresenta outras enfermidades?: Arritimia cardíaca (taquicardia).

- Tratamentos que realiza:

- Seloken $100 \mathrm{mg} 1 \mathrm{cpr}$ de 12/12 horas

- Exame oftalmológico: A.O.= emetropia (20/20 A.O.) / Biomicroscopia normal A.O. /

Fundo de olho normal A.O. / Tonometria normal A.O.

-Taxas glicemia capilar:

\begin{tabular}{|l|l|l|l|}
\hline DATA COLETA & $\begin{array}{l}\text { GLICEMIA } \\
\text { CAPILAR }\end{array}$ & JEJUM & $\begin{array}{l}\text { GLICEMIA } \\
\text { VENOSA }\end{array}$ \\
\hline $10 / 06 / 2003$ & 78 & - & \\
\hline $17 / 06 / 2003$ & 133 & - & \\
\hline $01 / 07 / 2003$ & 127 & NÃO & \\
\hline $08 / 07 / 2003$ & 87 & SIM & \\
\hline $15 / 07 / 2003$ & 86 & SIM & \\
\hline $22 / 07 / 2003$ & 86 & - & \\
\hline $29 / 07 / 2003$ & 78 & SIM & \\
\hline $05 / 08 / 2003$ & 85 & - & 94 \\
\hline $19 / 08 / 2003$ & 85 & SIM & \\
\hline $26 / 08 / 2003$ & 124 & NÃO & \\
\hline
\end{tabular}

Íris Direita

\begin{tabular}{|l|l|l|l|l|l|l|l|l|l|}
\hline $\begin{array}{l}\text { Pos } \\
\text { mín }\end{array}$ & mín & $\begin{array}{l}\text { Pos } \\
\text { máx }\end{array}$ & máx & R med & G med & B med & H med & S med & I med \\
\hline R5Pu & -0.918 & G10Pu & 0.762 & 0.371 & 0.453 & 0.315 & 0.324 & 0.308 & 0.337 \\
\hline
\end{tabular}

Íris Esquerda

\begin{tabular}{|l|l|l|l|l|l|l|l|l|l|}
\hline $\begin{array}{l}\text { Pos } \\
\text { mín }\end{array}$ & mín & $\begin{array}{l}\text { Pos } \\
\text { máx }\end{array}$ & máx & R med & G med & B med & H med & S med & I med \\
\hline H11Co & -0.754 & H9Co & 0.725 & 0.296 & 0.218 & 0.186 & 0.270 & 0.189 & 0.172 \\
\hline
\end{tabular}


12 - LBG:

- Data de nascimento: 03/02/1952

- Sexo: Masculino

- Cor: Branca

- Procedência: Florianópolis

- Profissão: Médico

- Diabético (a): NÃO

- Apresenta outras enfermidades?: Enxaqueca

- Tratamentos que realiza:

- Enxaqueca: Depakote 2501 x pela manhã e Pamelor $25 \mathrm{mg} 1 \mathrm{cpr}$ ao deitar.

- Exame oftalmológico: A.O.= miopia e presbiopia (20/20 e J1 A.O.) / Biomicroscopia O.D. = normal / O.E.= pinguécula / Fundo de olho normal A.O. / Tonometria normal A.O.

-Taxas glicemia capilar:

\begin{tabular}{|l|l|l|l|}
\hline DATA COLETA & $\begin{array}{l}\text { GLICEMIA } \\
\text { CAPILAR }\end{array}$ & $\begin{array}{l}\text { JEJUM } \\
\text { VENOSA }\end{array}$ \\
\hline $10 / 06 / 2003$ & 107 & NÃO & \\
\hline $17 / 06 / 2003$ & 113 & NÃO & \\
\hline $01 / 07 / 2003$ & 104 & NÃO & \\
\hline $08 / 07 / 2003$ & 107 & NÃO & \\
\hline $15 / 07 / 2003$ & 115 & NÃO & \\
\hline $29 / 07 / 2003$ & 91 & NÃO & \\
\hline $05 / 08 / 2003$ & 93 & NÃO & \\
\hline $12 / 08 / 2003$ & 88 & NÃO & 82 \\
\hline $19 / 08 / 2003$ & 87 & NÃO & \\
\hline $26 / 08 / 2003$ & 85 & NÃO & \\
\hline
\end{tabular}

Íris Direita

\begin{tabular}{|l|l|l|l|l|l|l|l|l|l|}
\hline $\begin{array}{l}\text { Pos } \\
\text { mín }\end{array}$ & mín & $\begin{array}{l}\text { Pos } \\
\text { máx }\end{array}$ & máx & R med & G med & B med & H med & S med & I med \\
\hline G7Ci & -0.880 & G6Pu & 0.886 & 0.443 & 0.536 & 0.156 & 0.248 & 0.321 & 0.180 \\
\hline
\end{tabular}

Íris Esquerda

\begin{tabular}{|l|l|l|l|l|l|l|l|l|l|}
\hline $\begin{array}{l}\text { Pos } \\
\text { mín }\end{array}$ & mín & $\begin{array}{l}\text { Pos } \\
\text { máx }\end{array}$ & máx & R med & G med & B med & H med & S med & I med \\
\hline $\mathrm{H} 10 \mathrm{Pu}$ & -0.880 & $\mathrm{~B} 10 \mathrm{Pu}$ & 0.829 & 0.387 & 0.325 & 0.444 & 0.471 & 0.393 & 0.444 \\
\hline
\end{tabular}


13 - MTC:

- Data de nascimento: 24/03/1968

- Sexo: Feminino

- Cor: Branca

- Procedência: Florianópolis

- Profissão: Instrumentadora cirúrgica

- Diabético (a): NÃO

- Apresenta outras enfermidades?: Não

- Exame oftalmológico: A.O.= emetropia (20/20 A.O.) / Biomicroscopia normal A.O. / Fundo de olho normal A.O. / Tonometria normal A.O.

-Taxas glicemia capilar:

\begin{tabular}{|l|l|l|l|}
\hline DATA COLETA & $\begin{array}{l}\text { GLICEMIA } \\
\text { CAPILAR }\end{array}$ & JEJUM & $\begin{array}{l}\text { GLICEMIA } \\
\text { VENOSA }\end{array}$ \\
\hline $10 / 06 / 2003$ & 104 & - & \\
\hline $17 / 06 / 2003$ & 103 & - & \\
\hline $01 / 07 / 2003$ & 113 & NÃO & \\
\hline $08 / 07 / 2003$ & 130 & NÃO & \\
\hline $15 / 07 / 2003$ & 89 & SIM & \\
\hline $22 / 07 / 2003$ & 121 & - & \\
\hline $29 / 07 / 2003$ & 97 & NÃO & \\
\hline $05 / 08 / 2003$ & 85 & - & \\
\hline $12 / 08 / 2003$ & 89 & SIM & 151 \\
\hline $19 / 08 / 2003$ & 145 & - & \\
\hline
\end{tabular}

Íris Direita

\begin{tabular}{|l|l|l|l|l|l|l|l|l|l|}
\hline $\begin{array}{l}\text { Pos } \\
\text { mín }\end{array}$ & mín & $\begin{array}{l}\text { Pos } \\
\text { máx }\end{array}$ & máx & R med & G med & B med & H med & S med & I med \\
\hline I5Pu & -0.689 & S11Ci & 0.744 & 0.376 & 0.342 & 0.416 & 0.305 & 0.301 & 0.420 \\
\hline
\end{tabular}

Íris Esquerda

\begin{tabular}{|l|l|l|l|l|l|l|l|l|l|}
\hline $\begin{array}{l}\text { Pos } \\
\text { mín }\end{array}$ & mín & $\begin{array}{l}\text { Pos } \\
\text { máx }\end{array}$ & máx & R med & G med & B med & H med & S med & I med \\
\hline I9Pu & -0.710 & S7Pu & 0.694 & 0.313 & 0.285 & 0.379 & 0.322 & 0.263 & 0.391 \\
\hline
\end{tabular}


14- - MGS:

- Data de nascimento: 12/07/1952

- Sexo: Feminino

- Cor: Preta

- Procedência: Florianópolis

- Profissão: Telefonista

- Diabético (a): SIM

- Diabético (a) há quanto tempo?: Há quase 2 anos

- Apresenta outras enfermidades?: Não

- Tratamentos que realiza:

- Diabetes: Insulina N / Glifage 5001 cpr após café, após almoço e após jantar.

- Exame oftalmológico: A.O.= hipermetropia, astigmatismo e presbiopia (20/20 e J1

A.O.) / Biomicroscopia normal A.O. / Fundo de olho normal A.O. / Tonometria normal A.O.

-Taxas glicemia capilar:

\begin{tabular}{|l|l|l|l|}
\hline DATA COLETA & $\begin{array}{l}\text { GLICEMIA } \\
\text { CAPILAR }\end{array}$ & JEJUM & $\begin{array}{l}\text { GLICEMIA } \\
\text { VENOSA }\end{array}$ \\
\hline $10 / 06 / 2003$ & 270 & - & \\
\hline $17 / 06 / 2003$ & 295 & - & \\
\hline $01 / 07 / 2003$ & 102 & SIM & \\
\hline $29 / 07 / 2003$ & 87 & NÃO & \\
\hline $02 / 09 / 2003$ & 146 & NÃO & \\
\hline $23 / 09 / 2003$ & 94 & NÃO & \\
\hline $26 / 09 / 2003$ & 81 & NÃO & \\
\hline $30 / 09 / 2003$ & 123 & NÃO & \\
\hline $10 / 10 / 2003$ & & & \\
\hline $14 / 10 / 2003$ & 127 & NÃO & \\
\hline
\end{tabular}

Íris Direita

\begin{tabular}{|l|l|l|l|l|l|l|l|l|l|}
\hline $\begin{array}{l}\text { Pos } \\
\text { mín }\end{array}$ & mín & $\begin{array}{l}\text { Pos } \\
\text { máx }\end{array}$ & máx & R med & G med & B med & H med & S med & I med \\
\hline H9Co & -0.970 & $\mathrm{H} 8 \mathrm{Pu}$ & 0.956 & 0.607 & 0.565 & 0.558 & 0.659 & 0.450 & 0.570 \\
\hline
\end{tabular}

Íris Esquerda

\begin{tabular}{|l|l|l|l|l|l|l|l|l|l|}
\hline $\begin{array}{l}\text { Pos } \\
\text { mín }\end{array}$ & mín & $\begin{array}{l}\text { Pos } \\
\text { máx }\end{array}$ & máx & R med & G med & B med & H med & S med & I med \\
\hline R9Co & -0.958 & I3Pu & 0.978 & 0.623 & 0.731 & 0.565 & 0.533 & 0.368 & 0.677 \\
\hline
\end{tabular}


15- MSC:

- Data de nascimento: 23/05/1952

- Sexo: Feminino

- Cor: Branca

- Procedência: Florianópolis

- Profissão: Aposentada (costureira)

- Diabético (a): SIM

- Diabético (a) há quanto tempo?: Há 10 anos

- Apresenta outras enfermidades?: Hipercolesterolemia

- Tratamentos que realiza:

- Diabetes: Glifabe 500 antes café e antes jantar

- Hipercolesterolemia: Sinvalip $201 \mathrm{cpr}$ após jantar.

- Exame oftalmológico: A.O.= astigmatismo e presbiopia (20/20 e J1 A.O.) /

Biomicroscopia normal A.O. / Fundo de olho normal A.O. / Tonometria normal A.O.

-Taxas glicemia capilar:

\begin{tabular}{|l|l|l|l|}
\hline DATA COLETA & $\begin{array}{l}\text { GLICEMIA } \\
\text { CAPILAR }\end{array}$ & JEJUM & $\begin{array}{l}\text { GLICEMIA } \\
\text { VENOSA }\end{array}$ \\
\hline $19 / 08 / 2003$ & 151 & NÃO & 162 \\
\hline $26 / 08 / 2003$ & 195 & NÃO & \\
\hline $02 / 09 / 2003$ & 119 & NÃO & \\
\hline $09 / 09 / 2003$ & 126 & NÃO & \\
\hline $23 / 09 / 2003$ & 117 & NÃO & \\
\hline $30 / 09 / 2003$ & 158 & NÃO & \\
\hline $07 / 10 / / 2003$ & 190 & NÃO & \\
\hline $14 / 10 / 2003$ & 123 & NÃO & \\
\hline $21 / 10 / / 2003$ & 133 & NÃO & \\
\hline $04 / 11 / 2003$ & 104 & NÃO & \\
\hline
\end{tabular}

Íris Direita

\begin{tabular}{|l|l|l|l|l|l|l|l|l|l|}
\hline $\begin{array}{l}\text { Pos } \\
\text { mín }\end{array}$ & mín & $\begin{array}{l}\text { Pos } \\
\text { máx }\end{array}$ & máx & R med & G med & B med & H med & S med & I med \\
\hline $\mathrm{H} 3 \mathrm{Ci}$ & -0.640 & S5Co & 0.712 & 0.207 & 0.205 & 0.233 & 0.220 & 0.274 & 0.218 \\
\hline
\end{tabular}

Íris Esquerda

\begin{tabular}{|l|l|l|l|l|l|l|l|l|l|}
\hline $\begin{array}{l}\text { Pos } \\
\text { mín }\end{array}$ & mín & $\begin{array}{l}\text { Pos } \\
\text { máx }\end{array}$ & máx & R med & $\begin{array}{l}\text { G } \\
\text { med }\end{array}$ & B med & $\begin{array}{l}\text { H } \\
\text { med }\end{array}$ & S med & I med \\
\hline H12Co & -0.864 & G10Co & 0.919 & 0.509 & 0.524 & 0.354 & 0.357 & 0.374 & 0.453 \\
\hline
\end{tabular}


16- MF:

- Data de nascimento: 27/10/1942

- Sexo: Feminino

- Cor: Branca

- Procedência: São José

- Profissão: Aposentada

- Diabético (a): SIM

- Diabético (a) há quanto tempo?: Há 17 anos

- Apresenta outras enfermidades?: HAS, Hipercolesterolemia e osteoporose

- Tratamentos que realiza:

- Diabetes: Insulina NPH e R / Glicoformin 500 mg 1 cpr antes café e 1 cpr antes jantar

- HAS: Zestril $5 \mathrm{mg} 1 \mathrm{cpr}$ antes café.

- Hipercolesterolemia: Prevastatina 1 cpr após jantar

- Osteoporose: Kaotrac

- Exame oftalmológico: A.O.= hipermetropia e presbiopia (A.O. $=20 / 20$ e J1) /

Biomicroscopia A.O.= sp / Fundo de olho A.O.= sp / Tonometria normal A.O.

- Taxas glicemia capilar:

\begin{tabular}{|l|l|l|l|}
\hline DATA COLETA & $\begin{array}{l}\text { GLICEMIA } \\
\text { CAPILAR }\end{array}$ & JEJUM & $\begin{array}{l}\text { GLICEMIA } \\
\text { VENOSA }\end{array}$ \\
\hline $10 / 06 / 2003$ & 190 & - & \\
\hline $17 / 06 / 2003$ & 298 & - & \\
\hline $01 / 07 / 2003$ & 114 & - & \\
\hline $08 / 07 / 2003$ & 122 & SIM & \\
\hline $15 / 07 / 2003$ & 146 & SIM & \\
\hline $29 / 07 / 2003$ & 169 & - & \\
\hline $05 / 08 / 2003$ & 139 & - & \\
\hline $12 / 08 / 2003$ & 125 & - & 193 \\
\hline $19 / 08 / 2003$ & 193 & NÃO & \\
\hline $26 / 08 / 2003$ & 112 & SIM & \\
\hline
\end{tabular}

Íris Direita

\begin{tabular}{|l|l|l|l|l|l|l|l|l|l|}
\hline $\begin{array}{l}\text { Pos } \\
\text { mín }\end{array}$ & mín & $\begin{array}{l}\text { Pos } \\
\text { máx }\end{array}$ & máx & R med & G med & B med & H med & S med & I med \\
\hline H5Co & -0.743 & S6Ci & 0.678 & 0.249 & 0.204 & 0.296 & 0.245 & 0.313 & 0.263 \\
\hline
\end{tabular}

Íris Esquerda

\begin{tabular}{|l|l|l|l|l|l|l|l|l|l|}
\hline $\begin{array}{l}\text { Pos } \\
\text { mín }\end{array}$ & mín & $\begin{array}{l}\text { Pos } \\
\text { máx }\end{array}$ & máx & R med & G med & B med & H med & S med & I med \\
\hline H10Co & -0.876 & R3Ci & 0.924 & 0.622 & 0.341 & 0.647 & 0.526 & 0.573 & 0.532 \\
\hline
\end{tabular}


17- MJS:

- Data de nascimento: 13/02/1940

- Sexo: Feminino

- Cor: Branca

- Procedência: Flolrianópolis

- Profissão: Auxiliar de lavanderia

- Diabético (a): SIM

- Diabético (a) há quanto tempo?: Há 15 anos

- Apresenta outras enfermidades?: HAS

- Tratamentos que realiza:

- Diabetes: Gluformin 8501 cpr após café e após jantar / Daonil 1 x à noite

- HAS: Analapril $10 \mathrm{mg} 1 \mathrm{cpr}$ pela manhã

-Catarata: Clarvisol para ambos os olhos

- Exame oftalmológico: A.O.= hipermetropia, astigmatismo e presbiopia (A.O.= 20/20p e J1) / Biomicroscopia A.O.= catarata incipiente / Fundo de olho A.O.= sp / Tonometria normal A.O.

Taxas glicemia capilar:

\begin{tabular}{|l|l|l|l|}
\hline DATA COLETA & $\begin{array}{l}\text { GLICEMIA } \\
\text { CAPILAR }\end{array}$ & JEJUM & $\begin{array}{l}\text { GLICEMIA } \\
\text { VENOSA }\end{array}$ \\
\hline $10 / 06 / 2003$ & 170 & - & \\
\hline $17 / 06 / 2003$ & 130 & - & \\
\hline $01 / 07 / 2003$ & 162 & SIM & \\
\hline $08 / 07 / 2003$ & 154 & NÃO & \\
\hline $15 / 07 / 2003$ & 187 & NAO & \\
\hline $22 / 07 / 2003$ & 235 & - & \\
\hline $29 / 07 / 2003$ & 152 & SIM & \\
\hline $05 / 08 / 2003$ & 197 & SIM & 150 \\
\hline $19 / 08 / 2003$ & 146 & SIM & \\
\hline $26 / 08 / 2003$ & 100 & SIM & \\
\hline
\end{tabular}

Íris Direita

\begin{tabular}{|l|l|l|l|l|l|l|l|l|l|}
\hline $\begin{array}{l}\text { Pos } \\
\text { mín }\end{array}$ & mín & $\begin{array}{l}\text { Pos } \\
\text { máx }\end{array}$ & máx & R med & G med & B med & H med & S med & I med \\
\hline S7Ci & -0.746 & H9Pu & 0.690 & 0.262 & 0.177 & 0.338 & 0.278 & 0.358 & 0.288 \\
\hline
\end{tabular}

Íris Esquerda

\begin{tabular}{|l|l|l|l|l|l|l|l|l|l|}
\hline $\begin{array}{l}\text { Pos } \\
\text { mín }\end{array}$ & mín & $\begin{array}{l}\text { Pos } \\
\text { máx }\end{array}$ & máx & R med & G med & B med & H med & S med & I med \\
\hline R11Co & -0.738 & B2Ci & 0.747 & 0.395 & 0.328 & 0.209 & 0.274 & 0.223 & 0.191 \\
\hline
\end{tabular}


18 - NELIR REGINA GONZAGA:

- Data de nascimento: 30/03/1969

- Sexo: Feminino

- Cor: Preta

- Procedência: Florianpópolis

- Profissão: Atendente de Enfermagem

- Diabético (a): NÃO

Apresenta outras enfermidades?: Não

- Exame oftalmológico: A.O.= emetropia (A.O.=20/20) / Biomicroscopia A.O.= melanose conjuntival / Fundo de olho A.O.= sp / Tonometria normal A.O.

Taxas glicemia capilar:

\begin{tabular}{|l|l|l|l|}
\hline DATA COLETA & $\begin{array}{l}\text { GLICEMIA } \\
\text { CAPILAR }\end{array}$ & JEJUM & $\begin{array}{l}\text { GLICEMIA } \\
\text { VENOSA }\end{array}$ \\
\hline $10 / 06 / 2003$ & 88 & - & \\
\hline $17 / 06 / 2003$ & 75 & - & \\
\hline $08 / 07 / 2003$ & 101 & NÃO & \\
\hline $15 / 07 / 2003$ & 81 & SIM & \\
\hline $22 / 07 / 2003$ & 103 & - & \\
\hline $29 / 07 / 2003$ & 105 & NÃO & \\
\hline $05 / 08 / 2003$ & 93 & NÃO & 93 \\
\hline $19 / 08 / 2003$ & 107 & NÃO & \\
\hline $26 / 08 / 2003$ & 78 & NÃO & \\
\hline $02 / 09 / 2003$ & 76 & SIM & \\
\hline
\end{tabular}

Íris Direita

\begin{tabular}{|l|l|l|l|l|l|l|l|l|l|}
\hline $\begin{array}{l}\text { Pos } \\
\text { mín }\end{array}$ & mín & $\begin{array}{l}\text { Pos } \\
\text { máx }\end{array}$ & máx & R med & G med & B med & H med & S med & I med \\
\hline H4Ci & -0.860 & R4Ci & 0.755 & 0.271 & 0.292 & 0.195 & 0.293 & 0.248 & 0.262 \\
\hline
\end{tabular}

Íris Esquerda

\begin{tabular}{|l|l|l|l|l|l|l|l|l|l|}
\hline $\begin{array}{l}\text { Pos } \\
\text { mín }\end{array}$ & mín & $\begin{array}{l}\text { Pos } \\
\text { máx }\end{array}$ & máx & R med & G med & B med & H med & S med & I med \\
\hline S8Ci & -0.901 & B9Pu & 0.654 & 0.322 & 0.278 & 0.357 & 0.263 & 0.290 & 0.305 \\
\hline
\end{tabular}


19 - NMCV:

- Data de nascimento: 28/09/1943

- Sexo: Feminino

- Cor: Branca

- Procedência: Florianópolis

- Profissão: Não informada

- Diabético (a): SIM

- Diabético (a) há quanto tempo?: Há 5 anos

- Apresenta outras enfermidades?: HAS

- Tratamentos que realiza:

- Diabetes: Insulina R e NPH / Glicoformin $500 \mathrm{mg} 1 \mathrm{cpr}$ pela manhã e à noite

- HAS: Metil Dopa 500 mg 1 cpr pela manhã e 1 cpr à tarde / Natrilix 1 cpr pela manhã / Presotec $1 \mathrm{cpr}$ pela manhã e $1 \mathrm{cpr}$ à noite / AAS infantil $1 \mathrm{cpr}$ após almoço.

- Exame oftalmológico: A.O.= hipermetropia, astigmatismo e presbiopia (O.D. $=20 / 40 p$

/ O.E. $=20 / 20$ p e J1 O.E.) / Biomicroscopia A.O.= catarata (D>E) / Fundo de olho A.O. $=$ RDNP severa / Tonometria normal A.O.

Taxas glicemia capilar:

\begin{tabular}{|l|l|l|l|}
\hline DATA COLETA & $\begin{array}{l}\text { GLICEMIA } \\
\text { CAPILAR }\end{array}$ & JEJUM & $\begin{array}{l}\text { GLICEMIA } \\
\text { VENOSA }\end{array}$ \\
\hline $19 / 08 / 2003$ & 272 & NÃO & 273 \\
\hline $26 / 08 / 2003$ & 180 & NÃO & \\
\hline $02 / 09 / 2003$ & 129 & NÃO & \\
\hline $09 / 09 / 2003$ & 247 & NAO & \\
\hline $23 / 09 / 2003$ & 211 & SIM & \\
\hline $30 / 09 / 2003$ & 218 & NÃO & \\
\hline $07 / 10 / 2003$ & 283 & NÃO & \\
\hline $14 / 10 / 2003$ & 197 & NÃO & \\
\hline $21 / 10 / 2003$ & 188 & NÃO & \\
\hline $04 / 11 / 2003$ & 172 & NAO & \\
\hline
\end{tabular}

Íris Direita

\begin{tabular}{|l|l|l|l|l|l|l|l|l|l|}
\hline $\begin{array}{l}\text { Pos } \\
\text { mín }\end{array}$ & mín & $\begin{array}{l}\text { Pos } \\
\text { máx }\end{array}$ & máx & R med & G med & B med & H med & S med & I med \\
\hline R12Co & -0.692 & I7Ci & 0.688 & 0.210 & 0.213 & 0.158 & 0.164 & 0.172 & 0.169 \\
\hline
\end{tabular}

Íris Esquerda

\begin{tabular}{|l|l|l|l|l|l|l|l|l|l|}
\hline $\begin{array}{l}\text { Pos } \\
\text { mín }\end{array}$ & mín & $\begin{array}{l}\text { Pos } \\
\text { máx }\end{array}$ & máx & R med & G med & B med & H med & S med & I med \\
\hline R9Pu & -0.664 & G6Pu & 0.635 & 0.267 & 0.259 & 0.189 & 0.238 & 0.215 & 0.189 \\
\hline
\end{tabular}


20 - RMM:

- Data de nascimento: 02/10/1935

- Sexo: Feminino

- Cor: Branca

- Procedência: Florianópolis

- Profissão: do lar

- Diabético (a): SIM

- Diabético (a) há quanto tempo?: Não informado

- Apresenta outras enfermidades?: HAS

- Tratamentos que realiza:

- Diabetes: Clamiben 5 mg $1 \mathrm{cpr}$ às 11 hs

- HAS: Hidroclorotiazida $50 \mathrm{mg} 1 \mathrm{cpr}$ após café

- Catarata: Clarvisol em ambos os olhos

- Exame oftalmológico: A.O.= hipermetropia, astigmatismo e presbiopia (O.D. = 20/40P / O.E. $=$ PL e J3) / Biomicroscopia O.D.= pterígio nasal II + catarata / O.E.= pterígio nasal III + catarata / Fundo de olho O.D.= venodilatação, tortuosidades vasculares / O.E. = inviável / Tonometria normal A.O.

Taxas glicemia capilar:

\begin{tabular}{|l|l|l|l|}
\hline DATA COLETA & $\begin{array}{l}\text { GLICEMIA } \\
\text { CAPILAR }\end{array}$ & JEJUM & $\begin{array}{l}\text { GLICEMIA } \\
\text { VENOSA }\end{array}$ \\
\hline $22 / 07 / 2003$ & 60 & - & \\
\hline $05 / 08 / 2003$ & 87 & NAO & \\
\hline $12 / 08 / 2003$ & 77 & NAO & \\
\hline $19 / 08 / 2003$ & 77 & NAO & 86 \\
\hline $26 / 08 / 2003$ & 65 & - & \\
\hline $02 / 09 / 2003$ & 67 & NÃO & \\
\hline $09 / 09 / 2003$ & 104 & NÃO & \\
\hline $23 / 09 / 2003$ & 121 & NÃO & \\
\hline $07 / 10 / 2003$ & 119 & NÃO & \\
\hline $14 / 10 / 2003$ & 109 & NÃO & \\
\hline
\end{tabular}

Íris Direita

\begin{tabular}{|l|l|l|l|l|l|l|l|l|l|}
\hline $\begin{array}{l}\text { Pos } \\
\text { mín }\end{array}$ & mín & $\begin{array}{l}\text { Pos } \\
\text { máx }\end{array}$ & máx & R med & G med & B med & H med & S med & I med \\
\hline I4Co & -0.669 & H10Pu & 0.838 & 0.267 & 0.254 & 0.187 & 0.261 & 0.208 & 0.187 \\
\hline
\end{tabular}

Íris Esquerda

\begin{tabular}{|l|l|l|l|l|l|l|l|l|l|}
\hline $\begin{array}{l}\text { Pos } \\
\text { mín }\end{array}$ & mín & $\begin{array}{l}\text { Pos } \\
\text { máx }\end{array}$ & máx & R med & G med & B med & H med & S med & I med \\
\hline $\mathrm{I} 9 \mathrm{Pu}$ & -0.710 & $\mathrm{~S} 7 \mathrm{Pu}$ & 0.694 & 0.313 & 0.285 & 0.379 & 0.322 & 0.263 & 0.391 \\
\hline
\end{tabular}


21 - SJT:

- Data de nascimento: 27/03/1948

- Sexo: Masculino

- Cor: reta

- Procedência: Florianópolis

- Profissão: Funcionário público

- Diabético (a): SIM

- Diabético (a) há quanto tempo?: Há 22 anos

- Apresenta outras enfermidades?: HAS

- Tratamentos que realiza:

- Diabetes: Glifage $1 \mathrm{mg} 1 \mathrm{cpr}$ antes café / Diamicron 1 cpr antes café

- HAS: Analapril $10 \mathrm{mg} 1 \mathrm{cpr}$ após café

- Exame oftalmológico: A.O.= emetropia e presbiopia (A.O. $=20 / 20$ e J1) /

Biomicroscopia A.O.= sp / Fundo de olho A.O.= RDNP inicial / Tonometria normal

A.O.

Taxas de glicemia capilar:

\begin{tabular}{|l|l|l|l|}
\hline DATA COLETA & $\begin{array}{l}\text { GLICEMIA } \\
\text { CAPILAR }\end{array}$ & JEJUM & $\begin{array}{l}\text { GLICEMIA } \\
\text { VENOSA }\end{array}$ \\
\hline $17 / 06 / 2003$ & 242 & - & \\
\hline $01 / 07 / 2003$ & 186 & SIM & \\
\hline $08 / 07 / 2003$ & 154 & SIM & \\
\hline $15 / 07 / 2003$ & 171 & SIM & \\
\hline $22 / 07 / 2003$ & 93 & - & \\
\hline $29 / 07 / 2003$ & 163 & SIM & \\
\hline $12 / 08 / 2003$ & 201 & SIM & \\
\hline $19 / 08 / 2003$ & 173 & SIM & 189 \\
\hline $26 / 08 / 2003$ & 227 & SIM & \\
\hline $09 / 09 / 2003$ & 201 & NAO & \\
\hline $07 / 10 / 2003$ & 155 & NAO & \\
\hline
\end{tabular}

Íris Direita

\begin{tabular}{|l|l|l|l|l|l|l|l|l|l|}
\hline $\begin{array}{l}\text { Pos } \\
\text { mín }\end{array}$ & mín & $\begin{array}{l}\text { Pos } \\
\text { máx }\end{array}$ & máx & R med & G med & B med & H med & S med & I med \\
\hline $\mathrm{I} 5 \mathrm{Pu}$ & -0.689 & $\mathrm{~S} 11 \mathrm{Ci}$ & 0.744 & 0.376 & 0.342 & 0.416 & 0.305 & 0.301 & 0.420 \\
\hline
\end{tabular}

Íris Esquerda

\begin{tabular}{|l|l|l|l|l|l|l|l|l|l|}
\hline $\begin{array}{l}\text { Pos } \\
\text { mín }\end{array}$ & mín & $\begin{array}{l}\text { Pos } \\
\text { máx }\end{array}$ & máx & R med & G med & B med & H med & S med & I med \\
\hline H7Co & -0.727 & R12Ci & 0.886 & 0.394 & 0.277 & 0.271 & 0.396 & 0.262 & 0.277 \\
\hline
\end{tabular}


22 - SRSM:

- Data de nascimento: 06/01/1965

- Sexo: Feminino

- Cor: Branca

- Procedência: Florianópolis

- Profissão: Não informada

- Diabético (a): SIM

- Diabético (a) há quanto tempo?: Há 11 anos

- Apresenta outras enfermidades?: HAS

- Tratamentos que realiza:

- Diabetes: Metformina 8501 cpr café, almoço e jantar

- HAS: Diovan 80 mg 2 cpr após café / Hidroclorotiazida 50 mg 1 cpr após café /

Aspirina $100 \mathrm{mg} 2 \mathrm{cpr}$ após almoço

- Hipercolesterolemia: Sinvastatina $20 \mathrm{mg} 1 \mathrm{cpr}$ após jantar

- Exame oftalmológico: A.O.= emetropia (A.O.=20/20 e J1) / Biomicroscopia A.O.= sp / Fundo de olho A.O.= sp / Tonometria normal A.O.

Taxas glicemia capilar:

\begin{tabular}{|l|l|l|l|}
\hline DATA COLETA & $\begin{array}{l}\text { GLICEMIA } \\
\text { CAPILAR }\end{array}$ & JEJUM & $\begin{array}{l}\text { GLICEMIA } \\
\text { VENOSA }\end{array}$ \\
\hline $12 / 08 / 2003$ & 147 & NAO & \\
\hline $19 / 08 / 2003$ & 151 & NÃO & 137 \\
\hline $02 / 09 / 2003$ & 125 & NÃO & \\
\hline $09 / 09 / 2003$ & 138 & NÃO & \\
\hline $30 / 09 / 2003$ & 159 & NÃO & \\
\hline $07 / 10 / 2003$ & 125 & SIM & \\
\hline $14 / 10 / 2003$ & 131 & SIM & \\
\hline $21 / 10 / 2003$ & 118 & SIM & \\
\hline $04 / 11 / 2003$ & 83 & SIM & \\
\hline
\end{tabular}

Íris Direita

\begin{tabular}{|l|l|l|l|l|l|l|l|l|l|}
\hline $\begin{array}{l}\text { Pos } \\
\text { mín }\end{array}$ & mín & $\begin{array}{l}\text { Pos } \\
\text { máx }\end{array}$ & máx & R med & G med & B med & H med & S med & I med \\
\hline S7Pu & -0.763 & I5Pu & 0.820 & 0.268 & 0.323 & 0.406 & 0.242 & 0.387 & 0.379 \\
\hline
\end{tabular}

Íris Esquerda

\begin{tabular}{|l|l|l|l|l|l|l|l|l|l|}
\hline $\begin{array}{l}\text { Pos } \\
\text { mín }\end{array}$ & mín & $\begin{array}{l}\text { Pos } \\
\text { máx }\end{array}$ & máx & R med & G med & B med & H med & S med & I med \\
\hline R3Co & -0.892 & S2Co & 0.951 & 0.363 & 0.270 & 0.232 & 0.240 & 0.247 & 0.191 \\
\hline
\end{tabular}


23 - VMBL:

- Data de nascimento:

- Sexo: Feminino

- Cor: Branca

- Procedência: Florianópolis

- Profissão: Escriturária (HIJG)

- Diabético (a): SIM

- Diabético (a) há quanto tempo?:

- Apresenta outras enfermidades?: HAS, catarata

- Tratamentos que realiza:

- Diabetes: Insulina NPH e R

- HAS: Captopril $0.25 \mathrm{mg} 1 \mathrm{cpr}$ pela manhã e à noite / Furosemida $1 \mathrm{cpr}$ pela manhã /

AAS infantil 1 cpr após almoço

-Catarata: Clarvisol em ambos os olhos.

- Exame oftalmológico: A.O.= hipermetropia, astigmatismo e presbiopia (A.O. $=20 / 20 p$

e J1) / Biomicroscopia A.O.= catarata / Fundo de olho A.O.= RDNP inicial /

Tonometria normal A.O.

- Taxas glicemia capilar:

\begin{tabular}{|l|l|l|l|}
\hline DATA COLETA & $\begin{array}{l}\text { GLICEMIA } \\
\text { CAPILAR }\end{array}$ & JEJUM & $\begin{array}{l}\text { GLICEMIA } \\
\text { VENOSA }\end{array}$ \\
\hline $12 / 08 / 2003$ & 220 & NÃO & \\
\hline $19 / 08 / 2003$ & 286 & NÃO & 305 \\
\hline $26 / 08 / 2003$ & 66 & NÃO & \\
\hline $02 / 09 / 2003$ & 147 & NÃO & \\
\hline $09 / 09 / 2003$ & 200 & NÃO & \\
\hline $23 / 09 / 2003$ & 98 & NÃO & \\
\hline $30 / 09 / 2003$ & 52 & NÃO & \\
\hline $07 / 10 / 2003$ & 57 & NÃO & \\
\hline $14 / 10 / 2003$ & 125 & NÃO & \\
\hline $21 / 10 / 2003$ & 276 & NAO & \\
\hline
\end{tabular}

Íris Direita

\begin{tabular}{|l|l|l|l|l|l|l|l|l|l|}
\hline $\begin{array}{l}\text { Pos } \\
\text { mín }\end{array}$ & mín & $\begin{array}{l}\text { Pos } \\
\text { máx }\end{array}$ & máx & R med & G med & B med & H med & S med & I med \\
\hline S8Ci & -0.773 & S11Co & 0.806 & 0.299 & 0.289 & 0.258 & 0.179 & 0.341 & 0.252 \\
\hline
\end{tabular}

Íris Esquerda

\begin{tabular}{|l|l|l|l|l|l|l|l|l|l|}
\hline $\begin{array}{l}\text { Pos } \\
\text { mín }\end{array}$ & mín & $\begin{array}{l}\text { Pos } \\
\text { máx }\end{array}$ & máx & R med & G med & B med & H med & S med & I med \\
\hline B4Ci & -0.802 & S4Ci & 0.835 & 0.215 & 0.164 & 0.224 & 0.170 & 0.246 & 0.205 \\
\hline
\end{tabular}


24 - VIPG:

- Data de nascimento: 04/07/1952

- Sexo: Feminino

- Cor: Branca

- Procedência:

- Profissão: Serviços gerais (aposentada)

- Diabético (a): SIM

- Diabético (a) há quanto tempo?: Há 6 anos

Apresenta outras enfermidades?: Não

Tratamentos que realiza:

Diabetes: Glibenclamida 1 cpr café, almoço e jantar / metformina $8501 \mathrm{cpr}$ antes café e $1 \mathrm{cpr}$ antes jantar/ AAS $100 \mathrm{mg} 1 \mathrm{cpr}$ após almoço.

- Exame oftalmológico: A.O.= hipermetropia, astigmatismo e presbiopia (O.D. $=20 / 20$ / O.E. $=30 \mathrm{P}$ e J1) / Biomicroscopia O.D.= pterígio nasal II / O.E. = cicatriz limbar às 9 horas com desvio pupilar na mesma direção / Fundo de olho A.O.= sp / Tonometria normal A.O.

OBS.: Operou olho esquerdo aos 10 anos de idade, por traumatismo perfurante.

- Taxas glicemia capilar:

\begin{tabular}{|l|l|l|l|}
\hline DATA COLETA & $\begin{array}{l}\text { GLICEMIA } \\
\text { CAPILAR }\end{array}$ & JEJUM & $\begin{array}{l}\text { GLICEMIA } \\
\text { VENOSA }\end{array}$ \\
\hline $22 / 07 / 2003$ & 351 & - & \\
\hline $29 / 07 / 2003$ & 361 & NÃO & \\
\hline $05 / 08 / 2003$ & 325 & NÃO & \\
\hline $12 / 08 / 2003$ & 289 & NÃO & \\
\hline $19 / 08 / 2003$ & 212 & NÃO & 248 \\
\hline $26 / 08 / 2003$ & 345 & NÃO & \\
\hline $02 / 09 / 2003$ & 121 & SIM & \\
\hline $09 / 09 / 2003$ & 326 & NÃO & \\
\hline $23 / 09 / 2003$ & 176 & NÃO & \\
\hline $30 / 09 / 2003$ & 150 & SIM & \\
\hline
\end{tabular}

Íris Direita

\begin{tabular}{|l|l|l|l|l|l|l|l|l|l|}
\hline $\begin{array}{l}\text { Pos } \\
\text { mín }\end{array}$ & mín & $\begin{array}{l}\text { Pos } \\
\text { máx }\end{array}$ & máx & R med & G med & B med & H med & S med & I med \\
\hline G1Ci & -0.755 & R12Ci & 0.606 & 0.268 & 0.266 & 0.291 & 0.250 & 0.286 & 0.279 \\
\hline
\end{tabular}

Íris Esquerda

\begin{tabular}{|l|l|l|l|l|l|l|l|l|l|}
\hline $\begin{array}{l}\text { Pos } \\
\text { mín }\end{array}$ & mín & $\begin{array}{l}\text { Pos } \\
\text { máx }\end{array}$ & máx & R med & G med & B med & H med & S med & I med \\
\hline B9Pu & -0.629 & B4Ci & 0.652 & 0.152 & 0.166 & 0.228 & 0.223 & 0.218 & 0.189 \\
\hline
\end{tabular}

